\title{
Asymmetric Total Syntheses and Biological Studies of Tuberostemoamide and Sessilifoliamide A
}

Yongsheng Hou, ${ }^{\ddagger}{ }^{\S}$ Tao Shi, ${ }^{\ddagger}{ }^{\S}$ Yuhang Yang, ${ }^{\ddagger}$ Xiaohong Fan, ${ }^{\ddagger}$ Jinhong Chen, ${ }^{\star}$ Fei Cao, ${ }^{\dagger}$ and Zhen Wang* ${ }^{*}, \dagger$

${ }^{*}$ School of Pharmacy, Lanzhou University, West Donggang Road. No. 199, Lanzhou 730000, Gansu, China.

${ }^{\dagger}$ State Key Laboratory of Applied Organic Chemistry, College of Chemistry and Chemical Engineering, Lanzhou University, Lanzhou 730000, Gansu, China.

${ }^{\S}$ Y.H. and T. S. contributed equally to this work.

\section{Table of Contents}

I General Information 1

II Experimental Procedures and Spectroscopic Data of Compounds 1

III Proposed Thermodynamic and Kinetic Analysis for the Stereoselective Reduction of C=C Bond in $\mathbf{1 2} 14$

IV Comparison of NMR of Natural and Synthetic Tuberostemoamide, Sessilifoliamide A and Their Epimers 16

V ${ }^{1} \mathrm{H}$ and ${ }^{13} \mathrm{C}$ NMR Spectra of Compounds 24

$\begin{array}{lr}\text { VI Biological Studies } & 50\end{array}$

$\begin{array}{ll}\text { VII Reference } & 54\end{array}$

VIII A Map of Structural Relationship of Some Stemona Alkaloids 55

IX Cif Check Reports $\quad 56$ 


\section{General Information}

All reactions were performed in oven-dried glassware fitted with rubber septa under an argon atmosphere with dry solvents under anhydrous conditions, unless otherwise noted. Reagents were purchased at the highest commercial quality and used without further purification, unless otherwise stated. Methylene chloride $\left(\mathrm{CH}_{2} \mathrm{Cl}_{2}\right)$ was distilled immediately before use from calcium hydride. Diethyl ether and tetrahydrofuran (THF) was distilled immediately before use from sodium-benzophenone ketyl. All other solvents were processed through the reference Purification of Laboratory Chemicals (Seventh Edition). External bath temperatures were used to record all reaction temperatures. Silica gel (300 400 mesh) and petroleum ether, EtOAc, $\mathrm{CH}_{2} \mathrm{Cl}_{2}$ and $\mathrm{MeOH}$ are used for product purification by flash column chromatography. NMR spectra were recorded on Bruker $400 \mathrm{MHz}$ (400 MHz for ${ }^{1} \mathrm{H}$ NMR and $101 \mathrm{MHz}$ for ${ }^{13} \mathrm{C}$ NMR) spectrometers. Proton chemical shifts are reported relative to a residual solvent peak $\left(\mathrm{CDCl}_{3}\right.$ at $\left.7.26 \mathrm{ppm}\right)$ and carbon chemical shifts are reported relative to a residual solvent peak $\left(\mathrm{CDCl}_{3}\right.$ at $\left.77.0 \mathrm{ppm}\right)$ in order to compare with natural products conveniently. The following abbreviations were used to designate multiplicities: $\mathrm{s}=$ singlet, $\mathrm{d}=$ doublet, $\mathrm{t}=$ triplet, $\mathrm{q}=$ quartet, quint $=$ quintet, $\mathrm{m}=$ multiplet, br $=$ broad. High-resolution mass spectra (HRMS) were measured on a BruckerDaltonics Apex II $47 \mathrm{e}$ Specification (for HRMS).

\section{Experimental Procedures and Spectroscopic Data of Compounds}

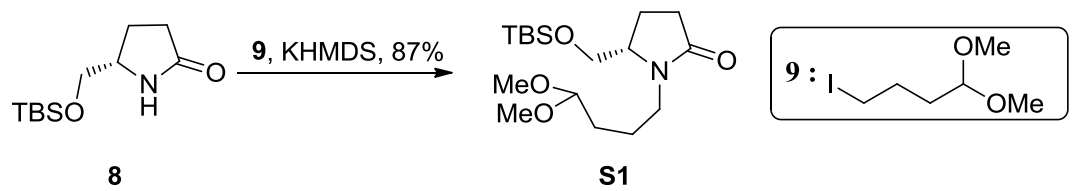

S1: To a stirred mixture of 8 (3.2 g, $14.0 \mathrm{mmol}, 1.0$ equiv) and $\mathbf{9}(4.4 \mathrm{~g}, 18.2 \mathrm{mmol}, 1.3$ equiv) in DMF (64.4 mL) was added KHMDS (1M in THF, $21.0 \mathrm{~mL}, 21.0 \mathrm{mmol}, 1.5$ equiv) at $-15{ }^{\circ} \mathrm{C}$ under Ar atmosphere. The resulting mixture was stirred at that temperature for $40 \mathrm{~min}$, and then was warmed to room temperature and stirred for another $3 \mathrm{~h}$. After quenching with aqueous saturated $\mathrm{NH}_{4} \mathrm{Cl}$ solution $(50 \mathrm{~mL})$, diluted with water $(200 \mathrm{~mL})$, the organic layer was separated. Then the aqueous layer was extracted with EtOAc $(3 \times 50 \mathrm{~mL})$ and the combined organic phase was washed with water $(20 \mathrm{~mL})$ and brine $(3 \times 15 \mathrm{~mL})$, dried over anhydrous $\mathrm{Na}_{2} \mathrm{SO}_{4}$, filtered, and evaporated under vacuum. The residue so obtained was purified by flash column chromatography with EtOAc/petroleum ether (1:1) to give the TBS-ether product $\mathbf{S 1}(4.2 \mathrm{~g}, 87 \%)$ as a colorless oil. $[\boldsymbol{\alpha}]_{\mathbf{D}}^{\mathbf{2 3 . 5}}=+5.00(\mathrm{c}$ $=2.0$ in $\mathrm{CH}_{2} \mathrm{Cl}_{2}$ ), [Lit. ${ }^{1}$ for the observed specific rotation of the compound with similar structure: $[\alpha]_{\mathrm{D}}^{20}=+5.76$ $\left(\mathrm{c}=1.0\right.$ in $\left.\left.\mathrm{CHCl}_{3}\right)\right] .{ }^{1} \mathbf{H}$ NMR (400 MHz, $\left.\mathbf{C D C l}_{3}\right) \delta 4.36(\mathrm{t}, J=5.2 \mathrm{~Hz}, 1 \mathrm{H}), 3.72-3.54(\mathrm{~m}, 4 \mathrm{H}), 3.31(\mathrm{~s}, 6 \mathrm{H})$, $3.04-2.95(\mathrm{~m}, 1 \mathrm{H}), 2.50-2.38(\mathrm{~m}, 1 \mathrm{H}), 2.33-2.24(\mathrm{~m}, 1 \mathrm{H}), 2.11-2.00(\mathrm{~m}, 1 \mathrm{H}), 1.87-1.78(\mathrm{~m}, 1 \mathrm{H}), 1.68-$ 1.49 (m, 4H), 0.87 (s, 9H), 0.04 (d, $J=2.3 \mathrm{~Hz}, 6 \mathrm{H}) .{ }^{13} \mathbf{C}$ NMR (101 MHz, $\left.\mathbf{C D C l}_{3}\right) \delta$ 175.44, 104.22, 63.86, 58.84, 53.04, 52.91, 40.35, 30.43, 29.81, 25.74, 22.48, 21.48, 18.10. IR (KBr, v / $\left.\mathbf{~ m}^{-1}\right)$ 2954, 2932, 2859, 1689, 1463 , 1422, 1254, 1128, 1079. HRMS (ESI, m/z): $[\mathrm{M}+\mathrm{Na}]^{+}$calcd for $\mathrm{C}_{17} \mathrm{H}_{35} \mathrm{NO}_{4} \mathrm{SiNa}^{+}$368.2228, found 368.2249. 


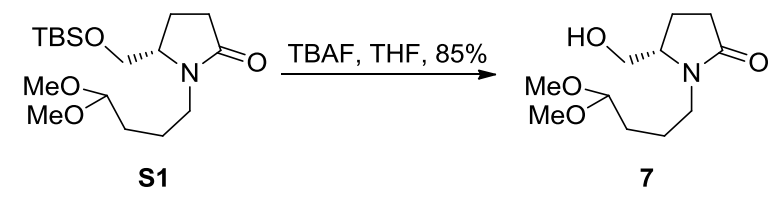

(S)-1-(4,4-dimethoxybutyl)-5-(hydroxymethyl)pyrrolidin-2-one 7: The TBS-ether product (3.2 g, $9.3 \mathrm{mmol}, 1$ equiv) in THF (46.4 mL) was added TBAF (1M in THF, $10.2 \mathrm{~mL}, 10.2 \mathrm{mmol}, 1.1$ equiv) at $0{ }^{\circ} \mathrm{C}$ stirred for 10 min before stirred at room temperature for $2 \mathrm{~h}$. The mixture was directly purified by flash column chromatography with $\mathrm{CH}_{2} \mathrm{Cl}_{2} / \mathrm{MeOH}(30: 1)$ to give $7(1.83 \mathrm{~g}, 85 \%)$ as a colorless oil. $[\boldsymbol{\alpha}]_{\mathbf{D}}^{24.1}=+5.0(\mathrm{c}=2.0$ in $\left.\mathrm{CH}_{2} \mathrm{Cl}_{2}\right)$, [Lit. ${ }^{1}$ for the observed specific rotation of the compound with similar structure: $[\alpha]_{\mathrm{D}}^{20}=+6.40(\mathrm{c}=1.0$ in $\left.\left.\mathrm{CHCl}_{3}\right)\right]$. ${ }^{\mathbf{1}} \mathbf{H}$ NMR (400 MHz, $\left.\mathbf{C D C l}_{3}\right) \delta 4.34(\mathrm{t}, J=5.1 \mathrm{~Hz}, 1 \mathrm{H}), 3.82-3.75(\mathrm{~m}, 1 \mathrm{H}), 3.69-3.52(\mathrm{~m}, 3 \mathrm{H})$, $3.29(\mathrm{~d}, J=2.1 \mathrm{~Hz}, 6 \mathrm{H}), 3.07-2.98(\mathrm{~m}, 1 \mathrm{H}), 2.50-2.38(\mathrm{~m}, 1 \mathrm{H}), 2.33-2.22(\mathrm{~m}, 1 \mathrm{H}), 2.11-2.00(\mathrm{~m}, 1 \mathrm{H}), 2.00$ - 1.90 (m, 1H), 1.66 - 1.45 (m, 4H). ${ }^{13} \mathbf{C}$ NMR (101 MHz, $\left.\mathbf{C D C l}_{3}\right) \delta$ 175.95, 104.12, 62.83, 59.10, 53.26, 52.87, 40.40, 30.46, 29.67, 22.46, 21.08. IR (KBr, v / $\mathbf{c m}^{-1}$ ) 3401 (br), 2947, 2835, 1664, 1461, 1424, 1129, 1068. HRMS (ESI, m/z): $[\mathrm{M}+\mathrm{Na}]^{+}$calcd for $\mathrm{C}_{11} \mathrm{H}_{21} \mathrm{NO}_{4} \mathrm{Na}^{+} 254.1363$, found 254.1367.

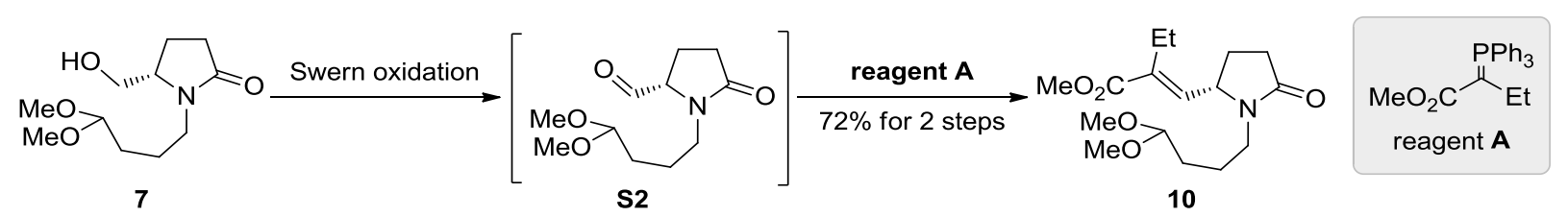

(S)-methyl 2-((1-(4,4-dimethoxybutyl)-5-oxopyrrolidin-2-yl)methylene)butanoat 10: To a stirred solution of oxalyl chloride (2.9 mL, $33.8 \mathrm{mmol}, 2.6$ equiv) in $\mathrm{CH}_{2} \mathrm{Cl}_{2}(32.5 \mathrm{~mL})$ was slowly added DMSO (5.0 mL, 77.9 mmol, 6.0 equiv) at $-78{ }^{\circ} \mathrm{C}$ and the solution was stirred for $10 \mathrm{~min}$. A solution of 7 ( $3.0 \mathrm{~g}, 13.0 \mathrm{mmol}, 1$ equiv) in $\mathrm{CH}_{2} \mathrm{Cl}_{2}(26.0 \mathrm{~mL})$ was added, and the mixture was stirred at the same temperature for $30 \mathrm{~min}$. To this solution, $\mathrm{Et}_{3} \mathrm{~N}$ (13.5 mL, $103.9 \mathrm{mmol}, 8.0$ equiv) was added and stirred for another 10 min before quenched with $\mathrm{H}_{2} \mathrm{O}$. Subsequently, the mixture was warmed to room temperature and stirred for $5 \mathrm{~min}$. The mixture was extracted with DCM $(3 \times 50 \mathrm{~mL})$ and aqueous saturated $\mathrm{NaCl}$ solution $(200 \mathrm{~mL})$. The combined organic extracts were washed with brine $(3 \times 15 \mathrm{~mL})$, dried over $\mathrm{Na}_{2} \mathrm{SO}_{4}$, concentrated. Then the mixture was concentrated under reduced pressure and the crude $\mathbf{S 2}$ product was subjected to the Wittig reaction conditions as soon as possible without further purification by flash column chromatography. To a stirred solution of the crude aldehyde $\mathbf{S 2}$ in DCM $(65.0 \mathrm{~mL})$ was added methyl 2-(triphenylphosphoranylidene)butanoate reagent A $(7.0 \mathrm{~g}, 19.5 \mathrm{mmol}, 1.5$ equiv), and the resulting mixture was stirred at room temperature for $12 \mathrm{~h}$. Then the mixture was purified by flash column chromatography (petroleum ether/ EtOAc, 1:2) to give $\mathbf{1 0}(2.9 \mathrm{~g}, 72 \%$ for 2 steps) as a colorless oil. $[\boldsymbol{\alpha}]_{\mathbf{D}}^{22.2}=+10.00\left(\mathrm{c}=3.0\right.$ in $\left.\mathrm{CH}_{2} \mathrm{Cl}_{2}\right)$, [Lit. ${ }^{1}$ for the observed specific rotation of the compound with similar structure: $[\alpha]_{\mathrm{D}}^{20}=+5.30\left(\mathrm{c}=0.9\right.$ in $\left.\left.\mathrm{CHCl}_{3}\right)\right] .{ }^{1} \mathbf{H} \mathbf{~ N M R}\left(\mathbf{4 0 0} \mathbf{~ M H z}, \mathbf{C D C l}_{3}\right) \delta 6.49(\mathrm{~d}, J=9.8 \mathrm{~Hz}, 1 \mathrm{H}), 4.52-$ $4.40(\mathrm{~m}, 1 \mathrm{H}), 4.32(\mathrm{t}, J=4.9 \mathrm{~Hz}, 1 \mathrm{H}), 3.75(\mathrm{~s}, 3 \mathrm{H}), 3.60-3.50(\mathrm{~m}, 1 \mathrm{H}), 3.28(\mathrm{~s}, 6 \mathrm{H}), 2.99-2.70(\mathrm{~m}, 1 \mathrm{H}), 2.52-$ $2.18(\mathrm{~m}, 5 \mathrm{H}), 1.81-1.69(\mathrm{~m}, 1 \mathrm{H}), 1.61-1.41(\mathrm{~m}, 4 \mathrm{H}), 1.05(\mathrm{t}, J=7.5 \mathrm{~Hz}, 3 \mathrm{H}) .{ }^{13} \mathbf{C} \mathbf{N M R}\left(\mathbf{1 0 1} \mathbf{~ M H z}, \mathbf{C D C l}_{3}\right) \delta$ 174.63, 167.26, 139.87, 136.65, 104.11, 55.34, 52.97, 52.93, 51.99, 40.63, 30.13, 29.79, 25.24, 22.51, 20.28, 14.50. IR (KBr, v / $\mathbf{~ m}^{-1}$ ) 2952, 2835, 1716, 1690, 1439, 1415, 1306, 1239, 1163, 1128, 1072, 1049. HRMS (ESI, $\mathbf{m} / \mathbf{z}$ ): $[\mathrm{M}+\mathrm{Na}]^{+}$calcd for $\mathrm{C}_{16} \mathrm{H}_{27} \mathrm{NO}_{5} \mathrm{Na}^{+} 336.1781$, found 336.1762 

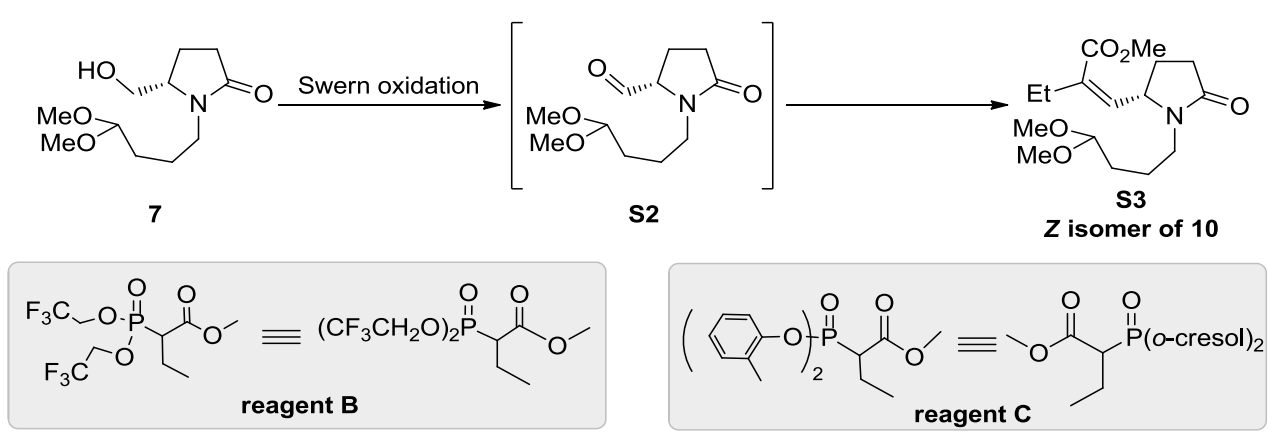

Table S1. Optimization of the reaction conditions to get $Z$ isomer of $\mathbf{1 0}$

\begin{tabular}{cccc}
\hline entry & condition & yield & $Z: E$ \\
\hline $1^{[\mathrm{a}]}$ & reagent B (1.4 equiv), KHMDS(1.5 equiv), & $74 \%$ & $61.3: 28.7$ \\
& 18 -crown-6 (7.0 equiv), THF, $-78{ }^{\circ} \mathrm{C}$ & & $26.9: 73.1$ \\
2 & reagent C (1.4 equiv), KHMDS $(1.5$ equiv), & $43 \%$ & $94.6: 5.4$ \\
& 18 -crown-6 (7.0 equiv), THF, $-78^{\circ} \mathrm{C}$ & & \\
\hline
\end{tabular}

[a] Still, W. C.; Gennari, C. Tetrahedron Lett. 1983, 24, 4405-4408.

[b] (1) Ando, K. J. Org. Chem. 1997, 62, 1934-1939. (2) Ando, K. J. Org. Chem. 1998, 63, 8411-8416. (3) Ando, K. J. Org. Chem. 1999, 64, 8406-8408. (4) Ando, K. J. Org. Chem. 2000, 65, 4745-4749.

S3: To a stirred solution of oxalyl chloride $\left(1.5 \mathrm{~mL}, 16.9 \mathrm{mmol}, 2.6\right.$ equiv) in $\mathrm{CH}_{2} \mathrm{Cl}_{2}(17 \mathrm{~mL})$ was added DMSO (2.5 mL, $39 \mathrm{mmol}, 6$ equiv) at $-78{ }^{\circ} \mathrm{C}$ and the solution was stirred for $10 \mathrm{~min}$. A solution of 7 (1.5 g, 6.5 mmol, 1 equiv) in $\mathrm{CH}_{2} \mathrm{Cl}_{2}(13 \mathrm{~mL})$ was added, and the mixture was stirred at the same temperature for $30 \mathrm{~min}$. To this solution, $\mathrm{Et}_{3} \mathrm{~N}(6.7 \mathrm{~mL}, 52.0 \mathrm{mmol}, 8.0$ equiv) was added and stirred for another $5 \mathrm{~min}$ before quenched with $\mathrm{H}_{2} \mathrm{O}$. Subsequently, the mixture was warmed to room temperature and stirred for $10 \mathrm{~min}$. The mixture was extracted with DCM and aqueous saturated $\mathrm{NaCl}$ solution. The combined organic extracts were washed with brine, dried over $\mathrm{Na}_{2} \mathrm{SO}_{4}$, concentrated. The residue was subjected to the modified Ando's conditions as soon as possible after further purification by very flash column chromatography.

To a stirred solution of reagent $\mathbf{C}(3.3 \mathrm{~g}, 9.11 \mathrm{mmol}, 1.4$ equiv) in THF $(45.6 \mathrm{~mL})$ was added $\mathrm{NaH}(234 \mathrm{mg}, 9.76$ mmol, 1.5 equiv) at $0{ }^{\circ} \mathrm{C}$. After being stirred for $15 \mathrm{~min}$ at this temperature, the above aldehyde $\mathbf{S 2}(1.5 \mathrm{~g}, 6.51$ mmol, 1.0 equiv) was added to the mixture. Three hours later, the mixture was quenched with saturated aqueous $\mathrm{NH}_{4} \mathrm{Cl}$ solution $(20 \mathrm{~mL})$ and diluted with water $(100 \mathrm{~mL})$, the organic layer was separated. Then the aqueous layer was extracted with EtOAc $(3 \times 40 \mathrm{~mL})$, the combined organic phase was washed with brine $(20 \mathrm{~mL})$, dried over anhydrous $\mathrm{Na}_{2} \mathrm{SO}_{4}$, filtered, and evaporated under vacuum. The residue was purified by flash column chromatography $\left(\mathrm{CH}_{2} \mathrm{Cl}_{2} / \mathrm{MeOH}=30: 1\right)$ to give product $\mathbf{S 3}(1.7 \mathrm{~g}, 82 \%$ for 2 steps $)$ as a colorless oil. [ $\left.\boldsymbol{\alpha}\right]_{\mathbf{D}}^{24.3}$ $=+23.3\left(\mathrm{c}=3.0\right.$ in $\left.\mathrm{CH}_{2} \mathrm{Cl}_{2}\right) .{ }^{1} \mathbf{H}$ NMR $\left(400 \mathbf{M H z} \mathbf{C D C l}_{3}\right) \delta 5.66(\mathrm{~d}, J=9.3 \mathrm{~Hz}, 1 \mathrm{H}), 4.95-4.79(\mathrm{~m}, 1 \mathrm{H}), 4.33(\mathrm{t}$, $J=4.8 \mathrm{~Hz}, 1 \mathrm{H}), 3.77(\mathrm{~s}, 3 \mathrm{H}), 3.56-3.44(\mathrm{~m}, 1 \mathrm{H}), 3.29$ (s, 6H), $2.96-2.84(\mathrm{~m}, 1 \mathrm{H}), 2.48-2.25(\mathrm{~m}, 5 \mathrm{H}), 1.74-$ $1.62(\mathrm{~m}, 1 \mathrm{H}), 1.58-1.44(\mathrm{~m}, 4 \mathrm{H}), 1.04$ (t, $J=7.4 \mathrm{~Hz}, 3 \mathrm{H}) .{ }^{13} \mathbf{C} \mathbf{~ N M R}\left(\mathbf{1 0 1} \mathbf{~ M H z}, \mathbf{C D C l}_{3}\right)$ 8175.09, 167.95, 139.14, 137.12, 104.45, 56.57, 53.20, 53.02, 51.96, 40.94, 30.42, 30.11, 27.43, 25.74, 22.88, 13.41. IR (KBr, v / 
$\mathbf{c m}^{-1}$ ) 2954, 2941, 2883, 2837, 1716, 1690, 1439, 1416, 1228, 1163, 1129, 1070. HRMS (ESI, m/z): [M + Na $]^{+}$ calcd for $\mathrm{C}_{16} \mathrm{H}_{27} \mathrm{NO}_{5} \mathrm{Na}^{+} 336.1781$, found 336.1775.

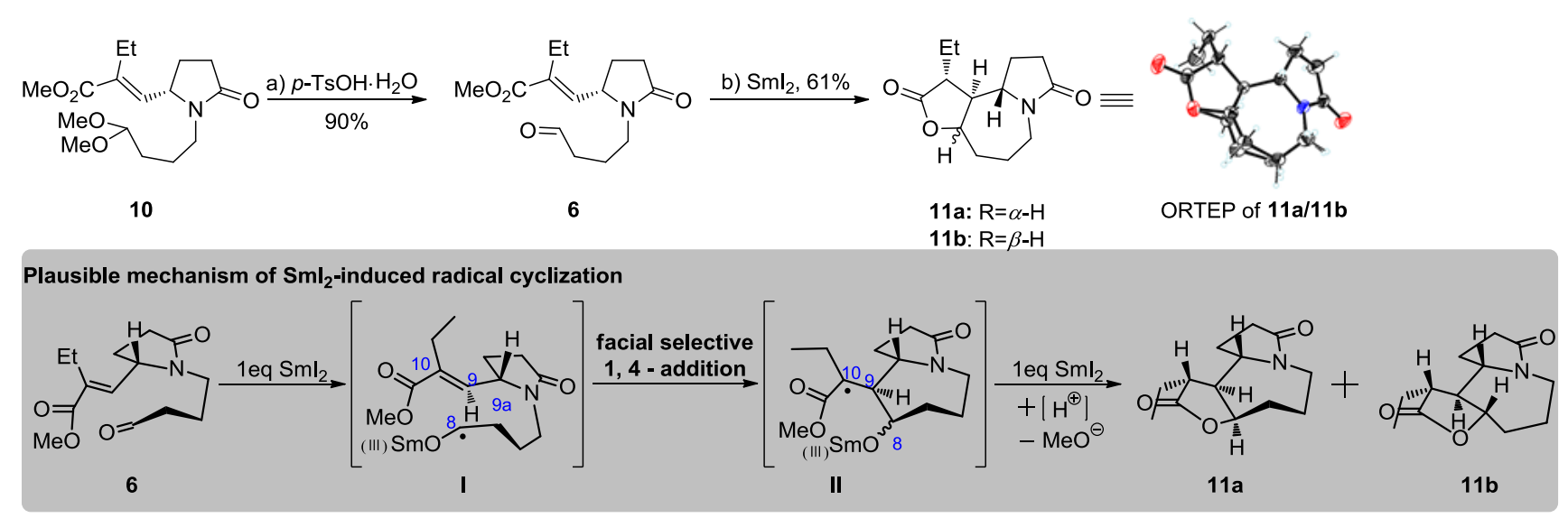

Radical cyclization product 11a/11b: A mixture of $\mathbf{1 0}\left(2.2 \mathrm{~g}, 7.0 \mathrm{mmol}, 1.0\right.$ equiv) and $p-\mathrm{TsOH} \cdot \mathrm{H}_{2} \mathrm{O}(532 \mathrm{mg}$, $2.8 \mathrm{mmol}, 0.4$ equiv) in acetone $(46.7 \mathrm{~mL})$ was stirred for $8 \mathrm{~h}$ at ambient temperature before quenched with aqueous saturated $\mathrm{NaHCO}_{3}$ solution $(20 \mathrm{~mL})$. The acetone was removed in vacuo, the residue was diluted with water $(60 \mathrm{~mL})$ and extracted with EtOAc $(3 \times 30 \mathrm{~mL})$. The combined organic extracts were washed with with brine, dried over $\mathrm{Na}_{2} \mathrm{SO}_{4}$, filtered, concentrated and evaporated under vacuum. The residue so obtained was purified by flash column chromatography (EtOAc/petroleum ether $=20: 1 \rightarrow$ EtOAc) as soon as possible to give the aldehyde 6 (1.68 g, 90\%).

To a stirred solution of the aldehyde $6(1.21 \mathrm{~g}, 4.53 \mathrm{mmol}, 1.0$ equiv) in THF (157 mL) in the presence of $\mathrm{MeOH}$ (0.92 mL, $22.7 \mathrm{mmol}, 5.0$ equiv) was added $\mathrm{SmI}_{2}\left(0.1 \mathrm{M}\right.$ in THF, $145 \mathrm{~mL}, 14.5 \mathrm{mmol}, 3.2$ equiv) at $0{ }^{\circ} \mathrm{C}$ under argon. After being stirred for $1 \mathrm{~h}$ at this temperature, the resulting mixture was quenched with saturated aqueous $\mathrm{NH}_{4} \mathrm{Cl}$ solution $(400 \mathrm{~mL})$. The organic layer was separated and the aqueous layer extracted with EtOAc $(5 \times 80$ $\mathrm{mL})$. The combined organic layers were washed with saturated aqueous $\mathrm{Na}_{2} \mathrm{~S}_{2} \mathrm{O}_{3}(30 \mathrm{~mL})$ and brine $(3 \times 20 \mathrm{~mL})$, filtered, dried over $\mathrm{Na}_{2} \mathrm{SO}_{4}$, and evaporated. The residue was purified by flash column chromatography (EtOAc $\rightarrow$ EtOAc $/ \mathrm{MeOH}=5: 1)$ to give products $\mathbf{1 1 a} / \mathbf{1 1 b}(654.9 \mathrm{mg}, 61 \%)$ as white solids. CCDC 1874368 contains the supplementary crystallographic data of $\mathbf{1 1 a} / \mathbf{1 1} \mathbf{b}$. These data can be obtained free of charge from The Cambridge Crystallographic Data Centre via www.ccdc.cam.ac.uk/data_request/cif.

\section{Plausible mechanism of $\mathrm{SmI}_{2}$-induced radical cyclization:}

Although the precise reaction mechanism of $\mathrm{SmI}_{2}$-induced radical cyclization remained unclear, the observed stereoselectivity would be rationalized by assuming that: the first single-electron reduction of aldehyde $\mathbf{6}$ with $\mathrm{SmI}_{2}$ gives a ketyl radical (transition state $\mathbf{I}$ ), then a facial selective 1,4-addition reaction of the newly formed radical proceeds to give transition state II. The radical in II is reduced by $\mathrm{SmI}_{2}$ again and then quenched by MeOH to give 11a or 11b. (see ref. Honda, T., Matsukawa, T. \& Takahashi, K. Org. Biomol. Chem. 9, 673-675, (2011); Kimura, T. \& Nakata, T. Tetrahedron: Asymmetry 21, 1389-1395, (2010); Wang, X. D., Wang, H. H., Wu, X., Yu, T. Q., Gao, W. W, Shi, T., Peng, X., He, D. \& Wang, Z. Synlett 28, 1660-1662, (2017).) 

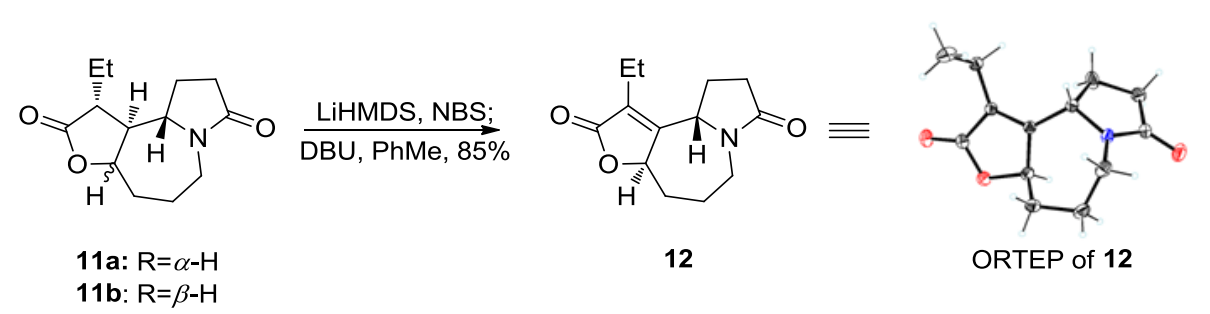

(3aR,10aS)-1-ethyl-3a,4,5,6,10,10a-hexahydro-2H-furo[3,2-c]pyrrolo[1,2-a]azepine-2,8(9H)-dione 12 : To a stirred solution of 11a/11b (1.62 g, $6.83 \mathrm{mmol}, 1.0$ equiv) in THF (68 mL) was added LiHMDS (1.0 in THF, 10.2 $\mathrm{mL}, 10.25 \mathrm{mmol}, 1.5$ equiv) at $-78{ }^{\circ} \mathrm{C}$ under argon atmosphere. After being stirred at the same temperature for $1 \mathrm{~h}$, N-bromosuccinimide (1.81 g, $10.25 \mathrm{mmol}, 1.5$ equiv) in THF (30 mL) was added. The resulting mixture was slowly warmed to room temperature. After being quenched with saturated aqueous $\mathrm{NH}_{4} \mathrm{Cl}$ solution, the organic layer was separated and the aqueous layer extracted with EtOAc $(3 \times 60 \mathrm{~mL})$. The combined organic layers were washed with brine, filtered and dried over $\mathrm{Na}_{2} \mathrm{SO}_{4}$, and concentrated under reduced pressure to leave the residue, which was then purified by column chromatography (EtOAc $\rightarrow \mathrm{CH}_{2} \mathrm{Cl}_{2} / \mathrm{MeOH}=30: 1$ ) to give the bromo intermediate. Then the intermediate was dissolved in toluene $(136 \mathrm{~mL})$ followed by a subsequent addition of 1,8-Diazabicyclo[5.4.0]undec-7-ene (3.12 g, $20.49 \mathrm{mmol}, 3$ equiv). After stirred at $80{ }^{\circ} \mathrm{C}$ for $2 \mathrm{~h}$, the mixture was quenched with saturated aqueous $\mathrm{NH}_{4} \mathrm{Cl}$ solution $(100 \mathrm{~mL})$. The organic layers were separated, and the aqueous layer was extracted with EtOAc $(3 \times 40 \mathrm{~mL})$. The combined organic layer was washed with brine and dried over $\mathrm{Na}_{2} \mathrm{SO}_{4}$, filtered and concentrated under reduced pressure to leave a residue, which was subjected to column chromatography on silica gel (EtOAc $\left.\rightarrow \mathrm{CH}_{2} \mathrm{Cl}_{2} / \mathrm{MeOH}=30: 1\right)$ to afford $\mathbf{1 2}(1.36 \mathrm{~g}, 85 \%$ for two steps) as a white solid: mp $163-165{ }^{\circ} \mathrm{C}$. (Lit. ${ }^{2-3} 127-129{ }^{\circ} \mathrm{C}$; Lit. ${ }^{4} 166-167{ }^{\circ} \mathrm{C}$; Lit. $\left.{ }^{5} 168-170{ }^{\circ} \mathrm{C}\right) .[\boldsymbol{\alpha}]_{\mathrm{D}}^{24.2}=-240.0(\mathrm{c}=1.0$ in $\mathrm{CH}_{2} \mathrm{Cl}_{2}$ ), [the observed specific rotation of the reported compound with similar structure: Lit. ${ }^{1}[\alpha]_{\mathrm{D}}=-204.0$ $\left(\mathrm{c}=0.4\right.$ in $\left.\mathrm{CHCl}_{3}\right) ;$ Lit. $^{2-3}[\alpha]_{\mathrm{D}}^{27}=-246.3(\mathrm{c}=0.63$ in $\mathrm{MeOH}) ;$ Lit. $^{4}[\alpha]_{\mathrm{D}}^{24}=-261.1(\mathrm{c}=1.33$ in $\mathrm{MeOH})$; Lit. $^{5}[\alpha]_{\mathrm{D}}^{27}=-261.1(\mathrm{c}=0.33$ in $\left.\mathrm{MeOH})\right] .{ }^{1} \mathbf{H} \mathbf{~ N M R}\left(\mathbf{4 0 0} \mathbf{M H z}, \mathbf{C D C l}_{3}\right) \delta 4.87(\mathrm{dd}, J=11.6,3.1 \mathrm{~Hz}, 1 \mathrm{H}), 4.79-$ $4.73(\mathrm{~m}, 1 \mathrm{H}), 4.31-4.22(\mathrm{~m}, 1 \mathrm{H}), 2.56-2.44(\mathrm{~m}, 5 \mathrm{H}), 2.35-2.23(\mathrm{~m}, 2 \mathrm{H}), 1.92-1.60(\mathrm{~m}, 3 \mathrm{H}), 1.38-1.22(\mathrm{~m}$, $1 \mathrm{H}), 1.14(\mathrm{t}, J=7.6 \mathrm{~Hz}, 3 \mathrm{H}) .{ }^{13} \mathbf{C}$ NMR (101 MHz, $\left.\mathbf{C D C l}_{3}\right) \delta 174.14,172.68,164.18,129.26,80.88,57.31$, 43.32, 34.95, 30.13, 26.61, 25.62, 17.46, 12.55. IR (KBr, v / $\left.\mathbf{c m}^{-1}\right)$ 2939, 2881, 1750, 1690, 1444, 1415, 1359, 1320, 1258, 1163, 1109, 1027. HRMS (ESI, m/z): $[\mathrm{M}+\mathrm{Na}]^{+}$calcd for $\mathrm{C}_{13} \mathrm{H}_{17} \mathrm{NO}_{3} \mathrm{Na}^{+} 258.1101$, found 258.1105. CCDC 1874370 contains the supplementary crystallographic data of $\mathbf{1 2}$. These data can be obtained free of charge from The Cambridge Crystallographic Data Centre via www.ccdc.cam.ac.uk/data_request/cif. 


\section{Reduction of $\mathrm{C}=\mathrm{C}$ bond in 12}

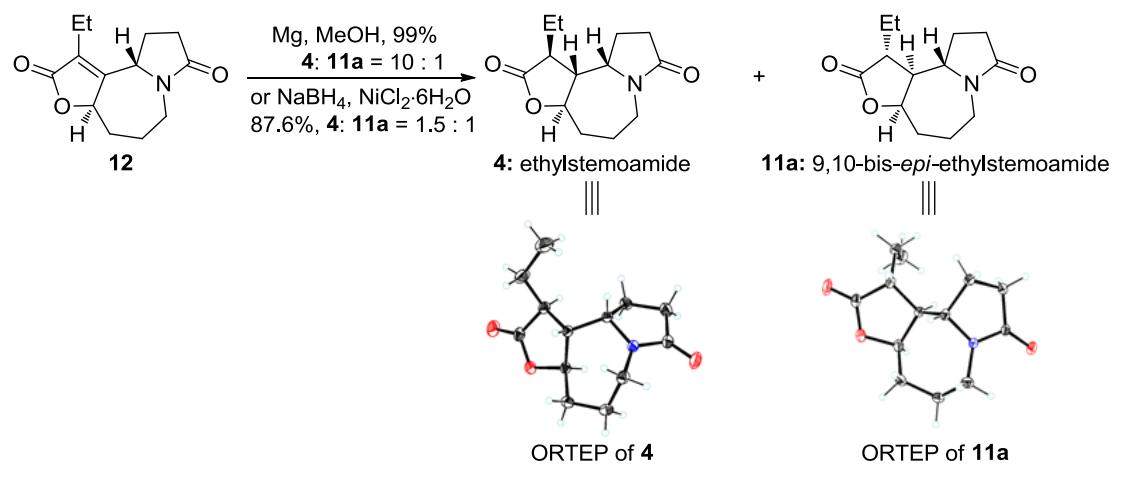

Table S2. Optimization of the Stereoselective Reduction of Double-Bond in Unsaturated Ester 12.

\begin{tabular}{|c|c|c|c|}
\hline entry & conditions $^{[\mathrm{a}]}$ & $\begin{array}{l}4: 11 a_{a} \\
\text { ratio }^{d]}\end{array}$ & $\begin{array}{l}\text { yield }(\%)^{[\mathrm{e}]} \\
\end{array}$ \\
\hline $1^{[\mathrm{b}]}$ & $\mathrm{NaBH}_{4}, \mathrm{NiCl}_{2} \cdot 6 \mathrm{H}_{2} \mathrm{O}$, r.t. & $1.12: 1$ & 90 \\
\hline $2^{[\mathrm{b}]}$ & $\mathrm{NaBH}_{4}, \mathrm{NiCl}_{2} \cdot 6 \mathrm{H} 2 \mathrm{O},-30{ }^{\circ} \mathrm{C}$ & $1.50: 1$ & 82 \\
\hline $3^{[b]}$ & $\begin{array}{c}\mathrm{NaBH}_{4}, \text { anhydrous } \mathrm{NiCl}_{2}, \\
-30^{\circ} \mathrm{C}, 16 \mathrm{~h}\end{array}$ & $1.92: 1$ & 57 \\
\hline $4^{[\mathrm{b}]}$ & $\mathrm{NaBH}_{4}, \mathrm{CuCl}$, r.t., 36h & $N \cdot R \cdot{ }^{[f]}$ & - \\
\hline $5^{[\mathrm{cc}]}$ & $\mathrm{NaBH}_{4}, \mathrm{CeCl}_{3} \cdot 7 \mathrm{H}_{2} \mathrm{O}$, r.t., $36 \mathrm{~h}$ & N.R. ${ }^{[f]}$ & - \\
\hline $8^{[\mathrm{cc}]}$ & $\mathrm{Mg}, 80^{\circ} \mathrm{C}, 1 \mathrm{~h}$ & $2.02: 1$ & 89 \\
\hline $9^{[\mathrm{c}]}$ & $\mathrm{Mg}, 40^{\circ} \mathrm{C}, 2 \mathrm{~h}$ & $2.18: 1$ & 99 \\
\hline $10^{[c]}$ & $\mathrm{Mg}, 0{ }^{\circ} \mathrm{C}$ & $2.80: 1$ & 83 \\
\hline $11^{[\mathrm{cc}]}$ & $\mathrm{Mg},-10{ }^{\circ} \mathrm{C}$ & $3.30: 1$ & 99 \\
\hline $12^{[\mathrm{cc}]}$ & $\mathrm{Mg},-20{ }^{\circ} \mathrm{C}$ & $3.7: 1$ & 99 \\
\hline $13^{[\mathrm{cc}]}$ & $\mathrm{Mg},-30{ }^{\circ} \mathrm{C}$ & $6: 1$ & 99 \\
\hline $14^{[\mathrm{c}]}$ & $\mathrm{Mg},-40{ }^{\circ} \mathrm{C}, 36 \mathrm{~h}$ & $10: 1$ & 99 \\
\hline $15^{[\mathrm{c}]}$ & $\mathrm{Mg},-50{ }^{\circ} \mathrm{C}, 3$ days & $N . R \cdot{ }^{[f]}$ & - \\
\hline
\end{tabular}

[a] Reactions were carried out in $\mathrm{MeOH}(0.05 \mathrm{M})$ at the indicated temperatures under argon atmosphere. [b] 10 equiv of $\mathrm{NaBH}_{4}$ and 0.25 equiv $\mathrm{NiCl}_{2} \cdot 6 \mathrm{H}_{2} \mathrm{O}$ or anhydrous $\mathrm{NiCl}_{2}$ or $\mathrm{CuCl}$ or $\mathrm{CeCl}_{3} \cdot 7 \mathrm{H}_{2} \mathrm{O}$ were used. [c] 30 equiv of $\mathrm{Mg}$ was used after washed with $3 \mathrm{M} \mathrm{HCl}$ and sanded with sandpaper. [d] Determined by ${ }^{1} \mathrm{H} \mathrm{NMR}$ spectroscopic analysis of the inseparable mixture of 4/11a after purification. [e] Yield of a pure mixture of 4/11a isolated by aqueous workup followed by flash silica column chromatography. [f] No consumption of $\mathbf{1 2}$ was observed. 


\section{Reduction of 12 using $\mathrm{NaBH}_{4} / \mathrm{NiCl}_{2} \cdot 6 \mathrm{H}_{2} \mathrm{O}$ :}

Butenolide 12 (517 mg, $2.20 \mathrm{mmol}, 1$ equiv) and $\mathrm{NiCl}_{2} \cdot 6 \mathrm{H}_{2} \mathrm{O}$ (131 mg, $0.55 \mathrm{mmol}, 0.25$ equiv) was dissolved in anhyd $\mathrm{MeOH}(27.5 \mathrm{~mL})$. After cooling to $-30{ }^{\circ} \mathrm{C}$, one portion of $\mathrm{NaBH}_{4}(250 \mathrm{mg}, 6.60 \mathrm{mmol}, 3$ equiv) was added. The resulting mixture was stirred at $-30{ }^{\circ} \mathrm{C}$ for 20 min followed by addition of another portion of $\mathrm{NaBH}_{4}$ (250 mg, $6.60 \mathrm{mmol}, 3$ equiv). After stirring at this temperature for $6 \mathrm{~h}, 1 \mathrm{M} \mathrm{HCl} \mathrm{(30} \mathrm{mL)} \mathrm{was} \mathrm{added} \mathrm{to} \mathrm{quench}$ the reaction, and continuously stirred until the solution became clear. Then $\mathrm{MeOH}$ was evaporated under reduced pressure. The aqueous layer was extracted with $\mathrm{CH}_{2} \mathrm{Cl}_{2}(3 \times 20 \mathrm{~mL})$ and the combined organic layers were washed with saturated aqueous $\mathrm{NaHCO}_{3}$ solution $\left(10 \mathrm{~mL}\right.$ ), dried (anhyd $\left.\mathrm{Na}_{2} \mathrm{SO}_{4}\right)$, filtered and concentrated. The residue was purified by silica column chromatography $\left(\mathrm{CH}_{2} \mathrm{Cl}_{2} / \mathrm{MeOH}=15: 1\right)$ to give 4 and 11a with a ratio of 1.5:1 (457 mg, 87.6\%). ethylstemoamide 4 : mp 179-181 ${ }^{\circ} \mathrm{C}$. (mp of the reported compound with similar structure: Lit. ${ }^{1} 184-185{ }^{\circ} \mathrm{C}$; Lit. ${ }^{2-3} 187-188{ }^{\circ} \mathrm{C}$; Lit. ${ }^{4} 186-187{ }^{\circ} \mathrm{C}$; Lit. ${ }^{5} 181-183{ }^{\circ} \mathrm{C}$; Lit. ${ }^{6} 185-186{ }^{\circ} \mathrm{C}$; Lit. ${ }^{7}$ $185-186{ }^{\circ} \mathrm{C}$; Lit. ${ }^{8} 190-191{ }^{\circ} \mathrm{C}$; Lit. ${ }^{9} 182-183{ }^{\circ} \mathrm{C}$; Lit. $\left.{ }^{10} 190-191{ }^{\circ} \mathrm{C}\right) .[\boldsymbol{\alpha}]_{\mathrm{D}}^{23.9}=-160.0(\mathrm{c}=1.0$ in $\mathrm{MeOH})$, [the observed specific rotation of the reported compound with similar structure: Lit. ${ }^{1}[\alpha]_{\mathrm{D}}^{20}=-138.0(\mathrm{c}=0.2$ in $\mathrm{MeOH}) ;$ Lit. $^{2-3}[\alpha]_{\mathrm{D}}^{30}=-219.3(\mathrm{c}=0.5$ in $\mathrm{MeOH}) ;$ Lit. $^{4}[\alpha]_{\mathrm{D}}^{25}=-183.5(\mathrm{c}=1.36$ in MeOH$) ;$ Lit. $^{5}[\alpha]_{\mathrm{D}}^{27}=-151.58$ $(\mathrm{c}=0.46$ in $\mathrm{MeOH}) ;$ Lit. $^{6}[\alpha]_{\mathrm{D}}^{25}=-187.0(\mathrm{c}=0.5$ in MeOH$) ;$ Lit. $^{7}[\alpha]_{\mathrm{D}}^{25}=-191.6(\mathrm{c}=0.5$ in MeOH$) ;$ Lit. $^{8}[\alpha]_{\mathrm{D}}^{20}$ $=-213.1(\mathrm{c}=0.5$ in $\mathrm{MeOH}) ;$ Lit. $^{9}[\alpha]_{\mathrm{D}}^{20}=-141(\mathrm{c}=0.3$ in MeOH$) ;$ Lit. $^{10}[\alpha]_{\mathrm{D}}^{26}=-141(\mathrm{c}=0.19$ in $\mathrm{MeOH})$ and -181 (c 0.89 in MeOH)]. ${ }^{1} \mathbf{H}$ NMR (400 MHz, $\left.\mathbf{C D C l}_{3}\right) \delta 4.22-4.07(\mathrm{~m}, 2 \mathrm{H}), 4.05-3.94(\mathrm{~m}, 1 \mathrm{H}), 2.71-2.61(\mathrm{~m}$, $1 \mathrm{H}), 2.57-2.45(\mathrm{~m}, 2 \mathrm{H}), 2.44-2.32(\mathrm{~m}, 3 \mathrm{H}), 2.07-1.99(\mathrm{~m}, 1 \mathrm{H}), 1.93-1.80(\mathrm{~m}, 2 \mathrm{H}), 1.78-1.47(\mathrm{~m}, 4 \mathrm{H})$, $1.03(\mathrm{t}, J=7.5 \mathrm{~Hz}, 3 \mathrm{H}) .{ }^{13} \mathbf{C}$ NMR (101 MHz, $\left.\mathbf{C D C l}_{3}\right) \delta 176.86,174.00,77.34,56.32,50.16,43.33,40.19,34.71$, 30.57, 25.47, 22.78, 22.58, 11.35. IR (KBr, v / $\left.\mathbf{~ c m}^{-1}\right)$ 2939, 2963, 2891, 1767, 1679, 1461, 1422, 1325, 1277 , 1187, 1016. HRMS (ESI, m/z): $[\mathrm{M}+\mathrm{Na}]^{+}$calcd for $\mathrm{C}_{13} \mathrm{H}_{19} \mathrm{NO}_{3} \mathrm{Na}^{+}$260.1257, found 260.1254. CCDC 1883782 contains the supplementary crystallographic data of 4 . These data can be obtained free of charge from The Cambridge Crystallographic Data Centre via www.ccdc.cam.ac.uk/data_request/cif.

9,10-bis-epi-ethylstemoamide 11a: mp $170-172{ }^{\circ} \mathrm{C}$. $[\boldsymbol{\alpha}]_{\mathrm{D}}^{23.7}=-150.0(\mathrm{c}=1.0$ in $\mathrm{MeOH})$; [Lit. ${ }^{11}$ for the observed specific rotation of the reported compound with similar structure: $\left.[\alpha]_{\mathrm{D}}^{21}=-63.3(\mathrm{c}=1.69 \mathrm{in} \mathrm{MeOH})\right]$. ${ }^{1}$ H NMR (400 MHz, CDCl $) \delta 4.67-4.59(\mathrm{~m}, 1 \mathrm{H}), 4.16-4.06(\mathrm{~m}, 1 \mathrm{H}), 3.69-3.60(\mathrm{~m}, 1 \mathrm{H}), 2.87-2.78(\mathrm{~m}$, $1 \mathrm{H}), 2.56-2.38(\mathrm{~m}, 3 \mathrm{H}), 2.37-2.18(\mathrm{~m}, 2 \mathrm{H}), 2.12-1.95(\mathrm{~m}, 2 \mathrm{H}), 1.94-1.73(\mathrm{~m}, 4 \mathrm{H}), 1.66-1.54(\mathrm{~m}, 1 \mathrm{H})$, $1.04(\mathrm{t}, J=7.4 \mathrm{~Hz}, 3 \mathrm{H}) .{ }^{13} \mathbf{C}$ NMR (101 MHz, $\left.\mathbf{C D C l}_{3}\right) \delta 177.42,174.68,80.34,58.86,47.61,46.02,43.73,29.82$, 28.79, 24.68, 23.06, 22.24, 10.89. IR (KBr, v / $\left.\mathbf{~ c m}^{-1}\right)$ 2935, 1765, 1679, 1461, 1426, 1385, 1286, 1260, 1187 , 1139, 1016. HRMS (ESI, m/z): $[\mathrm{M}+\mathrm{Na}]^{+}$calcd for $\mathrm{C}_{13} \mathrm{H}_{19} \mathrm{NO}_{3} \mathrm{Na}^{+}$260.1257, found 260.1262. CCDC 1883803 contains the supplementary crystallographic data of 11a. These data can be obtained free of charge from The Cambridge Crystallographic Data Centre via www.ccdc.cam.ac.uk/data_request/cif. 


\section{Reduction of 12 using $\mathrm{Mg} / \mathrm{MeOH}$ :}

To a stirred solution of butenolide 12 (240 mg, $1.02 \mathrm{mmol}, 1$ equiv) in anhyd $\mathrm{MeOH}$ (20.4 mL) was added $\mathrm{Mg}$ ribbon chips (734 mg, $30.6 \mathrm{mmol}, 30$ equiv) and the mixture was continually stirred at $-40{ }^{\circ} \mathrm{C}$. After $36 \mathrm{~h}$, the reaction was completed and $5 \mathrm{~N} \mathrm{HCl}$ was added to quench the reaction and the aqueous layer, then $\mathrm{MeOH}$ was evaporated under reduced pressure. The aqueous layer was extracted with $\mathrm{CH}_{2} \mathrm{Cl}_{2}(3 \times 20 \mathrm{~mL})$, washed with brine, dried (anhyd $\mathrm{Na}_{2} \mathrm{SO}_{4}$ ) and concentrated. The residue was purified by silica column chromatography $\left(\mathrm{CH}_{2} \mathrm{Cl}_{2} / \mathrm{MeOH}=15: 1\right)$ to a mixture of give 4 and 11a with a ratio of 10:1 (239 $\left.\mathrm{mg}, 99 \%\right)$.

\section{Reduction of 12 using $\mathrm{Pd} / \mathrm{C}$ catalyzed hydrogenation:}

Butenolide 12 (340 mg, $1.45 \mathrm{mmol}, 1$ equiv) and 10\% Pd/C (769 mg, $0.72 \mathrm{mmol}, 0.5$ equiv) were dissolved in anhyd $\mathrm{MeOH}(7.3 \mathrm{~mL})$ and the mixture was continually stirred under hydrogen atmosphere $(120 \mathrm{~atm})$ at $70{ }^{\circ} \mathrm{C}$ for 5 days. Then the mixture was filtered, and the filtrate was evaporated under reduced pressure. The residue was directly purified by silica column chromatography $\left(\mathrm{CH}_{2} \mathrm{Cl}_{2} / \mathrm{MeOH}=15: 1\right)$ to a mixture of give $\mathbf{1 3}$ and 11a with a ratio of 1:1.2 (309 $\mathrm{mg}, 90 \%)$.

A mixture of 13 and 11a (309 mg, $1.31 \mathrm{mmol}, 1.0$ equiv) was dissolved in $\mathrm{MeOH}$ (13.1 mL), and treated with $\mathrm{K}_{2} \mathrm{CO}_{3}(1.8 \mathrm{~g}, 13.1 \mathrm{mmol}, 10.0$ equiv). The resulting reaction mixture was stirred at room temperature for $24 \mathrm{~h}$ and concentrated. The residue was then treated with water, neutralized with $10 \%$ aqueous $\mathrm{HCl}$ solution, and extracted with $\mathrm{CH}_{2} \mathrm{Cl}_{2}(3 \times 20 \mathrm{~mL})$. The organic layers were isolated, dried over anhydrous $\mathrm{Na}_{2} \mathrm{SO}_{4}$, and concentrated in vacuo. The residue was purified by flash column chromatography $\left(\mathrm{CH}_{2} \mathrm{Cl}_{2} / \mathrm{MeOH}=15: 1\right)$ to give 11a $(263 \mathrm{mg}, 85 \%)$ as the only detectable product.

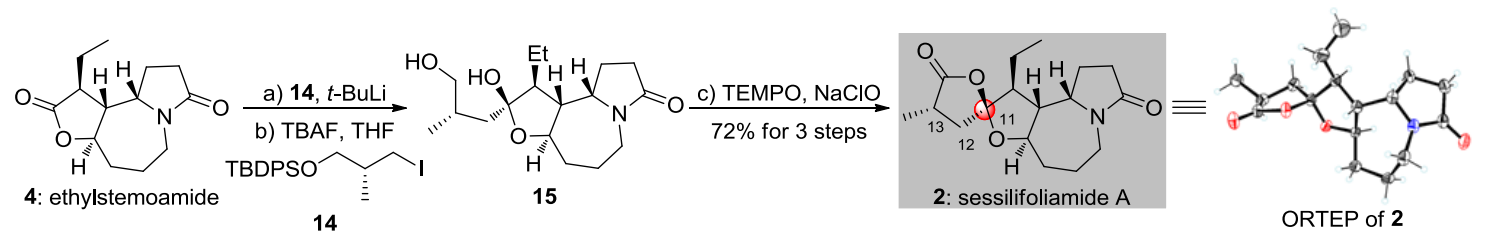

Sessilifoliamide A 2: To a stirred solution of (R)-tert-butyl(4-iodo-2-methylbutoxy)diphenylsilane 14 (370 mg, $0.84 \mathrm{mmol}, 2$ equiv) in $\mathrm{Et}_{2} \mathrm{O}(8 \mathrm{~mL})$ was added $t$-BuLi (1.3 in pentane, $1.3 \mathrm{~mL}, 1.64 \mathrm{mmol}, 3.9$ equiv) dropwise at $-78{ }^{\circ} \mathrm{C}$ and the solution was stirred at $-78{ }^{\circ} \mathrm{C}$ for $15 \mathrm{~min}$. The mixture was then warmed to $-50{ }^{\circ} \mathrm{C}$ and stirred for another $15 \mathrm{~min}$ followed by addition of 4 (100 mg, $0.42 \mathrm{mmol}, 1$ equiv) in $\mathrm{Et}_{2} \mathrm{O}$ and toluene (4.2 $\left.\mathrm{mL}, \mathrm{V} / \mathrm{V}=1: 5\right)$ at $-78{ }^{\circ} \mathrm{C}$. After stirring for $3 \mathrm{~h}$, the reaction was quenched by saturated aqueous $\mathrm{NH}_{4} \mathrm{Cl}$ solution $(5 \mathrm{~mL})$, then diluted with water $(40 \mathrm{~mL})$. The organic layer was separated and extracted with EtOAc $(3 \times 30 \mathrm{~mL})$. The combined organic layers were washed with brine, dried (anhyd $\mathrm{Na}_{2} \mathrm{SO}_{4}$ ) and concentrated. The residue was purified by silica column chromatography (petroleum ether/EtOAc $=1: 1 \rightarrow$ EtOAc) to give the protected product. To a solution of the above crude product in THF $(2.1 \mathrm{~mL}$ ) was added TBAF ( $1 \mathrm{M}$ in THF, $0.55 \mathrm{~mL}, 0.55 \mathrm{mmol}$, 1.3 equiv) in one portion at room temperature and the resultant mixture was stirred for $10 \mathrm{~min}$. Directly purified by flash column chromatography on neutral silica gel $\left(\mathrm{CH}_{2} \mathrm{Cl}_{2} / \mathrm{MeOH}, 30: 1 \rightarrow 15: 1\right)$ gave product $\mathbf{1 5}$. 
Product 15, $\mathrm{KBr}\left(54.7 \mathrm{mg}, 0.46 \mathrm{mmol}, 1.1\right.$ equiv), $\mathrm{NaHCO}_{3}(352.8 \mathrm{mg}, 4.2 \mathrm{mmol}, 10.0$ equiv) and TEMPO (27 $\mathrm{mg}, 0.17 \mathrm{mmol}, 0.4$ equiv) was dissolved in DCM $(4.2 \mathrm{~mL})$ and srirred at $0{ }^{\circ} \mathrm{C}$. Then to the mixture was added commercially available disinfectant $\mathrm{NaOCl}(0.12 \mathrm{~mL}, 1.68 \mathrm{mmol}, 4$ equiv). After stirring for another $15 \mathrm{~min}$, the mixture was added $\mathrm{NaOCl}(0.12 \mathrm{~mL}, 1.68 \mathrm{mmol}, 4$ equiv) again and stirred for another $15 \mathrm{~min}$ followed by the last portion of $\mathrm{NaOCl}(0.06 \mathrm{~mL}, 0.84 \mathrm{mmol}, 2$ equiv). After stirring for $6 \mathrm{~h}$, the aqueous layer was quenched with saturated aqueous $\mathrm{Na}_{2} \mathrm{~S}_{2} \mathrm{O}_{3}$ solution $(5 \mathrm{~mL})$, diluted with water $(10 \mathrm{~mL})$ and extracted with $\mathrm{CH}_{2} \mathrm{Cl}_{2}(3 \times 10 \mathrm{~mL})$. The combined organic layers were dried over $\mathrm{Na}_{2} \mathrm{SO}_{4}$ and concentrated. The residue was purified by silica column chromatography $\left(\mathrm{CH}_{2} \mathrm{Cl}_{2} / \mathrm{MeOH}, 30: 1 \rightarrow 15: 1\right)$ to give a single natural product sessilifoliamide A 2 (93 $\mathrm{mg}, 72 \%$ for 3 steps) as a white solid. mp: $162-164{ }^{\circ} \mathrm{C}$. $\left(\right.$ Lit. $\left.^{12} 166-168{ }^{\circ} \mathrm{C}\right) ;[\boldsymbol{\alpha}]_{\mathbf{D}}^{\mathbf{1 8 . 3}}=-145.0\left(\mathrm{c}=2.0\right.$ in $\left.\mathrm{CHCl}_{3}\right)$; [Lit. ${ }^{12}$ for the observed specific rotation of reported sessilifoliamide $\mathrm{A}:[\alpha]_{\mathrm{D}}^{27}=-128\left(\mathrm{c}=0.35\right.$ in $\left.\left.\mathrm{CHCl}_{3}\right)\right] .{ }^{1} \mathbf{H}$ NMR (400 MHz, $\left.\mathbf{C D C l}_{3}\right) \delta 4.09-3.97(\mathrm{~m}, 2 \mathrm{H}), 3.94-3.85(\mathrm{~m}, 1 \mathrm{H}), 3.01-2.88(\mathrm{~m}, 1 \mathrm{H}), 2.65(\mathrm{t}, J=13.2 \mathrm{~Hz}$, $1 \mathrm{H}), 2.57-2.48(\mathrm{~m}, 1 \mathrm{H}), 2.44-2.31(\mathrm{~m}, 3 \mathrm{H}), 2.14-2.06(\mathrm{~m}, 1 \mathrm{H}), 2.03-1.91(\mathrm{~m}, 3 \mathrm{H}), 1.77-1.66(\mathrm{~m}, 2 \mathrm{H})$, $1.66-1.42(\mathrm{~m}, 4 \mathrm{H}), 1.26(\mathrm{~d}, J=7.2 \mathrm{~Hz}, 3 \mathrm{H}), 1.02(\mathrm{t}, J=7.6 \mathrm{~Hz}, 3 \mathrm{H}) .{ }^{13} \mathbf{C} \mathbf{N M R}\left(\mathbf{1 0 1} \mathbf{~ M H z}, \mathbf{C D C l}_{\mathbf{3}}\right) \delta 178.80$, 173.86, 114.55, 79.75, 56.34, 52.02, 49.36, 40.25, 38.83, 36.09, 34.52, 30.76, 25.61, 22.10, 21.24, 15.17, 12.93. IR (KBr, v / cm $\left.{ }^{-1}\right)$ 2932, 1774, 1687, 1459， 1422， 1323， 1275， 1202, 1170, 1139, 965, 924. HRMS (ESI, $\mathbf{m} / \mathbf{z}):[\mathrm{M}+\mathrm{Na}]^{+}$calcd for $\mathrm{C}_{17} \mathrm{H}_{25} \mathrm{NO}_{4} \mathrm{Na}^{+}$330.1676, found 330.1667. CCDC 1883815 contains the supplementary crystallographic data of $\mathbf{2}$. These data can be obtained free of charge from The Cambridge Crystallographic Data Centre via www.ccdc.cam.ac.uk/data_request/cif.

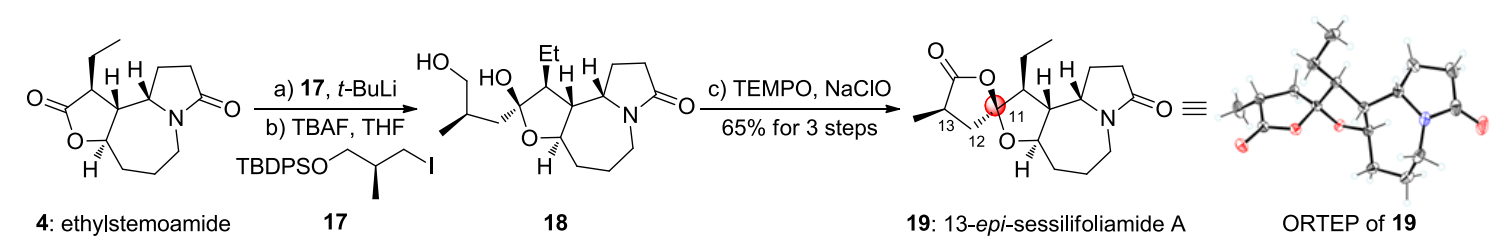

13-epi-sessilifoliamide A 20: To a stirred solution of (S)-tert-butyl(4-iodo-2-methylbutoxy)diphenylsilane 17 (184 mg, $0.42 \mathrm{mmol}, 2$ equiv) in $\mathrm{Et}_{2} \mathrm{O}(4 \mathrm{~mL})$ was added $t$-BuLi (1.3M in pentane, $0.63 \mathrm{~mL}, 0.82 \mathrm{mmol}, 3.9$ equiv) dropwise at $-78{ }^{\circ} \mathrm{C}$ and the solution was stirred at $-78{ }^{\circ} \mathrm{C}$ for $15 \mathrm{~min}$. The mixture was then warmed to -50 ${ }^{\circ} \mathrm{C}$ and stirred for another $15 \mathrm{~min}$ followed by addition of 4 (50 mg, $0.21 \mathrm{mmol}, 1$ equiv) in $\mathrm{Et}_{2} \mathrm{O}$ and toluene (2.1 $\mathrm{mL}, \mathrm{V} / \mathrm{V}=1: 5)$ at $-78{ }^{\circ} \mathrm{C}$. After stirring for $3 \mathrm{~h}$, saturated aqueous $\mathrm{NH}_{4} \mathrm{Cl}$ solution was employed to quench the reaction and EtOAc was used to extract the aqueous layer. The combined organic layers were washed with brine, dried (anhyd $\mathrm{Na}_{2} \mathrm{SO}_{4}$ ) and concentrated. The residue was purified by silica column chromatography (petroleum ether/EtOAc $=1: 1 \rightarrow$ EtOAc $)$ to give the protected product, THF $(1.1 \mathrm{~mL})$ solution of which was added TBAF ( $1 \mathrm{M}$ in THF, $0.27 \mathrm{~mL}, 0.27 \mathrm{mmol}, 1.3$ equiv) in one portion at room temperature and the resultant mixture was stirred for $10 \mathrm{~min}$. Directly silica flash chromatography $\left(\mathrm{CH}_{2} \mathrm{Cl}_{2} / \mathrm{MeOH}, 30: 1 \rightarrow 15: 1\right)$ gave product $\mathbf{1 8}$.

Product 18, $\mathrm{KBr}$ (27.5 mg, 0.23mmol, 1.1 equiv), $\mathrm{NaHCO}_{3}(176 \mathrm{mg}, 2.1 \mathrm{mmol}, 10$ equiv) and TEMPO (13 mg, 0.08 mmol, 0.4 equiv) was dissolved in DCM $(2.1 \mathrm{~mL})$ and stirred at $0{ }^{\circ} \mathrm{C}$. Then to the mixture was added commercially available disinfectant $\mathrm{NaClO}(0.06 \mathrm{~mL}, 0.84 \mathrm{mmol}, 4$ equiv $)$. After stirring for another $15 \mathrm{~min}$, the mixture was added $\mathrm{NaClO}(0.06 \mathrm{~mL}, 0.84 \mathrm{mmol}, 4$ equiv) again and stirred for another $15 \mathrm{~min}$ followed by the 
last portion of $\mathrm{NaClO}(0.03 \mathrm{~mL}, 0.42 \mathrm{mmol}, 2$ equiv). After stirring for $6 \mathrm{~h}$, the aqueous layer was quenched with saturated aqueous $\mathrm{Na}_{2} \mathrm{~S}_{2} \mathrm{O}_{3}$ solution and extracted with $\mathrm{CH}_{2} \mathrm{Cl}_{2}$. The combined organic layers were washed with brine, dried over $\mathrm{Na}_{2} \mathrm{SO}_{4}$ and concentrated. The residue was purified by silica column chromatography $\left(\mathrm{CH}_{2} \mathrm{Cl}_{2} / \mathrm{MeOH}, 30: 1 \rightarrow 15: 1\right)$ to give lactonization products $\mathbf{1 9}$ (42 $\mathrm{mg}, 65 \%$ for 3 steps) as a colorless solid. mp: 148-150 ${ }^{\circ} \mathrm{C}$. $\left(\mathrm{Lit}^{12} 166-168{ }^{\circ} \mathrm{C}\right) ;[\boldsymbol{\alpha}]_{\mathrm{D}}^{19.1}=-122.0\left(\mathrm{c}=5.0\right.$ in $\left.\mathrm{CHCl}_{3}\right)$ ]; [Lit. ${ }^{12}$ for the observed specific rotation of reported sessilifoliamide A: $\left.[\alpha]_{\mathrm{D}}^{27}=-128\left(\mathrm{c}=0.35 \mathrm{in} \mathrm{CHCl}_{3}\right)\right] .{ }^{\mathbf{1}} \mathbf{H} \mathbf{N M R}\left(\mathbf{4 0 0} \mathbf{~ M H z}, \mathbf{C D C l}_{3}\right) \delta 4.09-3.88(\mathrm{~m}$, $3 \mathrm{H}), 2.78-2.61(\mathrm{~m}, 2 \mathrm{H}), 2.59-2.49(\mathrm{~m}, 2 \mathrm{H}), 2.45-2.35(\mathrm{~m}, 2 \mathrm{H}), 2.18-2.10(\mathrm{~m}, 1 \mathrm{H}), 2.03-1.93(\mathrm{~m}, 3 \mathrm{H})$, $1.78-1.66(\mathrm{~m}, 2 \mathrm{H}), 1.65-1.42(\mathrm{~m}, 4 \mathrm{H}), 1.36(\mathrm{~d}, J=7.4 \mathrm{~Hz}, 3 \mathrm{H}), 1.02(\mathrm{t}, J=7.6 \mathrm{~Hz}, 3 \mathrm{H}) .{ }^{13} \mathbf{C}$ NMR (101 MHz, $\left.\mathbf{C D C l}_{3}\right) \delta 178.63,173.84,115.92,79.98,56.34,51.75,50.74,40.28,37.93,36.10,35.47,30.78,25.64,22.11$, 20.98, 17.39, 12.92. IR (KBr, v / $\left.\mathbf{~ c m}^{-1}\right)$ 2961, 2917, 2853, 1769, 1687, 1459, 1422, 1321, 1273, 1204, 960, 923. HRMS (ESI, m/z): $[\mathrm{M}+\mathrm{Na}]^{+}$calcd for $\mathrm{C}_{17} \mathrm{H}_{25} \mathrm{NO}_{4} \mathrm{Na}^{+}$330.1676, found 330.1680. CCDC 1883806 contains the supplementary crystallographic data of 19. These data can be obtained free of charge from The Cambridge Crystallographic Data Centre via www.ccdc.cam.ac.uk/data_request/cif
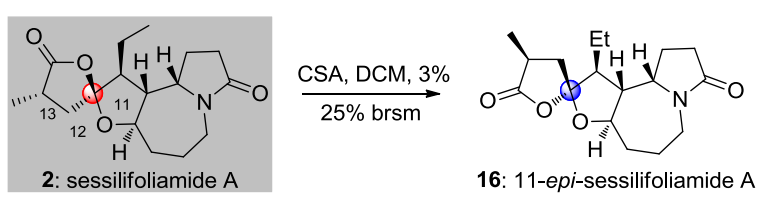

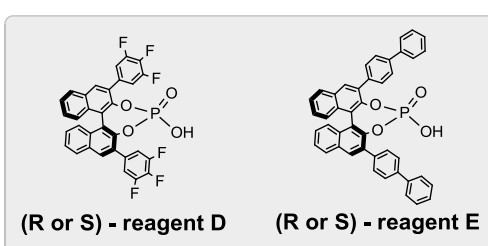

Table S3. Optimization of the acid-catalyzed chiral inversion of spirocenter in sessilifoliamide 2.

\begin{tabular}{|c|c|c|}
\hline entry & conditions & result $^{[\mathrm{a}]}$ \\
\hline 1 & TFA, DCM, $0{ }^{\circ} \mathrm{C}$ & trace \\
\hline 2 & TFA, DCM, r.t. & trace \\
\hline 3 & TFA, DCM, $40{ }^{\circ} \mathrm{C}$ & trace \\
\hline 4 & (R)-reagent $\mathbf{D}$, DCM, r.t. & trace \\
\hline 5 & (R)-reagent $\mathrm{D}, \mathrm{DCM}, 40^{\circ} \mathrm{C}$ & trace \\
\hline 6 & (S)-reagent $\mathbf{D}, \mathrm{DCM}, 40^{\circ} \mathrm{C}$ & trace \\
\hline 7 & (R)-reagent $\mathbf{E}$, toluene, $40{ }^{\circ} \mathrm{C}$. & trace \\
\hline 8 & (S)-reagent $\mathbf{E}$, toluene, $40{ }^{\circ} \mathrm{C}$. & trace \\
\hline 9 & $\mathrm{MgSO}_{4}$, toluene, $80{ }^{\circ} \mathrm{C}$ & slow degradation \\
\hline 10 & $\mathrm{ZnCl}_{2}$, DCM, r.t. & slow degradation \\
\hline 11 & $\mathrm{AcOH}^{[\mathrm{b}]}$ & trace \\
\hline 12 & PPTS & trace \\
\hline 13 & $p$-TsOH, DCM, r.t. & trace \\
\hline 14 & CSA, DCM, r.t. & $<5 \%$ \\
\hline
\end{tabular}

[a] Reactions was obtained by ${ }^{1} \mathrm{HNMR}$.

[b] directly used as solvent. 
11-epi-Sessilifoliamide A 16: To a stirred solution of sessilifoliamide A 2 (110 mg, $0.36 \mathrm{mmol}, 1.0$ equiv) in $\mathrm{CH}_{2} \mathrm{Cl}_{2}(5 \mathrm{~mL})$ was added camphorsulfonic acid (CSA) (16 mg, $0.072 \mathrm{mmol}, 0.2$ equiv) and the solution was stirred at room temperature for $12 \mathrm{~h}$. Then the mixture was quenched with saturated aqueous $\mathrm{NaHCO}_{3}$ solution $(10 \mathrm{~mL})$ and extracted with $\mathrm{CH}_{2} \mathrm{Cl}_{2}(3 \times 8 \mathrm{~mL})$. The combined organic layers were washed with brine, dried over $\mathrm{Na}_{2} \mathrm{SO}_{4}$ and concentrated. The residue was purified by silica column chromatography (EtOAc /petroleum ether $=$ $10: 1 \rightarrow$ EtOAc) to give $\mathbf{1 6}(3.3 \mathrm{mg}, 3 \%, 25 \% \mathrm{brsm}$, brsm = based on recovered starting material) as a amorphous solid and the recovered $2(97 \mathrm{mg}, 88 \%)$ was. mp: $156-158{ }^{\circ} \mathrm{C}$. $\left(\mathrm{Lit}^{12} 166-168{ }^{\circ} \mathrm{C}\right) ;[\boldsymbol{\alpha}]_{\mathrm{D}}^{22.2}=-132.0(\mathrm{c}=2.0$ in $\left.\mathrm{CHCl}_{3}\right)$; $\left[\right.$ Lit. $^{12}$ for the observed specific rotation of reported sessilifoliamide $\mathrm{A}:[\alpha]_{\mathrm{D}}^{27}=-128(\mathrm{c}=0.35$ in $\left.\left.\mathrm{CHCl}_{3}\right)\right] .{ }^{1} \mathbf{H}$ NMR (400 MHz, $\left.\mathbf{C D C l}_{3}\right) \delta 4.15-4.06(\mathrm{~m}, 1 \mathrm{H}), 4.03-3.89(\mathrm{~m}, 2 \mathrm{H}), 2.77-2.51(\mathrm{~m}, 3 \mathrm{H}), 2.43-$ $2.30(\mathrm{~m}, 2 \mathrm{H}), 2.27-2.14(\mathrm{~m}, 2 \mathrm{H}), 2.13-1.88(\mathrm{~m}, 4 \mathrm{H}), 1.83-1.68(\mathrm{~m}, 2 \mathrm{H}), 1.59-1.37(\mathrm{~m}, 4 \mathrm{H}), 1.29-1.24(\mathrm{~m}$, 2H), $0.97(\mathrm{t}, J=7.3 \mathrm{~Hz}, 3 \mathrm{H}) .{ }^{13} \mathbf{C}$ NMR (101 $\left.\mathbf{~ M H z}, \mathbf{C D C l}_{3}\right) \delta 178.43,174.43,116.33,78.50,57.47,53.62,50.00$, 40.31, 35.84, 35.61, 34.22, 30.69, 25.65, 25.50, 22.81, 16.91, 11.68. IR (KBr, v / $\left.\mathbf{~ m}^{-1}\right)$ 2965, 2929, 2885, 1776, 1687, 1459, 1422, 1323, 1273, 911. HRMS (ESI, m/z): $[\mathrm{M}+\mathrm{Na}]^{+}$calcd for $\mathrm{C}_{17} \mathrm{H}_{25} \mathrm{NO}_{4} \mathrm{Na}^{+}$330.1676, found 330.1682 .

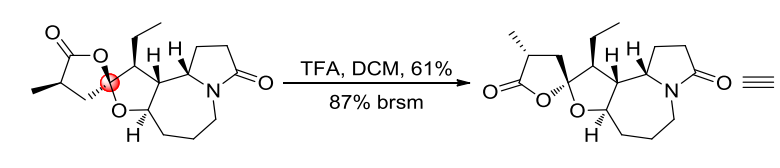

19: 13-epi-sessilifoliamide A

20: 11,13-bis-epi-sessilifoliamide A

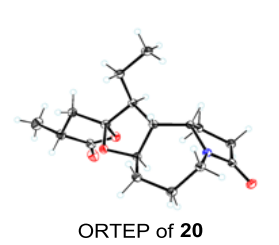

ORTEP of $\mathbf{2 0}$

11,13-bis-epi-sessilifoliamide A 20: To a stirred solution of $\mathbf{1 9}$ (220 mg, $0.72 \mathrm{mmol}, 1$ equiv) in $\mathrm{CH}_{2} \mathrm{Cl}_{2}(7.2 \mathrm{~mL})$ was added trifluoromethanesulfonic acid (TFA) $(22 \mathrm{mg}, 0.14 \mathrm{mmol}, 0.2$ equiv) and the solution was stirred at room temperature for $2 \mathrm{~h}$. Then the mixture was quenched with saturated aqueous $\mathrm{NaHCO}_{3}$ solution and extracted with $\mathrm{CH}_{2} \mathrm{Cl}_{2}(3 \times 20 \mathrm{~mL})$. The combined organic layers were washed with brine, dried over $\mathrm{Na}_{2} \mathrm{SO}_{4}$ and concentrated. The residue was purified by silica column chromatography (EtOAc /petroleum ether $=10: 1 \rightarrow$ EtOAc) to give $\mathbf{2 0}(134.8 \mathrm{mg}, 61 \%, 87 \% \mathrm{brsm})$ as a white solid and the recovered 19 (65 mg, 30\%). mp: $150-152{ }^{\circ} \mathrm{C} .\left(\mathrm{Lit}^{12} 166-168{ }^{\circ} \mathrm{C}\right) ;[\boldsymbol{\alpha}]_{\mathrm{D}}^{22.2}=-135.0\left(\mathrm{c}=2.0\right.$ in $\left.\mathrm{CHCl}_{3}\right) ;\left[\mathrm{Lit}^{12}\right.$ for the observed specific rotation of reported sessilifoliamide A: $[\alpha]_{\mathrm{D}}^{27}=-128\left(\mathrm{c}=0.35\right.$ in $\left.\left.\mathrm{CHCl}_{3}\right)\right] .{ }^{1} \mathbf{H}$ NMR $\left(\mathbf{4 0 0} \mathbf{~ M H z}, \mathbf{C D C l}_{3}\right) \delta 4.13-4.06(\mathrm{~m}$, $1 \mathrm{H}), 3.99-3.88(\mathrm{~m}, 2 \mathrm{H}), 3.01-2.86(\mathrm{~m}, 1 \mathrm{H}), 2.66(\mathrm{t}, J=12.7 \mathrm{~Hz}, 1 \mathrm{H}), 2.42-2.29(\mathrm{~m}, 3 \mathrm{H}), 2.26-2.15(\mathrm{~m}, 2 \mathrm{H})$, $2.13-1.92(\mathrm{~m}, 4 \mathrm{H}), 1.81-1.71(\mathrm{~m}, 2 \mathrm{H}), 1.61-1.35(\mathrm{~m}, 2 \mathrm{H}), 1.30-1.16(\mathrm{~m}, 4 \mathrm{H}), 0.97(\mathrm{t}, J=7.3 \mathrm{~Hz}, 3 \mathrm{H}) .{ }^{13} \mathbf{C}$ NMR (101 MHz, $\left.\mathbf{C D C l}_{3}\right) \delta 178.52,174.41,114.81,78.11,57.49,53.71,49.11,40.27,37.72,34.93,34.09,30.66$, 25.64, 24.85, 22.76, 14.82, 11.58. IR (KBr, v / $\left.\mathbf{~ c m}^{-1}\right)$ 2967, 2941, 2879, 1776, 1687, 1452, 1422, 1321, 1295, 1273, 1251, 1215, 1165, 1137, 1049, 1019, 960, 919. HRMS (ESI, m/z): $[\mathrm{M}+\mathrm{Na}]^{+}$calcd for $\mathrm{C}_{17} \mathrm{H}_{25} \mathrm{NO}_{4} \mathrm{Na}^{+}$ 330.1676, found 330.1673. CCDC 1883804 contains the supplementary crystallographic data of $\mathbf{2 0}$. These data can be obtained free of charge from The Cambridge Crystallographic Data Centre via www.ccdc.cam.ac.uk/data_request/cif. 


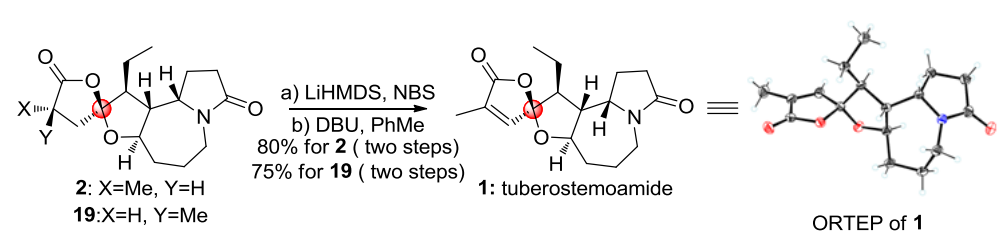

Tuberostemoamide 1 : To a stirred solution of 2 or $\mathbf{1 9}(950 \mathrm{mg}, 3.09 \mathrm{mmol}, 1.0$ equiv) in THF (31 mL) was added LiHMDS (1.0 in THF, $4.64 \mathrm{~mL}, 4.64 \mathrm{mmol}, 1.5$ equiv) at $-78{ }^{\circ} \mathrm{C}$. After being stirred at the same temperature for $1 \mathrm{~h}, \mathrm{~N}$-bromosuccinimide $(821 \mathrm{mg}, 4.64 \mathrm{mmol}, 1.5$ equiv) in THF (14 mL) was added. The resulting mixture was stirred for another $4 \mathrm{~h}$ at $-30{ }^{\circ} \mathrm{C}$, then warmed to room temperature and stirred for $10 \mathrm{~min}$. After being quenched with saturated aqueous $\mathrm{NH}_{4} \mathrm{Cl}$ solution and extracted with $\operatorname{EtOAc}(3 \times 50 \mathrm{~mL})$, the organic layer was washed with brine and dried over $\mathrm{Na}_{2} \mathrm{SO}_{4}$, and concentrated under reduced pressure to leave the residue, which was then purified by column chromatography (EtOAc $\rightarrow \mathrm{CH}_{2} \mathrm{Cl}_{2} / \mathrm{MeOH}=30: 1$ ) to give the bromo intermediate. Then the bromo intermediate was dissolved in toluene $(62 \mathrm{~mL})$ followed by a subsequent addition of 1,8-Diazabicyclo[5.4.0]undec-7-ene (1.41 g, $9.27 \mathrm{mmol}, 3.0$ equiv). After stirred at $80{ }^{\circ} \mathrm{C}$ for $2 \mathrm{~h}$, the mixture was quenched with saturated aqueous $\mathrm{NH}_{4} \mathrm{Cl}$ solution and the organic layer was separated. Then the aqueous layer was extracted with EtOAc $(3 \times 50 \mathrm{~mL})$ and the combined organic phase was washed with brine, dried over anhydrous $\mathrm{Na}_{2} \mathrm{SO}_{4}$, filtered, and evaporated under vacuum. which was subjected to column chromatography on silica gel (EtOAc $\left.\rightarrow \mathrm{CH}_{2} \mathrm{Cl}_{2} / \mathrm{MeOH}=30: 1\right)$ to afford tuberostemoamide $1(754 \mathrm{mg}, 80 \%$ for $2 ; 707 \mathrm{mg}, 75 \%$ for 19) as a white solid. mp: $150-152{ }^{\circ} \mathrm{C}$. $\left(\right.$ Lit. $\left.^{13-14} 155-157{ }^{\circ} \mathrm{C}\right) ; \quad[\boldsymbol{\alpha}]_{\mathrm{D}}^{\mathbf{2 4 . 8}}=-90.0(\mathrm{c}=0.08$ in MeOH$) ;\left[\right.$ Lit. ${ }^{13-14}$ for the observed specific rotation of reported tuberostemoamide: $[\alpha]_{\mathrm{D}}=-94(\mathrm{c}=0.06$ in $\left.\mathrm{MeOH})\right] .{ }^{1} \mathbf{H}$ NMR (400 $\left.\mathbf{M H z}, \mathbf{C D C l}_{3}\right) \delta 6.65(\mathrm{q}, J=1.4 \mathrm{~Hz}, 1 \mathrm{H}), 4.11-3.97(\mathrm{~m}, 3 \mathrm{H}), 2.77-2.57(\mathrm{~m}, 2 \mathrm{H}), 2.44-2.36(\mathrm{~m}, 2 \mathrm{H}), 2.19-$ $2.11(\mathrm{~m}, 2 \mathrm{H}), 2.04-1.96(\mathrm{~m}, 1 \mathrm{H}), 1.94(\mathrm{~d}, J=1.6 \mathrm{~Hz}, 3 \mathrm{H}), 1.81-1.59(\mathrm{~m}, 3 \mathrm{H}), 1.54-1.34(\mathrm{~m}, 3 \mathrm{H}), 0.89(\mathrm{t}, J=$ $7.6 \mathrm{~Hz}, 3 \mathrm{H}) .{ }^{13} \mathbf{C}$ NMR (101 MHz, $\left.\mathbf{C D C l}_{3}\right) \delta$ 173.73, 171.18, 143.87, 134.05, 113.53, 80.60, 56.02, 51.69, 49.56, 40.18, 35.68, 30.66, 25.48, 21.99, 20.19, 12.82, 10.50. IR (KBr, v/ $\left.\mathbf{~ c m}^{-1}\right)$ 3055, 2926, 2855, 1765, 1681, 1459, 1446, 1321, 1265, 973, 874, 736, 703. HRMS (ESI, m/z): $[\mathrm{M}+\mathrm{Na}]^{+}$calcd for $\mathrm{C}_{17} \mathrm{H}_{23} \mathrm{NO}_{4} \mathrm{Na}^{+} 328.1519$, found 328.1527. CCDC 1874369 contains the supplementary crystallographic data of $\mathbf{1}$. These data can be obtained free of charge from The Cambridge Crystallographic Data Centre via www.ccdc.cam.ac.uk/data_request/cif. 


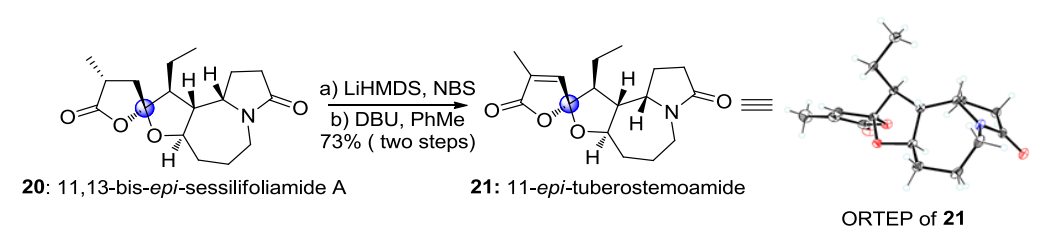

11-epi-tuberostemoamide 21: To a stirred solution of 20 (475 mg, $1.55 \mathrm{mmol}, 1.0$ equiv) in THF (15 mL) was added LiHMDS (1.0 in THF, $2.33 \mathrm{~mL}, 2.33 \mathrm{mmol}, 1.5$ equiv) at $-78{ }^{\circ} \mathrm{C}$. After being stirred at the same temperature for $1 \mathrm{~h}, \mathrm{~N}$-bromosuccinimide $(415 \mathrm{mg}, 2.33 \mathrm{mmol}, 1.5$ equiv) in THF (7 mL) was added. The resulting mixture was stirred for another $4 \mathrm{~h}$ at $-30{ }^{\circ} \mathrm{C}$, then warmed to room temperature and stirred for $10 \mathrm{~min}$. After being quenched with saturated aqueous $\mathrm{NH}_{4} \mathrm{Cl}$ solution and extracted with EtOAc, the organic layer was washed with brine and dried over $\mathrm{Na}_{2} \mathrm{SO}_{4}$, and concentrated under reduced pressure to leave the residue, which was then purified by column chromatography (EtOAc $\left.\rightarrow \mathrm{CH}_{2} \mathrm{Cl}_{2} / \mathrm{MeOH}=30: 1\right)$ to give the bromo intermediate. Then the bromo intermediate was dissolved in toluene $(30 \mathrm{~mL})$ followed by a subsequent addition of 1,8-Diazabicyclo[5.4.0]undec-7-ene (707 mg, $4.65 \mathrm{mmol}, 3.0$ equiv). After stirred at $80{ }^{\circ} \mathrm{C}$ for $2 \mathrm{~h}$, the mixture was quenched with saturated aqueous $\mathrm{NH}_{4} \mathrm{Cl}$ solution and the organic layer was separated. Then the aqueous layer was extracted with EtOAc $(3 \times 50 \mathrm{~mL})$ and the combined organic phase was washed with water $(20 \mathrm{ml})$ and brine $(3 \times 15 \mathrm{~mL})$, dried over anhydrous $\mathrm{Na}_{2} \mathrm{SO}_{4}$, filtered, and evaporated under vacuum. which was subjected to column chromatography on silica gel (EtOAc $\left.\rightarrow \mathrm{CH}_{2} \mathrm{Cl}_{2} / \mathrm{MeOH}=30: 1\right)$ to afford 21 (345 $\mathrm{mg}, 73 \%$ ) as a white solid. mp: $147-149^{\circ} \mathrm{C}$. $\left(\right.$ Lit. $\left.{ }^{13-14} 155-157{ }^{\circ} \mathrm{C}\right) ;[\boldsymbol{\alpha}]_{\mathbf{D}}^{24.7}=-101.0(\mathrm{c}=0.08$ in MeOH$)$; [Lit. ${ }^{13-14}$ for the observed specific rotation of reported tuberostemoamide: $[\alpha]_{\mathrm{D}}=-94(\mathrm{c}=0.06$ in $\left.\mathrm{MeOH})\right] .{ }^{1} \mathbf{H} \mathbf{~ N M R}\left(\mathbf{4 0 0} \mathbf{~ M H z}, \mathbf{C D C l}_{3}\right)$ $\delta 6.76(\mathrm{q}, J=1.7 \mathrm{~Hz}, 1 \mathrm{H}), 4.16-4.08(\mathrm{~m}, 2 \mathrm{H}), 3.99-3.91(\mathrm{~m}, 1 \mathrm{H}), 2.66(\mathrm{~m}, 1 \mathrm{H}), 2.42-2.32(\mathrm{~m}, 3 \mathrm{H}), 2.26-$ $2.16(\mathrm{~m}, 2 \mathrm{H}), 2.10-1.92(\mathrm{~m}, 5 \mathrm{H}), 1.71-1.35(\mathrm{~m}, 5 \mathrm{H}), 0.93(\mathrm{t}, J=7.4 \mathrm{~Hz}, 3 \mathrm{H}) .{ }^{13} \mathbf{C} \mathbf{N M R}\left(\mathbf{1 0 1} \mathbf{~ M H z}, \mathbf{C D C l}_{3}\right) \delta$ 174.29, 170.89, 142.39, 133.72, 114.15, 80.58, 57.18, 54.55, 50.92, 40.29, 34.38, 30.61, 26.43, 25.54, 22.87, 12.15, 10.63. IR (KBr, v / $\left.\mathbf{c m}^{-1}\right)$ 2933, 2874, 1765, 1687, 1448, 1422, 1318, 1293, 1273, 1172, 1103, 1023, 993 , 956, 926, 760. HRMS (ESI, m/z): $[\mathrm{M}+\mathrm{Na}]^{+}$calcd for $\mathrm{C}_{17} \mathrm{H}_{23} \mathrm{NO}_{4} \mathrm{Na}^{+} 328.1519$, found 328.1533. CCDC 1883814 contains the supplementary crystallographic data of $\mathbf{2 1}$. These data can be obtained free of charge from The Cambridge Crystallographic Data Centre via www.ccdc.cam.ac.uk/data_request/cif.

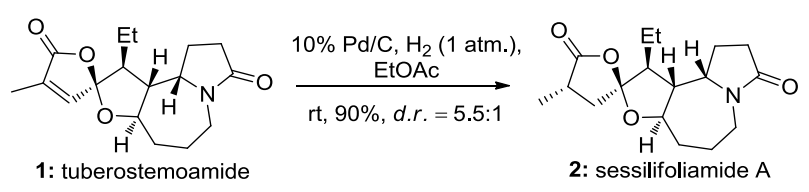

Transformation of Tuberostemoamide (1) to sessilifoliamide A (2) : Tuberostemoamide 1 (12 mg, 0.0393 mmol, 1.0 equiv) was dissolved in EtOAc $(1 \mathrm{~mL})$ and $10 \% \mathrm{Pd} / \mathrm{C}(12.5 \mathrm{mg}, 0.0118 \mathrm{mmol}, 0.3$ equiv) was added under argon atmosphere, then argon was replaced with $\mathrm{H}_{2}$ (in a balloon). The reaction mixture was stirred at room temperature for $12 \mathrm{~h}$. After completion of the reaction, $\mathrm{H}_{2}$ atmosphere was removed. The mixture was passed through Celite-sintered glass funnel, and the filtrate was evaporated under reduced pressure. The residue was directly purified by silica column chromatography $\left(\mathrm{CH}_{2} \mathrm{Cl}_{2} / \mathrm{MeOH}=15: 1\right)$ to give a mixture of sessilifoliamide A 2 and its epimer 13-epi-sessilifoliamide A 19 with a ratio of 5.5: 1 (10.9 $\mathrm{mg}, 90 \%)$. 
III. Proposed Thermodynamic and Kinetic Analysis for the Stereoselective Reduction of $\mathrm{C}=\mathrm{C}$ Bond in 12.

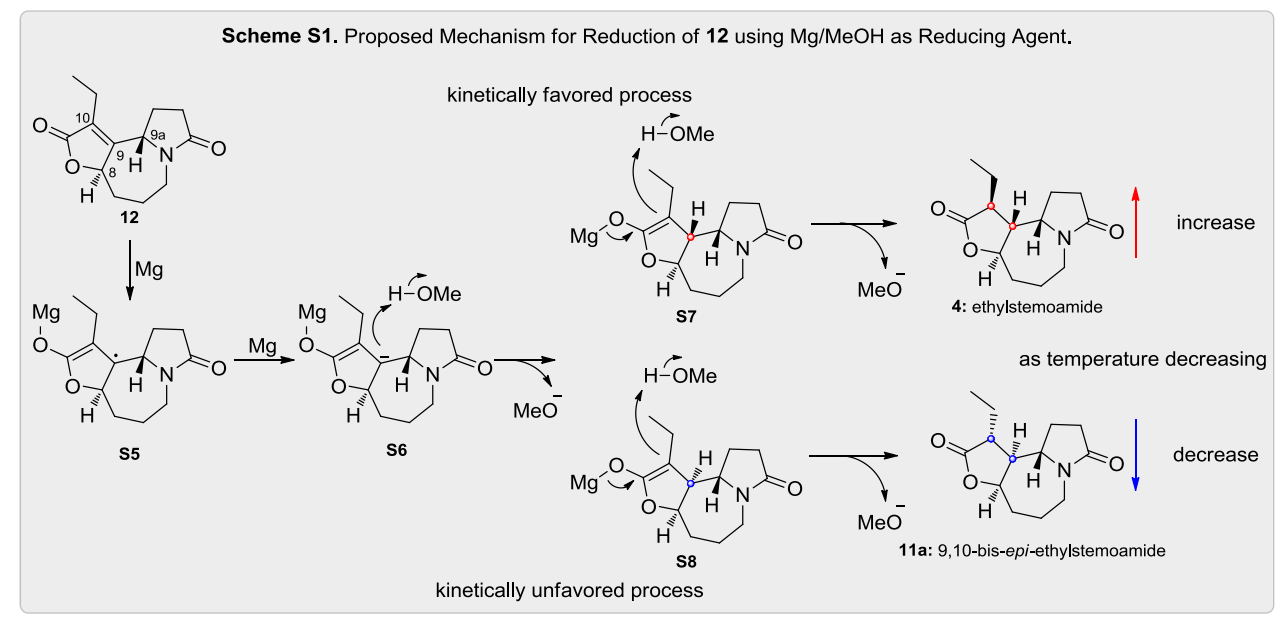

According to the experimental results in $\mathrm{Mg} / \mathrm{MeOH}$ reduction, we considered that the mechanism of the reduction process may be as follows (Scheme S1): compound $\mathbf{1 2}$ suffered from two subsequent reduction reactions by $\mathrm{Mg}$ and formed anion S6. S6 could spontaneously maintain the thermodynamically more stable configuration under thermodynamic control, then the thermodynamically more stable configuration of S6 was quenched by proton arised from $\mathrm{MeOH}$ to give two isomers $\mathbf{S 7}$ and $\mathbf{S 8}$ with a certain degree of stereoselectivity. When the temperature was lower, the above mentioned proton quench process was prior to be under kinetic control to give the kinetically more stable configuration $\mathbf{S 7}$ as the major product, while $\mathbf{S 8}$ as the minor product. So C9 position was not only under thermodynamic control but also under kinetic control. With stereochemistry at C9 determined, 4 and 11a with the determined stereochemistry at C10 were respectively obtained as the only product of the stereoselective proton quench of $\mathbf{S 7}$ and $\mathbf{S 8}$ under thermodynamic control. In other words, C10 position was under thermodynamic control.

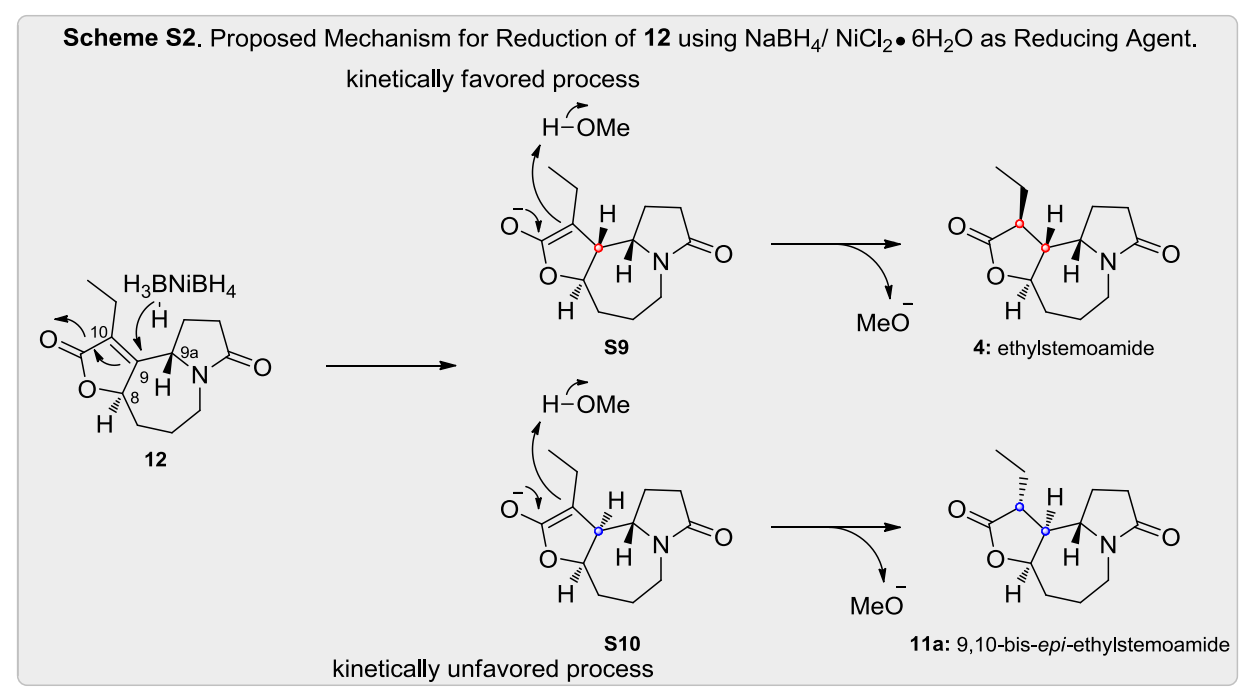

Based on the experimental results in $\mathrm{NaBH}_{4} / \mathrm{NiCl}_{2} \cdot 6 \mathrm{H}_{2} \mathrm{O}$ reduction, we considered that the mechanism of the reduction process may be as follows (Scheme S2): hydrogen anion was added to C9 position with a certain degree of stereoselectivity to afford two enol anions $\mathbf{S 9}$ and S10. When the temperature was lower, the above 
mentioned proton quench process was prior to be under kinetic control to give the kinetically more stable configuration $\mathbf{S 9}$ as the major product, while $\mathbf{S 1 0}$ as the minor product. The two enol anions were then suffered from the similar process as those of $\mathbf{S 7}$ and $\mathbf{S 8}$ to respectively give product $\mathbf{4}$ and $\mathbf{1 1 a}$ as the single product. As analyzed above, the whole processes in both $\mathrm{NaBH}_{4} / \mathrm{NiCl}_{2} \cdot 6 \mathrm{H}_{2} \mathrm{O}$ and $\mathrm{Mg} / \mathrm{MeOH}$ reduction were greatly similar to each other, and the mechanism was stereoselective hydrogen addition one by one to the $\mathrm{C}=\mathrm{C}$ bond. In conclusion, C9 position may be not only under thermodynamic but also under kinetic control; in the premise that stereochemistry of C9 was confirmed, C10 position may be under thermodynamic control, only in this way could a single product with the thermodynamically most stable configuration be obtained in the last quench step.

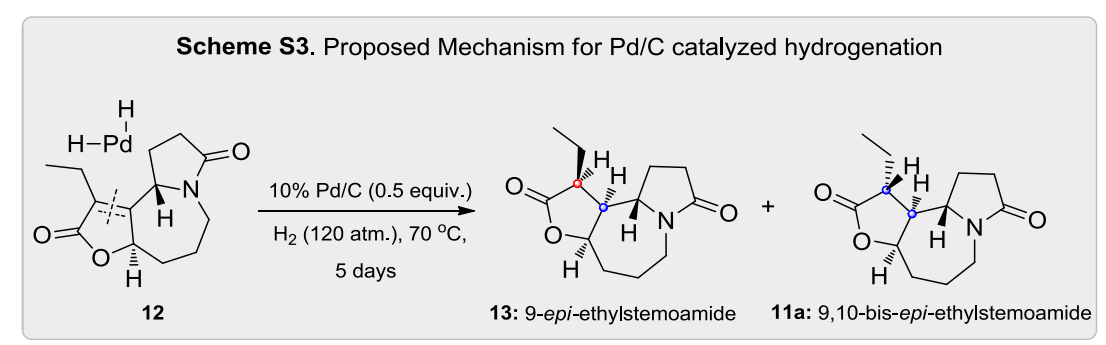

On the basis of the experimental result in $\mathrm{Pd} / \mathrm{C}$ reduction, we considered that the mechanism of the reduction process may be as follows (Scheme $\mathbf{S 3}$ ): under catalysis of $\mathrm{Pd} / \mathrm{C}$, cis-hydrogenation from the least hindered back face of $\mathrm{C}=\mathrm{C}$ bond in $\mathbf{1 2}$ was happened to form 9-epi-ethylstemoamide 13. 13 was then transformed into 9,10-bis-epi-ethylstemoamide 11a under this harsh condition, which led to the consequence that a mixture of $\mathbf{1 3}$ and 11a with a ratio of 1:1.2 was considered as the ultimate product of $\mathrm{Pd} / \mathrm{C}$ catalyzed hydrogenation. The facile epimerization at $\mathrm{C} 10$ of $\mathbf{1 3}$ to 11a is in good accordance with the fact that $\alpha$-Me isomer is thermodynamically more stable than $\beta$-Me isomer (MM2 calculations) in the synthesis of 9,10-bis-epi-stemoamide. ${ }^{4}$ Different from the one by one hydrogen addition to the $\mathrm{C}=\mathrm{C}$ bond, $\mathrm{Pd} / \mathrm{C}$ catalyzed hydrogenation was a facial selective cis-addition of a pair of hydrogens to the least hindered $\alpha$-face of $\mathrm{C}=\mathrm{C}$ bond, so the process was under kinetic control. 


\section{Epimers.}

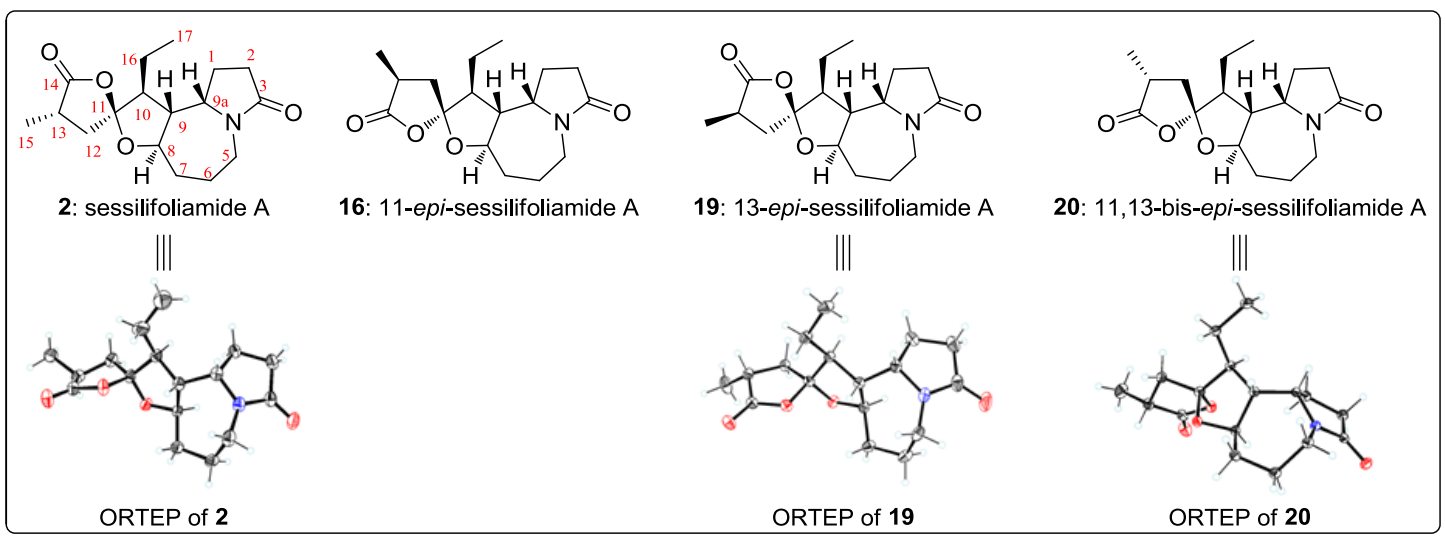

Table S4. Comparison of ${ }^{1} \mathrm{H}$ NMR data assignment of natural and synthetic sessilifoliamide A (2).

\begin{tabular}{|c|c|c|c|}
\hline${ }^{1} \mathbf{H}$ position & Natural $2^{\mathrm{a}, \mathrm{c}}$ & Synthetic 2 & leviation) $\mathrm{d}^{\mathrm{d}, \mathrm{e}}$ \\
\hline & $1.67(\mathrm{~m})$ & $1.66-1.42(\mathrm{~m})$ & - \\
\hline 1 & $1.98(\mathrm{~m})$ & $2.03-1.91(\mathrm{~m})$ & - \\
\hline 2 & $2.37(\mathrm{~m})$ & $2.44-2.31(\mathrm{~m})$ & - \\
\hline 5 & 2.64(brt, 12.4) & $2.65(\mathrm{t}, 13.2)$ & - \\
\hline J & 3.61(brd,14.0) & $3.94-3.85(\mathrm{~m})$ & $(-0.33 \sim-0.24)$ \\
\hline 6 & $1.44(\mathrm{~m})$ & $1.66-1.42(\mathrm{~m})$ & - \\
\hline & $1.69(\mathrm{~m})$ & $1.77-1.66(\mathrm{~m})$ & - \\
\hline 7 & $1.53(\mathrm{~m})$ & $1.77-1.66(\mathrm{~m})$ & - \\
\hline & $2.09(\mathrm{~m})$ & $2.14-2.06(\mathrm{~m})$ & - \\
\hline 8 & $3.90(\mathrm{ddd}, 2.6,9.9,10.6)$ & $4.09-3.97(\mathrm{~m})$ & - \\
\hline 9 & $2.52(\mathrm{~m})$ & $2.57-2.48(\mathrm{~m})$ & - \\
\hline 9a & $4.00(\mathrm{~m})$ & $4.09-3.97(\mathrm{~m})$ & - \\
\hline 10 & $1.93(\mathrm{~m})$ & $2.03-1.91(\mathrm{~m})$ & - \\
\hline 12 & $1.97(\mathrm{~m})$ & $2.03-1.91(\mathrm{~m})$ & - \\
\hline & $2.36(\mathrm{~m})$ & $2.44-2.31(\mathrm{~m})$ & - \\
\hline 13 & $2.93(\mathrm{~m})$ & $3.01-2.88(\mathrm{~m})$ & - \\
\hline 15 & $1.25(\mathrm{~d}, 7.2)$ & $1.26(\mathrm{~d}, 7.2)$ & - \\
\hline 16 & $1.56(\mathrm{~m})$ & $1.66-1.42(\mathrm{~m})$ & - \\
\hline 17 & $1.01(\mathrm{t}, 7.7)$ & $1.02(\mathrm{t}, 7.6)$ & - \\
\hline
\end{tabular}

${ }^{\text {a }}$ Recorded in $\mathrm{CDCl}_{3}, 300 \mathrm{MHz} .{ }^{\mathrm{b}}$ Recorded in $\mathrm{CDCl}_{3}, 400 \mathrm{MHz} .{ }^{\mathrm{c}}$ Multiplicity and $J$ values in $\mathrm{Hz}$ are given in parentheses. ${ }^{\mathrm{d}}$ Deviations $\left(\right.$ given in parentheses) $=$ Natural - Synthetic. ${ }^{e}$ Distinct ${ }^{1} \mathrm{H}$ NMR deviations was marked with red . 
Table S5. Comparison of ${ }^{1} \mathrm{H}$ NMR data assignment of natural and synthetic sessilifoliamide A (2) and its epimers.

\begin{tabular}{|c|c|c|c|c|c|}
\hline $\begin{array}{c}{ }^{1} \mathrm{H} \\
\text { Position } \\
\end{array}$ & Natural $2^{\mathrm{a}, \mathrm{e}}$ & $\begin{array}{l}\text { Synthetic } 2^{\mathrm{b}, \mathrm{c}} \\
\text { (deviation) }^{\mathrm{d}, \mathrm{e}}\end{array}$ & $\begin{array}{l}\text { Synthetic } 16^{\mathrm{b}, \mathrm{c}} \\
(\text { deviation })^{\mathrm{d}, \mathrm{e}}\end{array}$ & $\begin{array}{l}\text { Synthetic } 19^{\mathrm{b}, \mathrm{c}} \\
\text { (deviation) }^{\mathrm{d}, \mathrm{e}}\end{array}$ & $\begin{array}{l}\text { Synthetic } 20^{\mathrm{b}, \mathrm{c}} \\
(\text { deviation })^{\mathrm{d}, \mathrm{e}}\end{array}$ \\
\hline & 2.64(brt, 12.4) & $2.65(\mathrm{t}, 13.2)$ & $2.77-2.51(\mathrm{~m})$ & $2.78-2.61(\mathrm{~m})$ & $2.66(\mathrm{t}, 12.7)$ \\
\hline 5 & 3.61(brd,14.0) & $\begin{array}{c}4.09-3.97(\mathrm{~m}) \\
(-0.48 \sim-0.36)\end{array}$ & $\begin{array}{l}4.03-3.89(\mathrm{~m}) \\
(-0.42 \sim-0.28)\end{array}$ & $\begin{array}{c}4.09-3.88(\mathrm{~m}) \\
(-0.48 \sim-0.27)\end{array}$ & $\begin{array}{c}3.99-3.87(\mathrm{~m}) \\
(-0.38 \sim-0.26)\end{array}$ \\
\hline 15 & $1.25(\mathrm{~d}, 7.2)$ & $1.26(\mathrm{~d}, 7.2)$ & $\begin{array}{c}1.59-1.37(\mathrm{~m}) \\
(-0.34 \sim-0.12)\end{array}$ & $\begin{array}{c}1.36(d, 7.4) \\
(-0.11)\end{array}$ & $1.29-1.17(\mathrm{~m})$ \\
\hline
\end{tabular}

${ }^{\mathrm{a}}$ Recorded in $\mathrm{CDCl}_{3}, 300 \mathrm{MHz} .{ }^{\mathrm{b}}$ Recorded in $\mathrm{CDCl}_{3}, 400 \mathrm{MHz} .{ }^{\mathrm{c}}$ Multiplicity and $J$ values in $\mathrm{Hz}$ are given in parentheses. ${ }^{\mathrm{d}}$ Deviations $\left(\right.$ given in parentheses) $=$ Natural - Synthetic. ${ }^{e}$ Distinct ${ }^{1} \mathrm{H}$ NMR deviations was marked with red.

Comparison of ${ }^{1} \mathrm{H}$ NMR spectra of synthetic sessilifoliamide A (2) and its epimers.
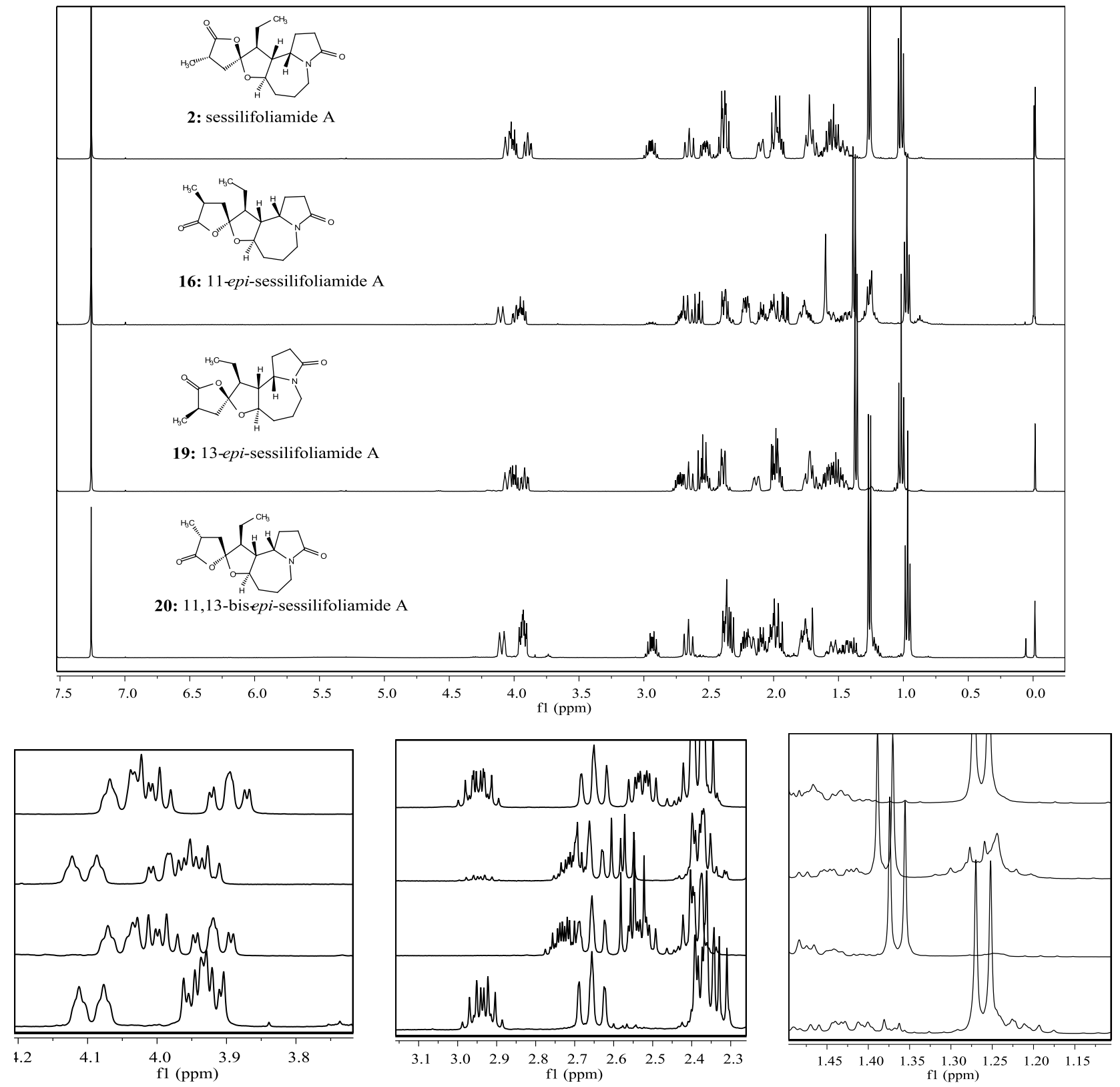
Table. S6 Comparison of ${ }^{13} \mathrm{C}$ NMR data assignment of natural and synthetic sessilifoliamide A (2) and its epimers.

\begin{tabular}{|c|c|c|c|c|c|c|c|c|c|}
\hline \multirow{2}{*}{ 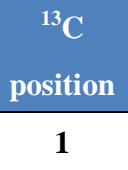 } & \multirow{2}{*}{$\frac{\text { Natural } 2^{\text {a }}}{22.1}$} & \multicolumn{2}{|c|}{$\begin{array}{l}\text { Synthetic } 2^{\mathrm{b}} \\
\text { (deviation) }^{\mathrm{c}, \mathrm{d}}\end{array}$} & \multicolumn{2}{|c|}{$\begin{array}{l}\text { Synthetic } 16^{\mathrm{b}} \\
\text { (deviation) }^{\mathrm{c}, \mathrm{d}}\end{array}$} & \multicolumn{2}{|c|}{$\begin{array}{l}\text { Synthetic } 19^{b} \\
\text { (deviation) }^{\mathrm{c}, \mathrm{d}}\end{array}$} & \multicolumn{2}{|c|}{$\begin{array}{l}\text { Synthetic } 20^{\mathbf{b}} \\
\text { (deviation) }^{\mathbf{c}, \mathbf{d}}\end{array}$} \\
\hline & & 22.1 & (0) & 25.5 & $(-3.4)$ & 22.1 & (0) & 24.9 & $(-2.8)$ \\
\hline 2 & 30.8 & 30.8 & $(0)$ & 30.7 & $(+0.1)$ & 30.8 & (0) & 30.7 & $(+0.1)$ \\
\hline 3 & 174.0 & 173.9 & $(+0.1)$ & 174.4 & $(-0.4)$ & 173.8 & $(+0.2)$ & 174.4 & $(-0.4)$ \\
\hline 5 & 40.3 & 40.3 & $(0)$ & 40.3 & $(0)$ & 40.3 & (0) & 40.3 & $(0)$ \\
\hline 6 & 25.6 & 25.6 & $(0)$ & 25.7 & $(-0.1)$ & 25.6 & $(0)$ & 25.6 & $(0)$ \\
\hline 7 & 36.1 & 36.1 & $(0)$ & 35.6 & $(+0.5)$ & 36.1 & (0) & 34.9 & $(+1.2)$ \\
\hline 8 & 79.7 & 79.8 & $(-0.1)$ & 78.5 & $(+1.2)$ & 80.0 & $(-0.3)$ & 78.1 & $(+1.6)$ \\
\hline 9 & 52.0 & 52.0 & (0) & 53.6 & $(-1.6)$ & 51.8 & $(+0.2)$ & 53.7 & $(-1.7)$ \\
\hline $9 a$ & 56.4 & 56.3 & $(+0.1)$ & 57.5 & $(-1.1)$ & 56.3 & $(+0.1)$ & 57.5 & $(-1.1)$ \\
\hline 10 & 49.4 & 49.4 & (0) & 50.0 & $(-0.6)$ & 50.7 & $(-1.3)$ & 49.1 & $(+0.3)$ \\
\hline 11 & 114.6 & 114.6 & $(0)$ & 116.3 & $(-1.7)$ & 115.9 & $(-1.3)$ & 114.8 & $(-0.2)$ \\
\hline 12 & 38.9 & 38.8 & $(+0.1)$ & 35.8 & $(+3.1)$ & 37.9 & $(-1.0)$ & 37.7 & $(+1.2)$ \\
\hline 13 & 34.5 & 34.5 & (0) & 34.2 & $(+0.3)$ & 35.5 & $(-1.0)$ & 34.1 & $(+0.4)$ \\
\hline 14 & 178.8 & 178.8 & (0) & 178.4 & $(+0.4)$ & 178.6 & $(+0.2)$ & 178.5 & $(+0.3)$ \\
\hline 15 & 15.2 & 15.2 & (0) & 16.9 & $(-1.7)$ & 17.4 & $(-2.2)$ & 14.8 & $(+0.4)$ \\
\hline 16 & 21.2 & 21.2 & $(0)$ & 22.8 & $(-1.6)$ & 21.0 & $(+0.2)$ & 22.8 & $(-1.6)$ \\
\hline 17 & 12.9 & 12.9 & (0) & 11.7 & $(+1.2)$ & 12.9 & (0) & 11.6 & $(+1.3)$ \\
\hline
\end{tabular}

${ }^{\mathrm{a}}$ Recorded in $\mathrm{CDCl}_{3}, 300 \mathrm{MHz} .{ }^{\mathrm{b}}$ Recorded in $\mathrm{CDCl}_{3}, 400 \mathrm{MHz} .{ }^{\mathrm{c}}$ Deviations (given in parentheses) = Natural - Synthetic. ${ }^{\mathrm{d}}{ }^{13} \mathrm{C}$ NMR deviations exceeding 0.2 were marked with red. ${ }^{\mathrm{e}}$ Multiplicity and $J$ values in $\mathrm{Hz}$ are given in parentheses. ${ }^{\mathrm{f}}$ Distinct ${ }^{1} \mathrm{H}$ NMR deviations of characteristic positions were marked with red. 
Comparison of ${ }^{13} \mathrm{C}$ NMR spectra of synthetic sessilifoliamide A (2) and its epimers.
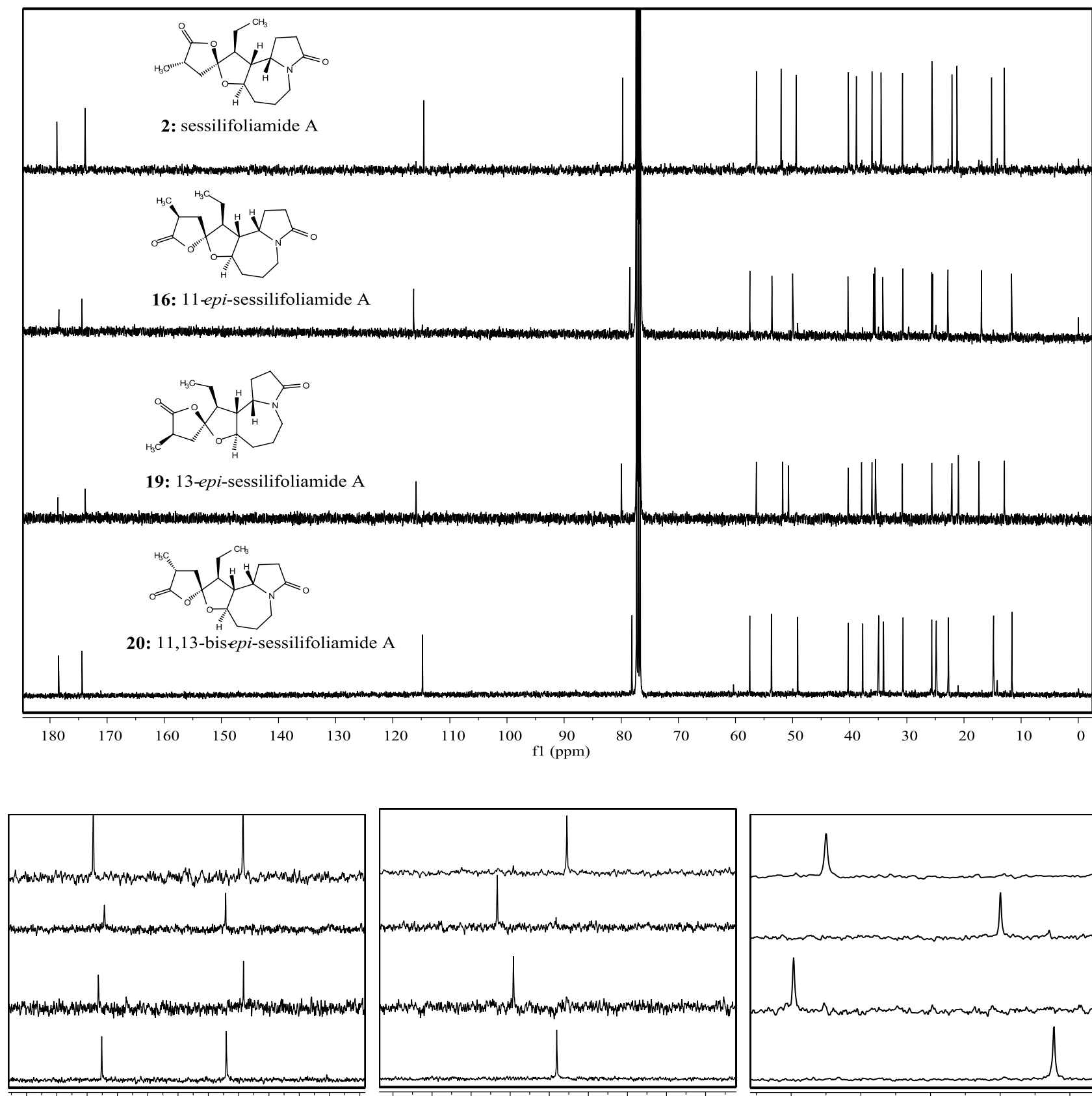

18118017917817717617517417317217117 f1 (ppm)
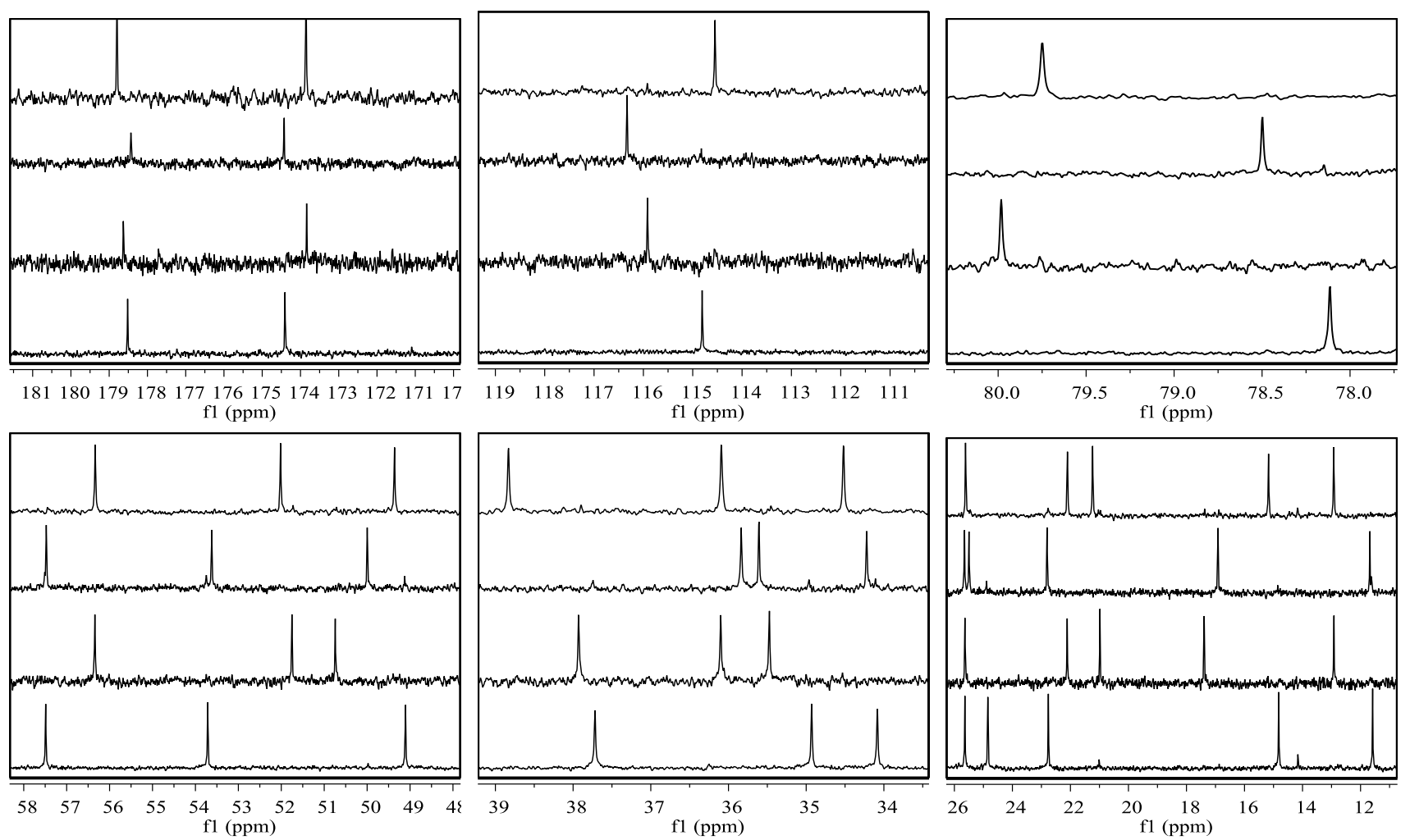


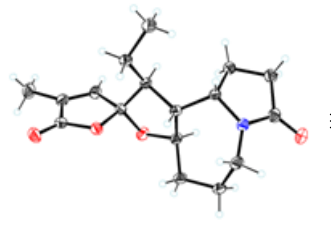

ORTEP of 1

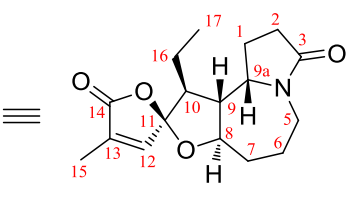

1: tuberostemoamide

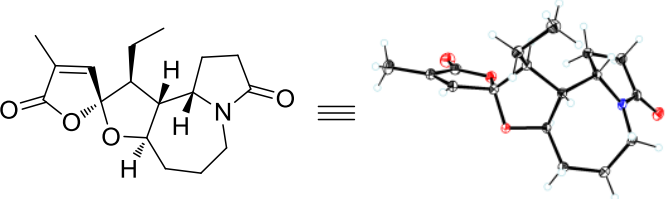

ORTEP of $\mathbf{2 1}$

Table S7. Comparison of ${ }^{13} \mathrm{C}$ NMR data assignment of tuberostemoamide (1) and its epimers.

\begin{tabular}{|c|c|c|c|c|c|}
\hline \multirow{2}{*}{$\frac{{ }^{13} \mathrm{C} \text { Position }}{1}$} & \multirow{2}{*}{$\frac{\text { Natural } 1^{\mathrm{a}}}{34.6}$} & \multicolumn{2}{|c|}{ Synthetic $1^{b}$ (deviation) $^{\mathrm{d}, \mathrm{f}}$} & \multicolumn{2}{|c|}{ Synthetic $21^{b}$ (deviation) $^{d, f}$} \\
\hline & & 30.7 & $(+3.9)^{\mathrm{g}}$ & 30.6 & $(+4.0)$ \\
\hline 2 & 35.7 & 35.7 & $(0)$ & 34.4 & $(+1.3)$ \\
\hline 3 & 173.8 & 173.7 & $(+0.1)$ & 174.3 & $(-0.5)$ \\
\hline 5 & 40.2 & 40.2 & $(0)$ & 40.3 & $(-0.1)$ \\
\hline 6 & 22.0 & 22.0 & $(0)$ & 25.5 & $(-3.5)$ \\
\hline 7 & 25.5 & 25.5 & $(0)$ & 26.4 & $(-0.9)$ \\
\hline 8 & 80.6 & 80.6 & $(0)$ & 80.6 & $(0)$ \\
\hline 9 & 49.6 & 49.6 & $(0)$ & 50.9 & $(-1.3)$ \\
\hline 9a & 56.1 & 56.0 & $(+0.1)$ & 57.2 & $(-1.1)$ \\
\hline 10 & 51.7 & 51.7 & $(0)$ & 54.6 & $(-2.9)$ \\
\hline 11 & 113.5 & 113.5 & $(0)$ & 114.2 & $(-0.7)$ \\
\hline 12 & 143.9 & 143.9 & (0) & 142.4 & $(+1.5)$ \\
\hline 13 & 134.0 & 134.1 & $(-0.1)$ & 133.7 & $(+0.3)$ \\
\hline 14 & 171.1 & 171.2 & $(-0.1)$ & 170.9 & $(+0.2)$ \\
\hline 15 & 10.4 & 10.5 & $(-0.1)$ & 10.6 & $(-0.2)$ \\
\hline 16 & 20.2 & 20.2 & (0) & 22.9 & $(-2.7)$ \\
\hline 17 & 12.7 & 12.8 & $(-0.1)$ & 12.2 & $(+0.5)$ \\
\hline
\end{tabular}

${ }^{\mathrm{a}}$ Recorded in $\mathrm{CDCl}_{3}, 300 \mathrm{MHz} .{ }^{\mathrm{b}}$ Recorded in $\mathrm{CDCl}_{3}, 400 \mathrm{MHz} .{ }^{\mathrm{c}}$ Multiplicity and $J$ values in $\mathrm{Hz}$ are given in parentheses. ${ }^{\mathrm{d}}$ Deviations (given in parentheses) $=$ Natural - Synthetic. ${ }^{\mathrm{e}}$ Distinct ${ }^{1} \mathrm{H}$ NMR deviations of characteristic positions were marked with red. ${ }^{\mathrm{f}}{ }^{13} \mathrm{C}$ NMR deviations exceeding 0.2 were marked with red. ${ }^{g} \mathrm{We}$ are especially grateful to Prof. Wenhan Lin for providing the original ${ }^{13} \mathrm{C}$ NMR spectrum of tuberostemoamide (1) when our work was about to be submitted. We found that ${ }^{13} \mathrm{C}$ NMR spectrum of our synthetic sample was in good accordance with the original spectrum of the natural sample, maybe the wrong ${ }^{13} \mathrm{C}$ NMR data at $\mathrm{C} 1$ position in reported literature was caused by writting error.

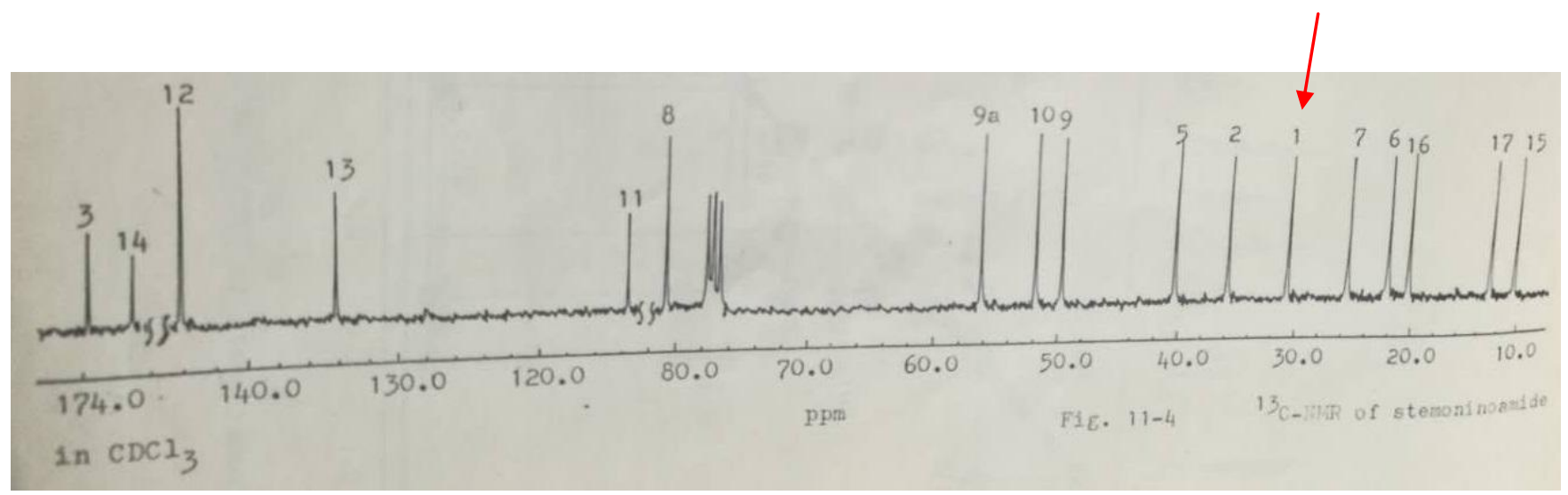


Comparison of ${ }^{1} \mathrm{H}$ NMR spectra of tuberostemoamide (1) and its epimers.
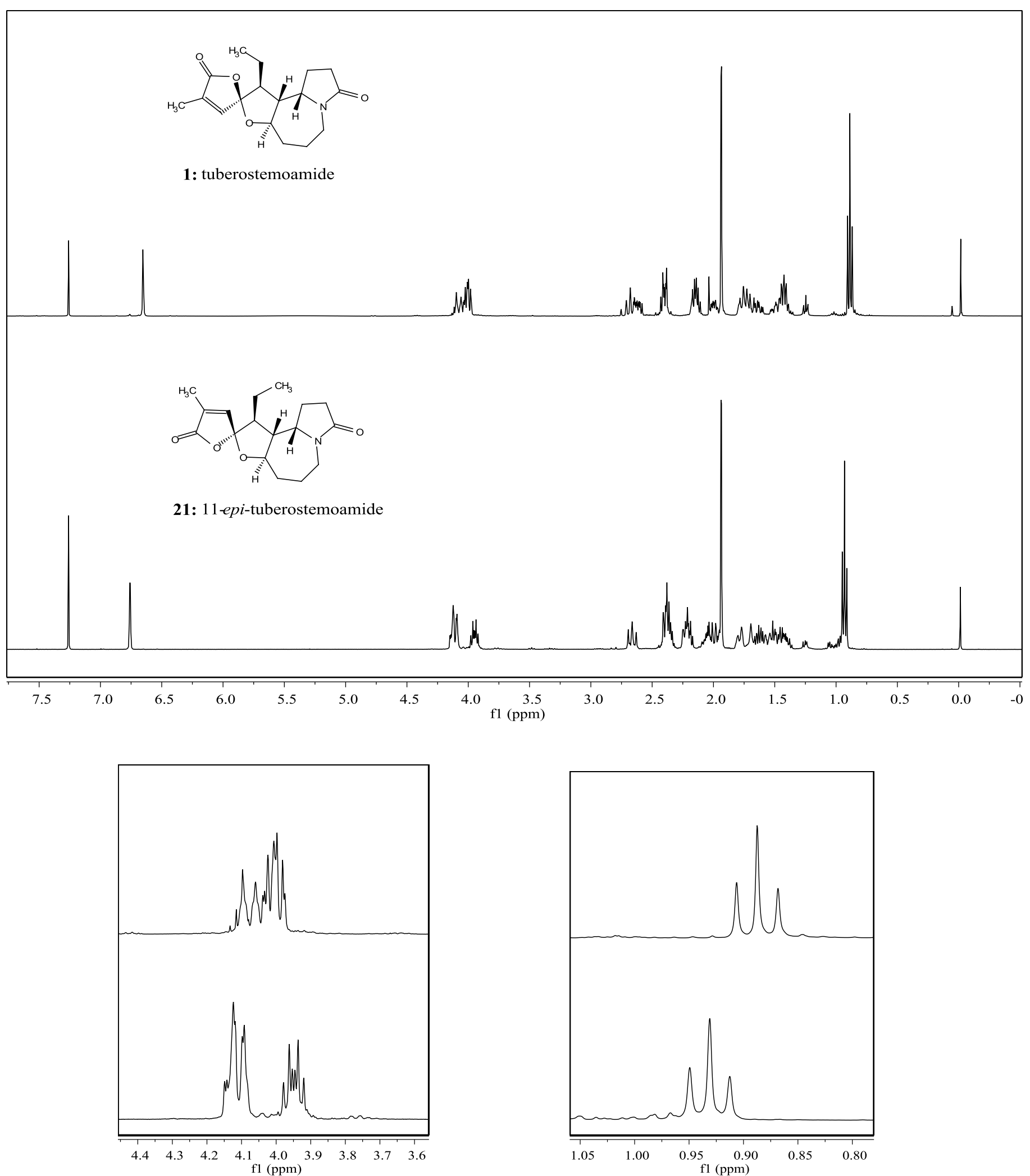
Comparison of ${ }^{13} \mathrm{C}$ NMR of tuberostemoamide (1) and its epimers.

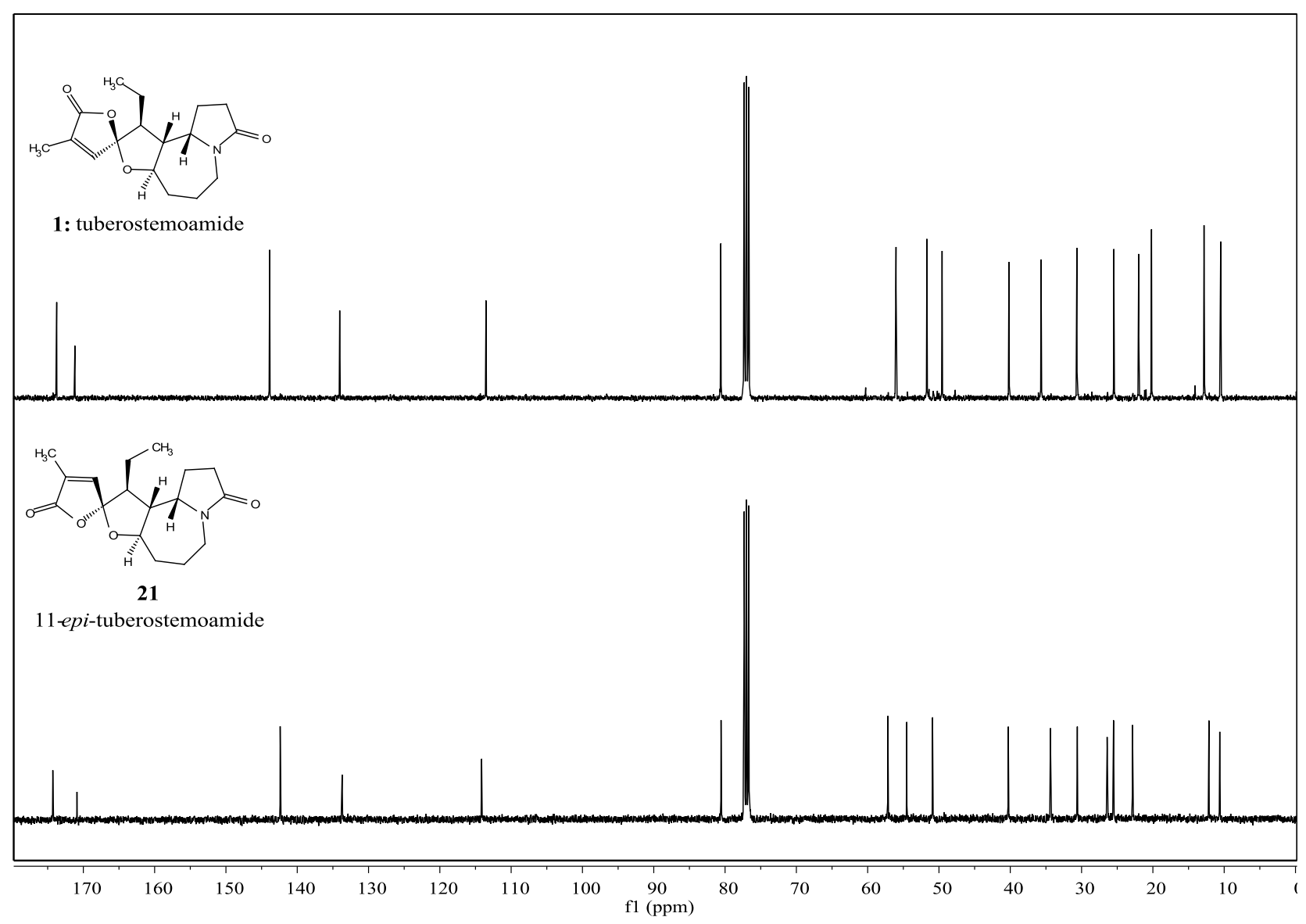

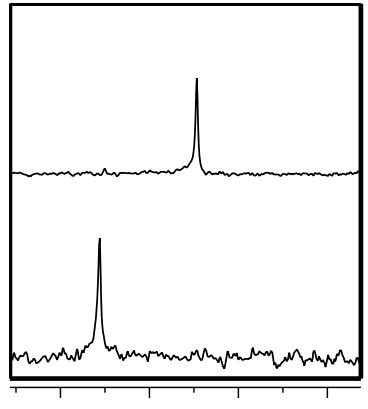

$\begin{array}{llll}174.5 & 174.0 & 173.5 & 173.0\end{array}$ f1 (ppm)
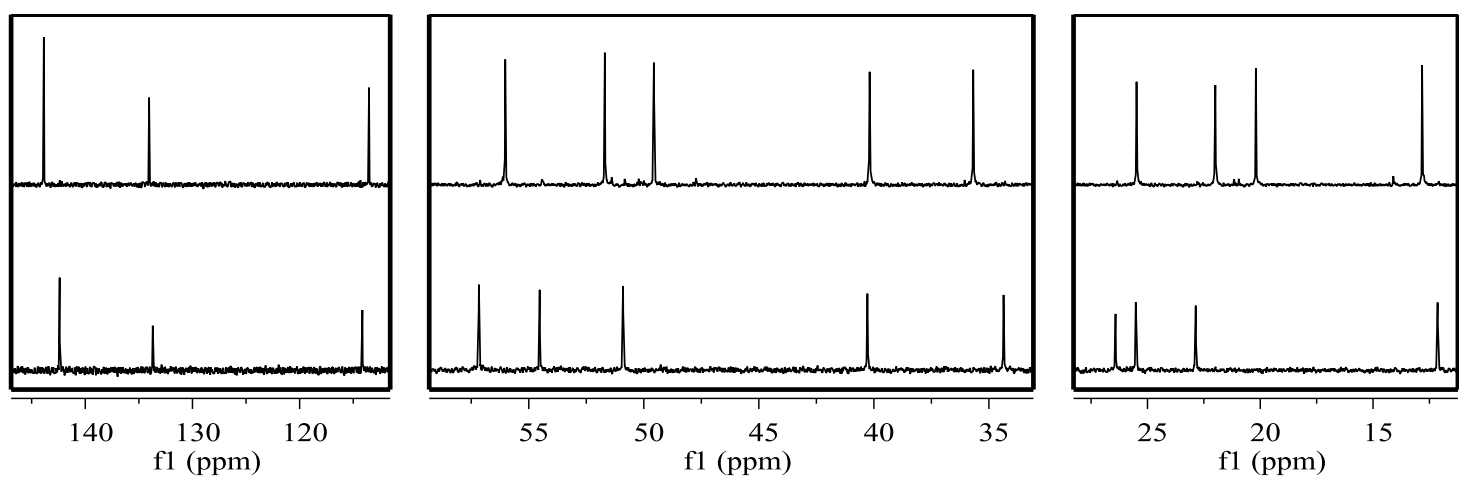
V. $\quad{ }^{1} \mathrm{H}$ and ${ }^{13} \mathrm{C}$ NMR Spectra of Compounds

${ }^{1} \mathrm{H}$ NMR Spectrum of $\mathrm{S1}\left(400 \mathrm{MHz}, \mathrm{CDCl}_{3}\right)$

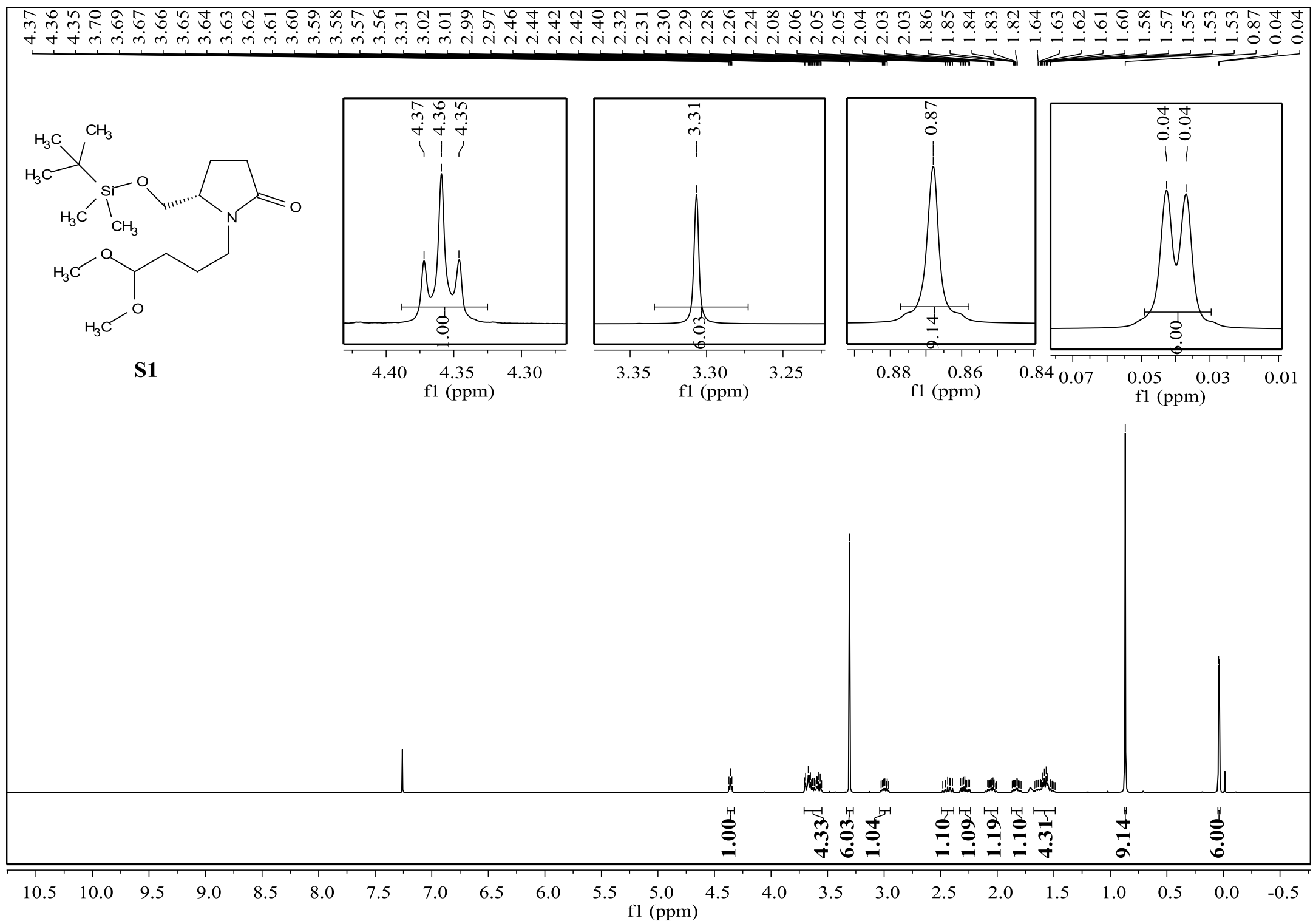


${ }^{13} \mathrm{C}$ NMR Spectrum of $\mathrm{S} 1\left(101 \mathrm{MHz}, \mathrm{CDCl}_{3}\right)$

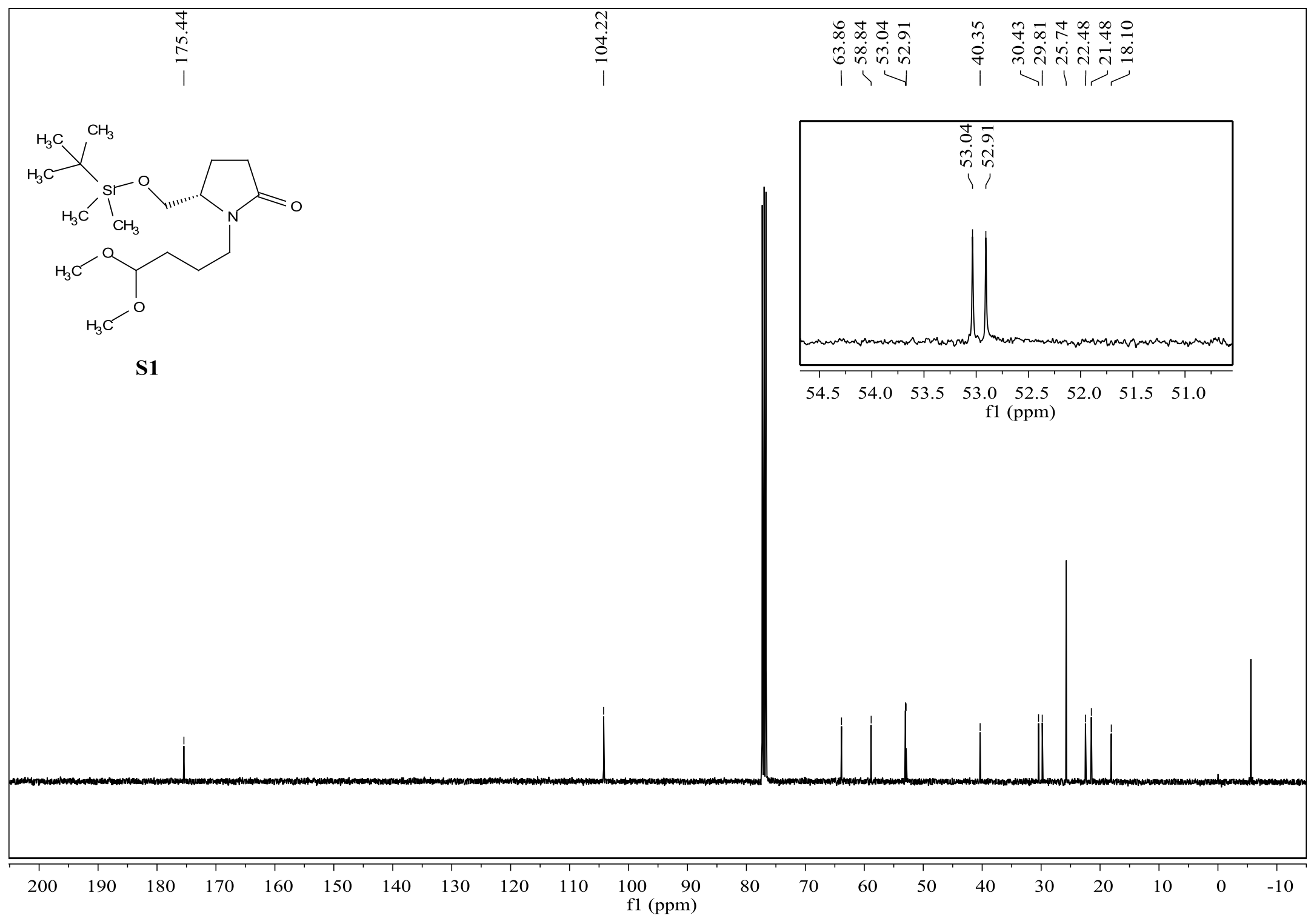


${ }^{1} \mathrm{H}$ NMR Spectrum of 7 (400 $\left.\mathrm{MHz}, \mathrm{CDCl}_{3}\right)$

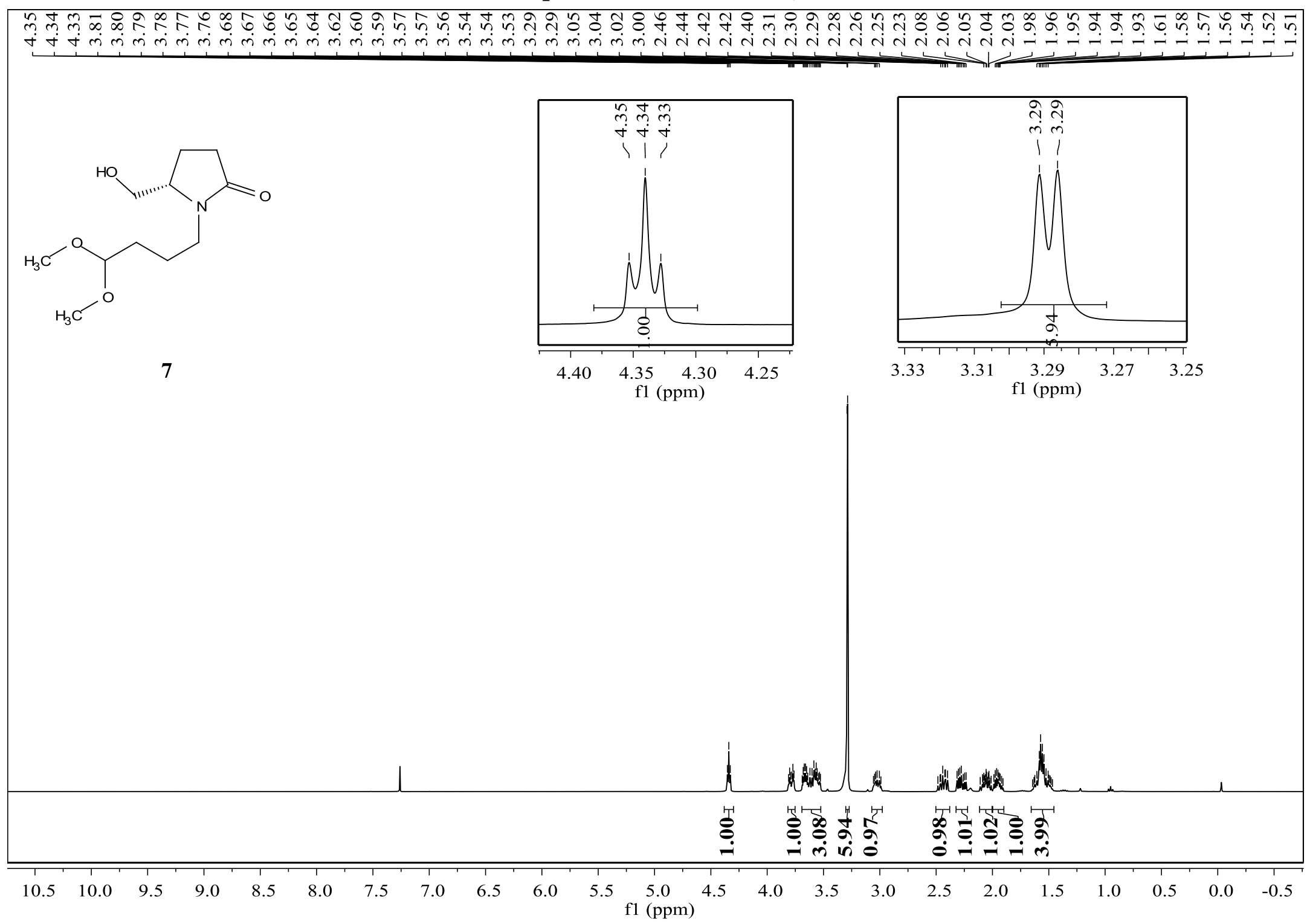


${ }^{13} \mathrm{C}$ NMR Spectrum of 7 (101 $\left.\mathrm{MHz}, \mathrm{CDCl}_{3}\right)$

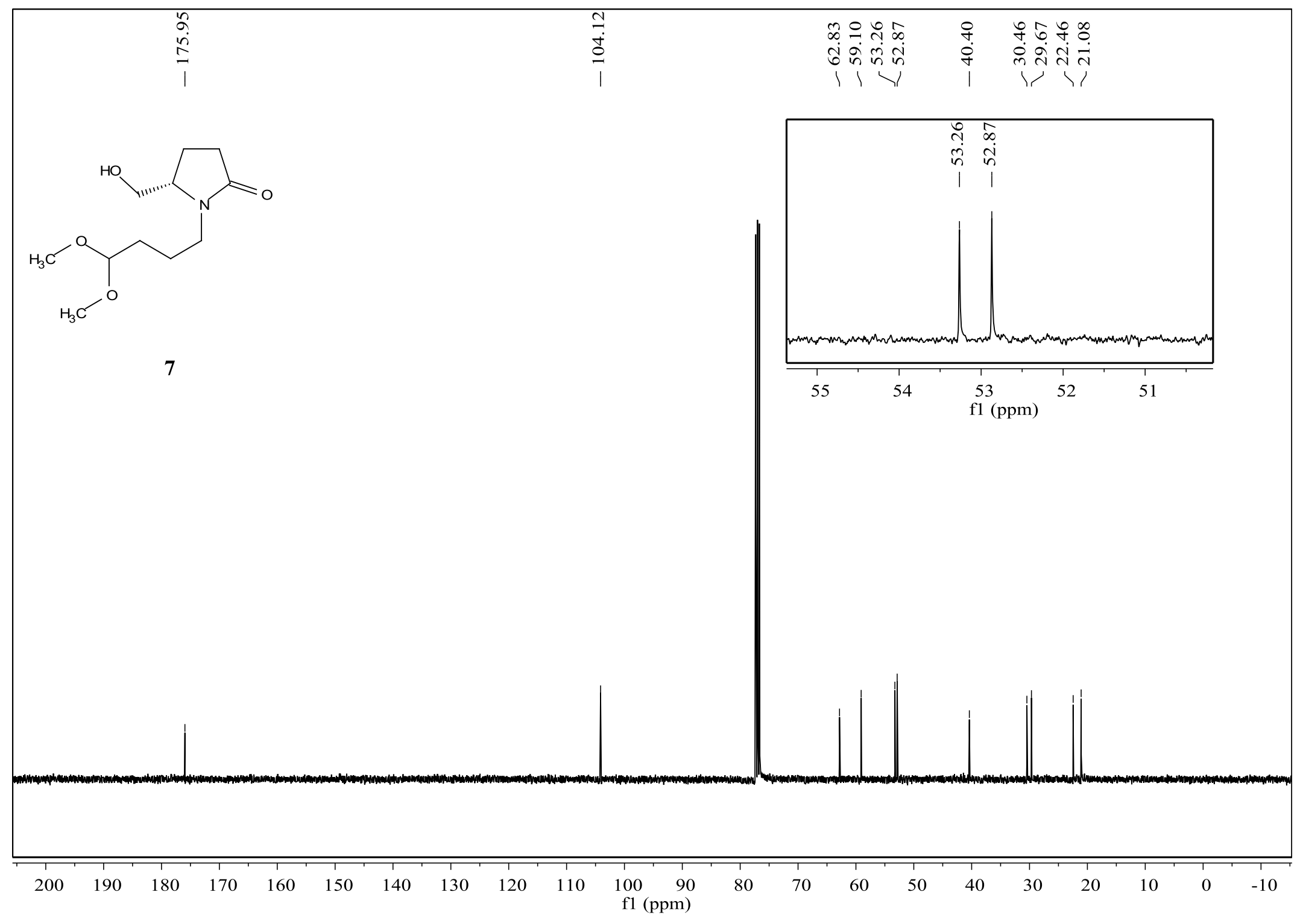


${ }^{1} \mathrm{H}$ NMR Spectrum of $10\left(400 \mathrm{MHz}, \mathrm{CDCl}_{3}\right)$

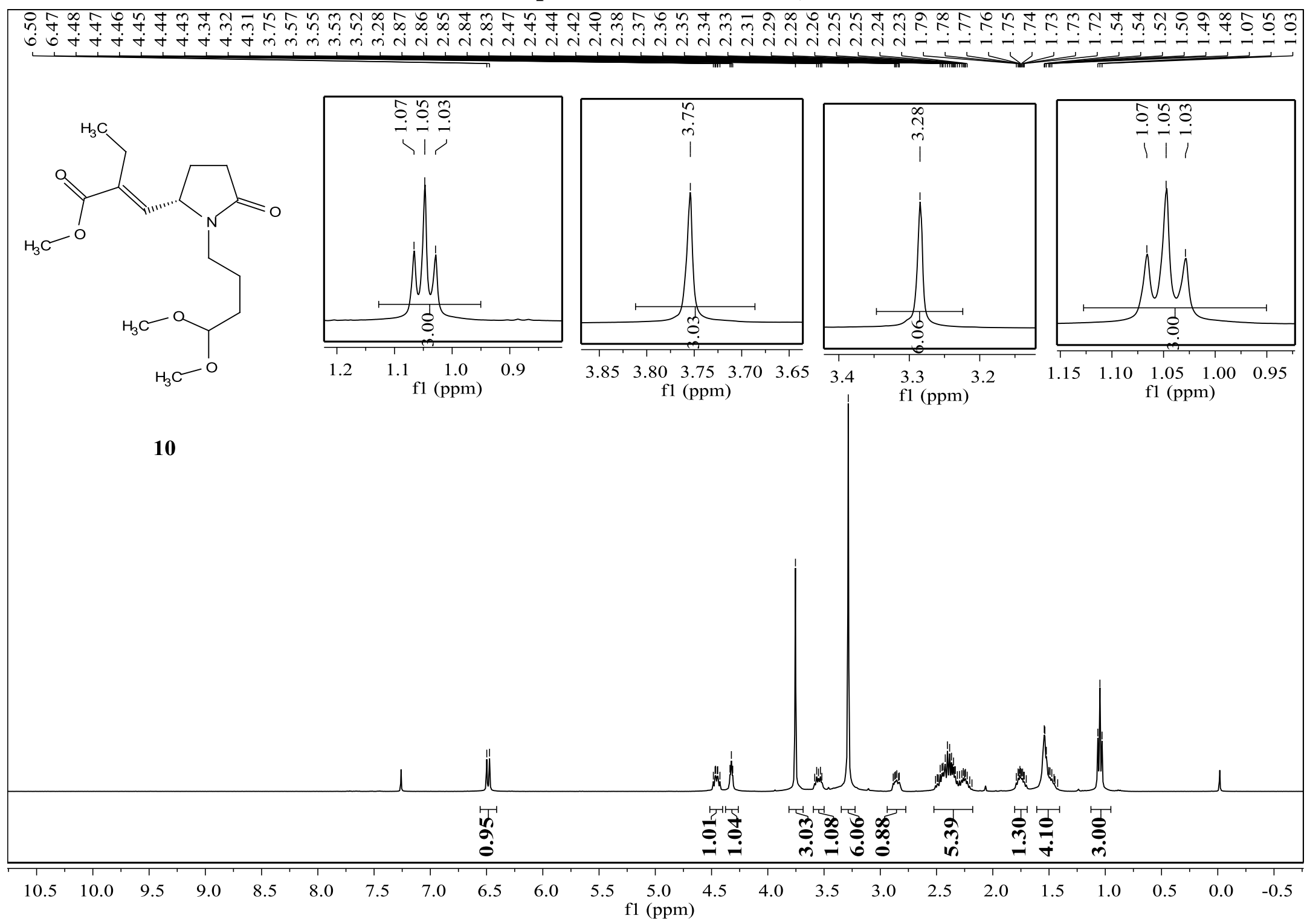




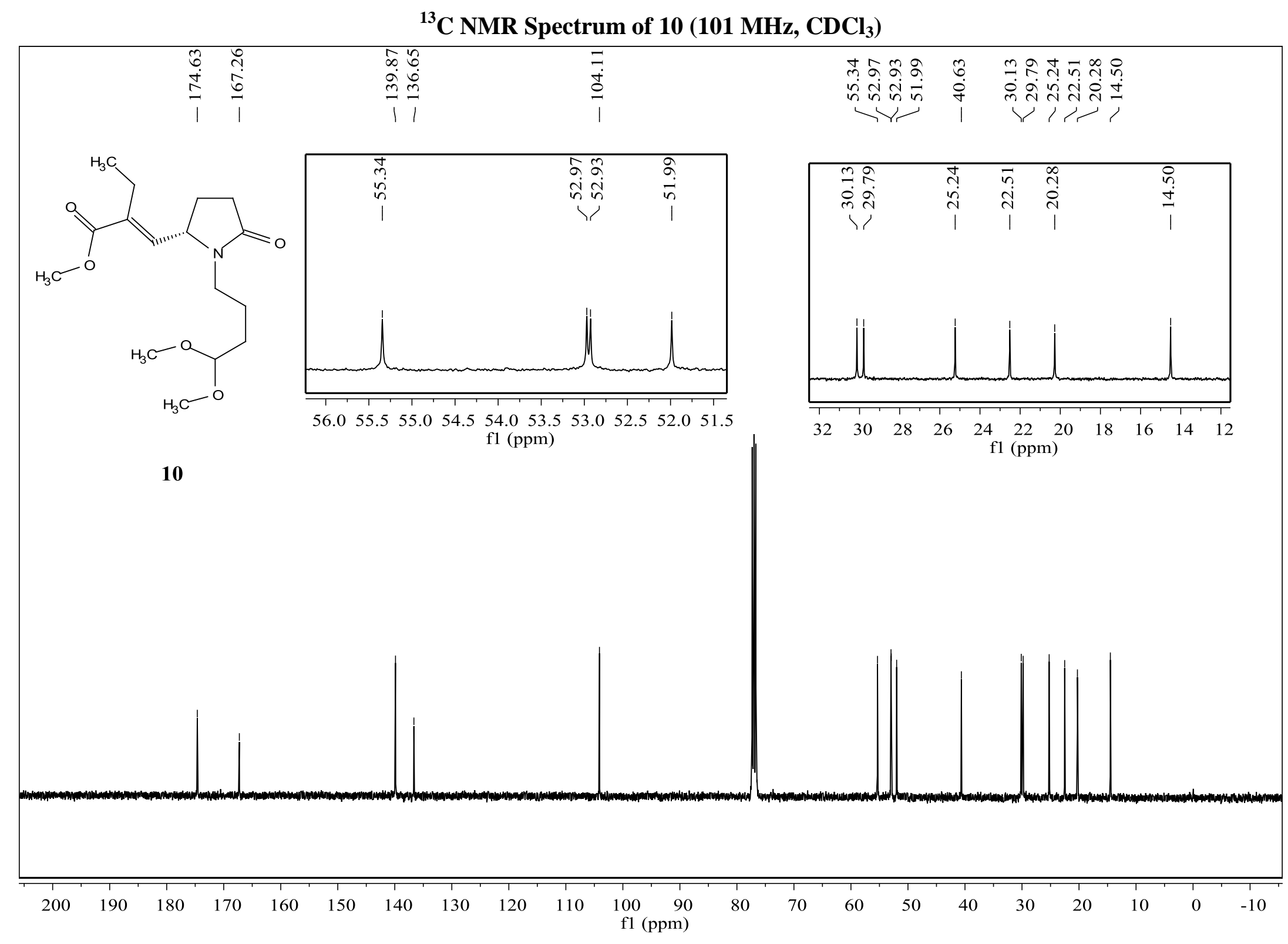


${ }^{1} \mathrm{H}$ NMR Spectrum of $\mathrm{S3}\left(400 \mathrm{MHz}, \mathrm{CDCl}_{3}\right)$

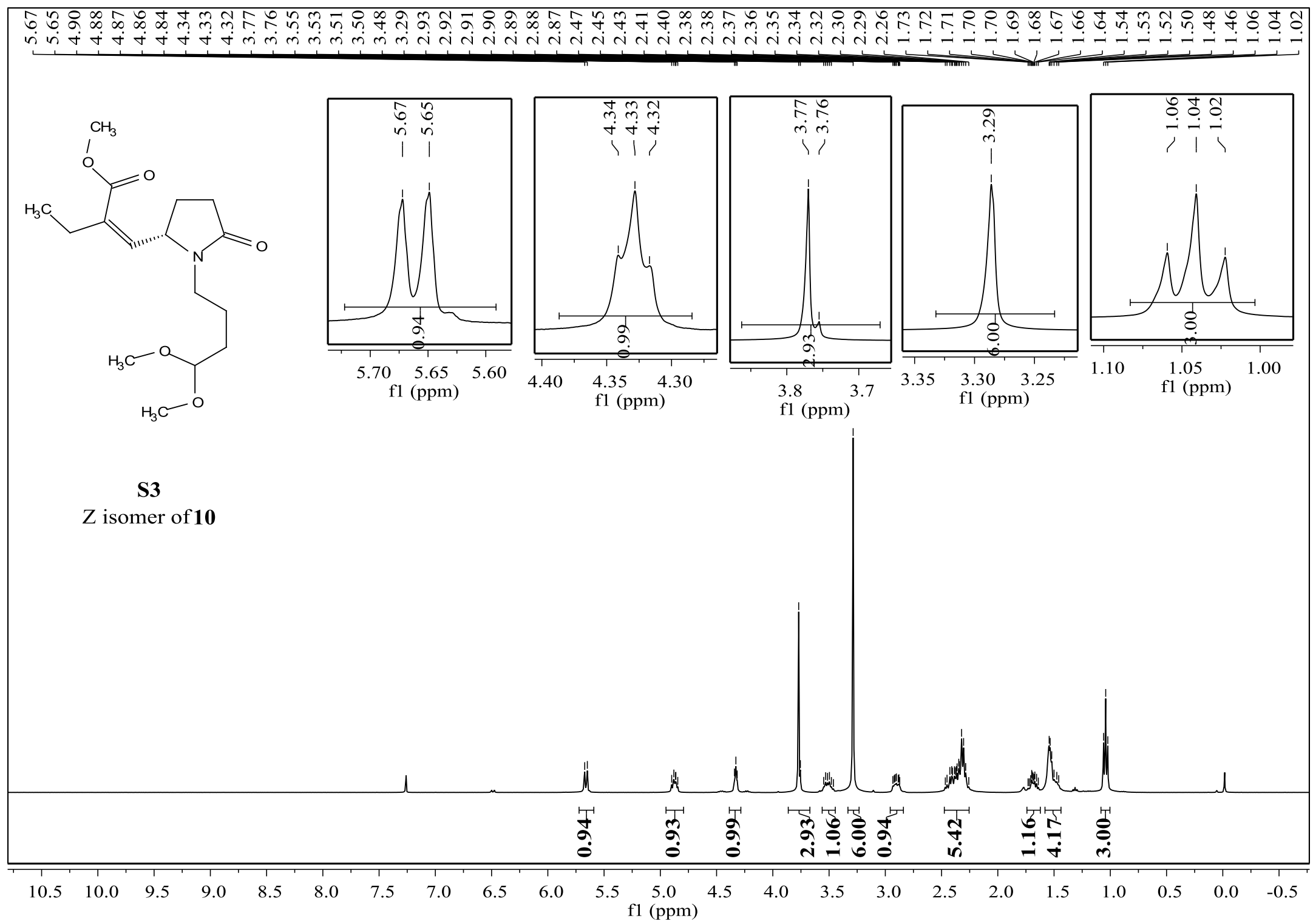




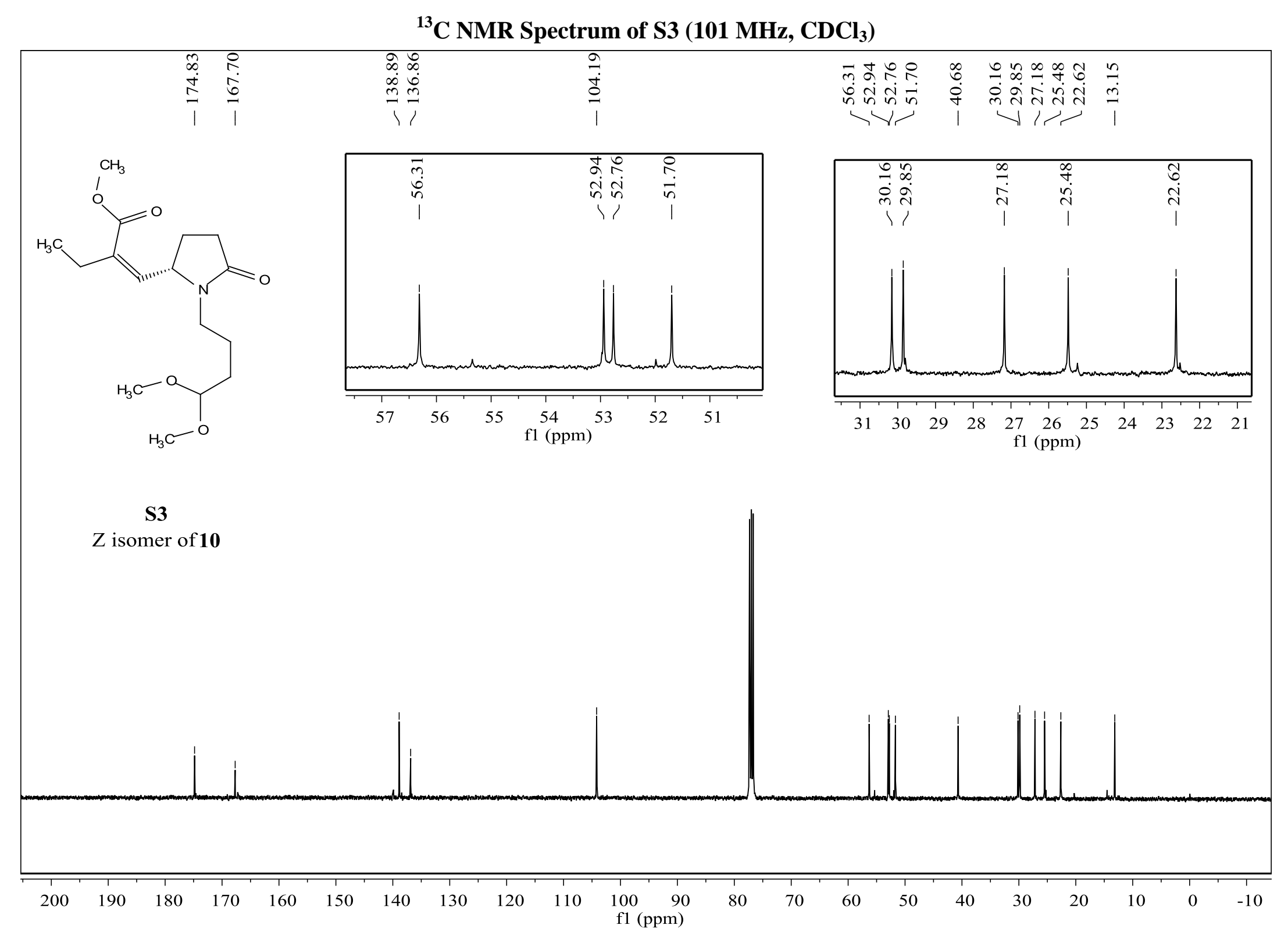


${ }^{1} \mathrm{H}$ NMR Spectrum of $12\left(400 \mathrm{MHz}, \mathrm{CDCl}_{3}\right)$

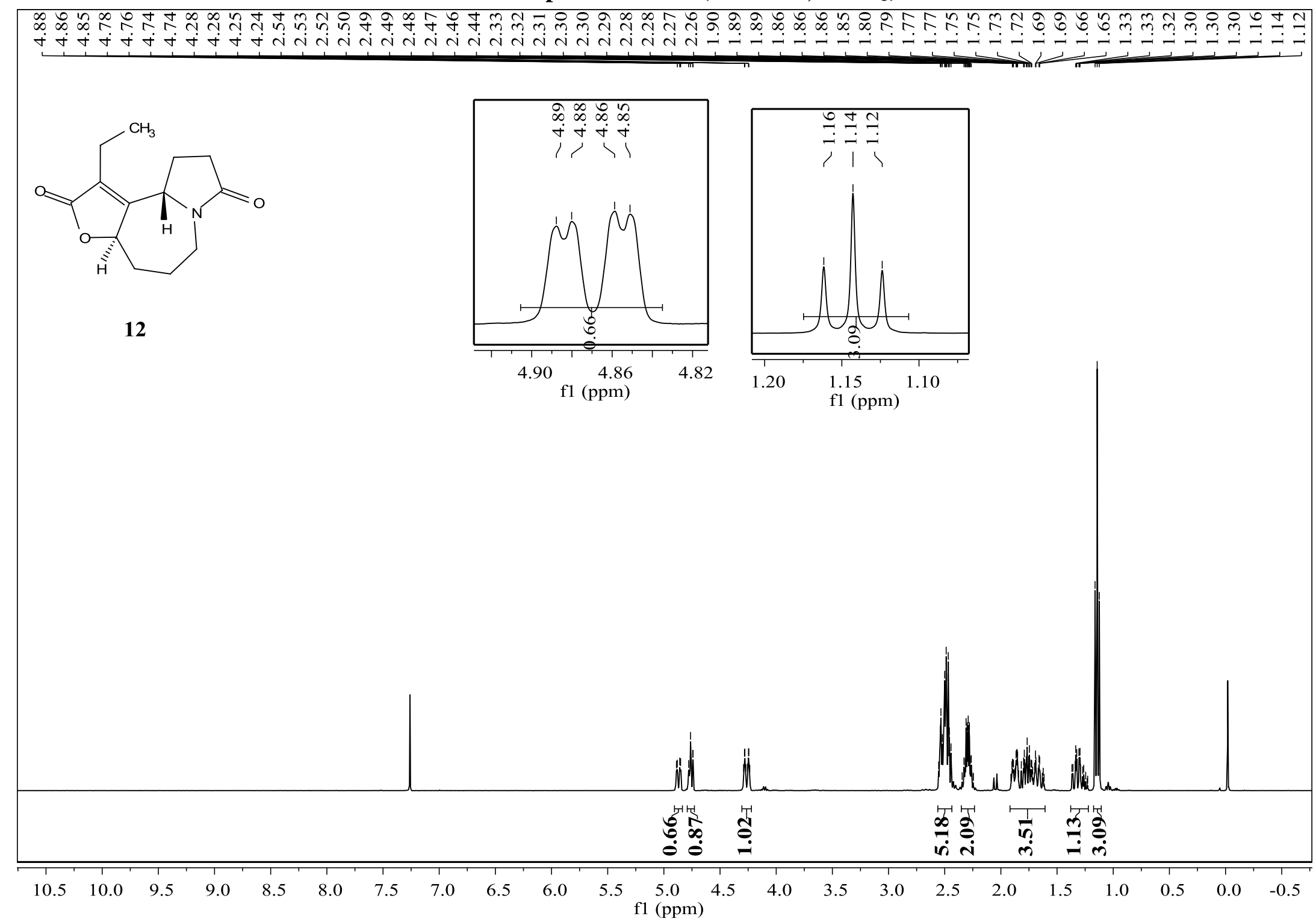


${ }^{13} \mathrm{C}$ NMR Spectrum of $12\left(101 \mathrm{MHz}, \mathrm{CDCl}_{3}\right)$

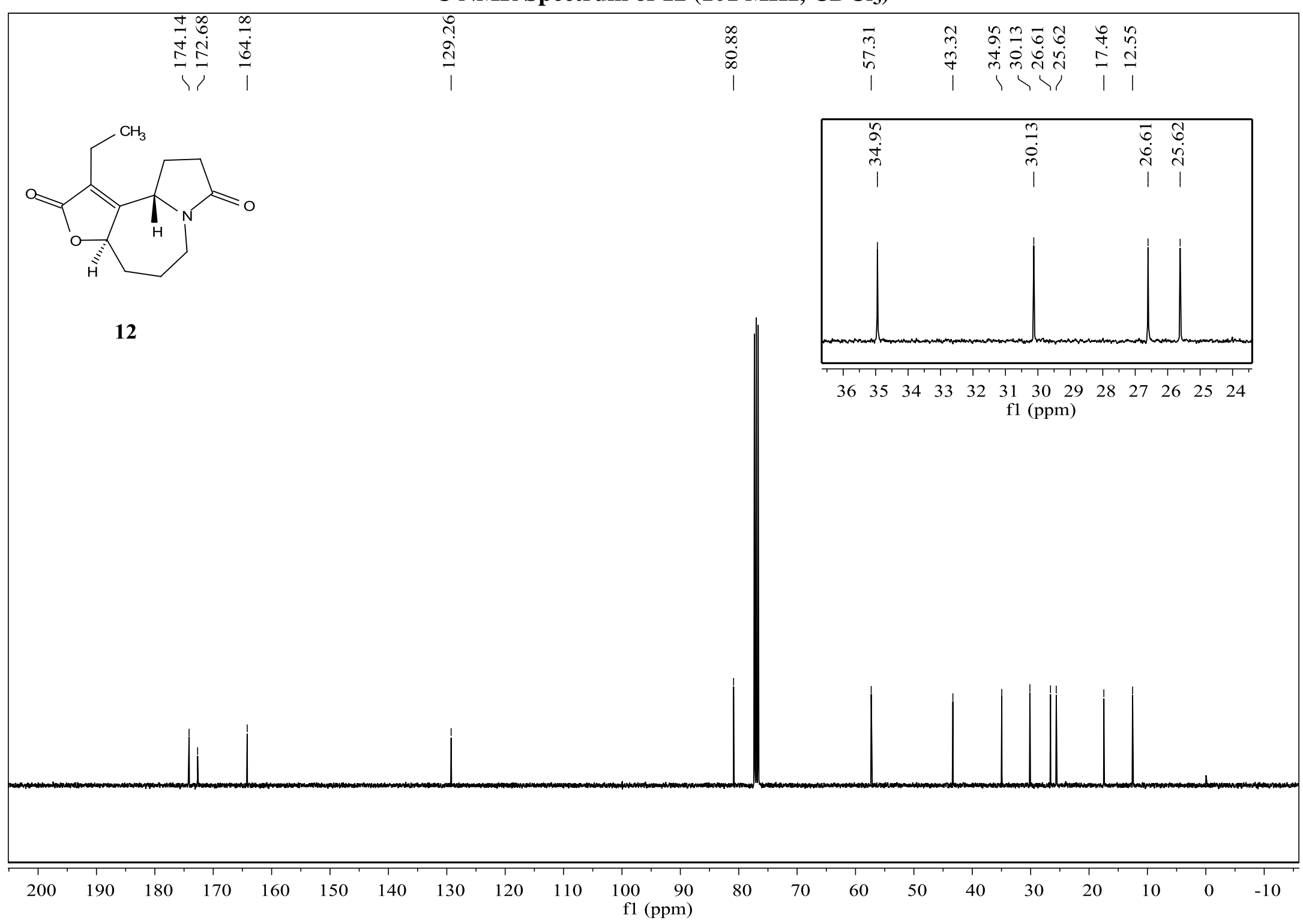


${ }^{1} \mathrm{H}$ NMR Spectrum of 4 (400 $\left.\mathrm{MHz}, \mathrm{CDCl}_{3}\right)$

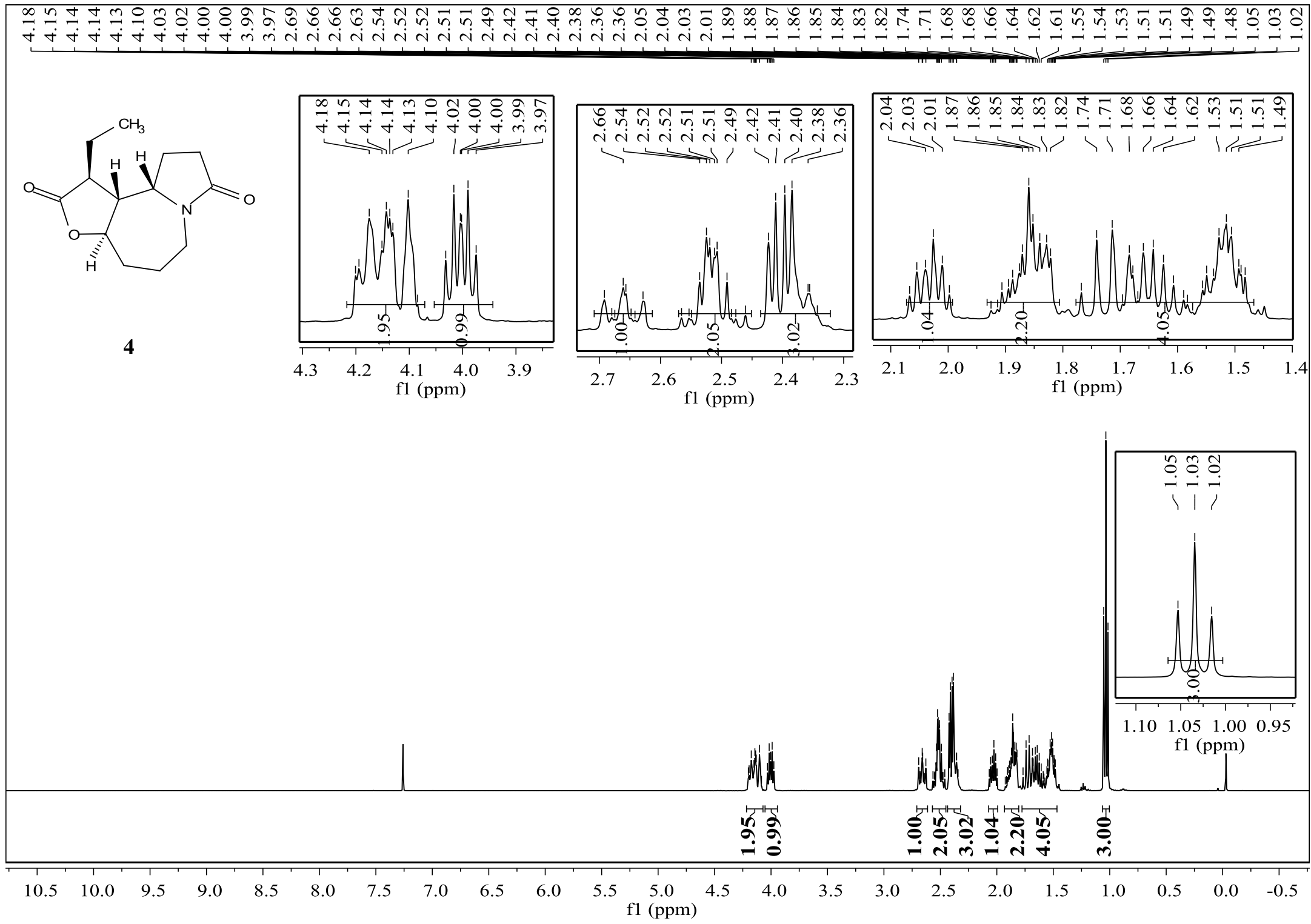


${ }^{13} \mathrm{C}$ NMR Spectrum of $4\left(101 \mathrm{MHz}, \mathrm{CDCl}_{3}\right)$

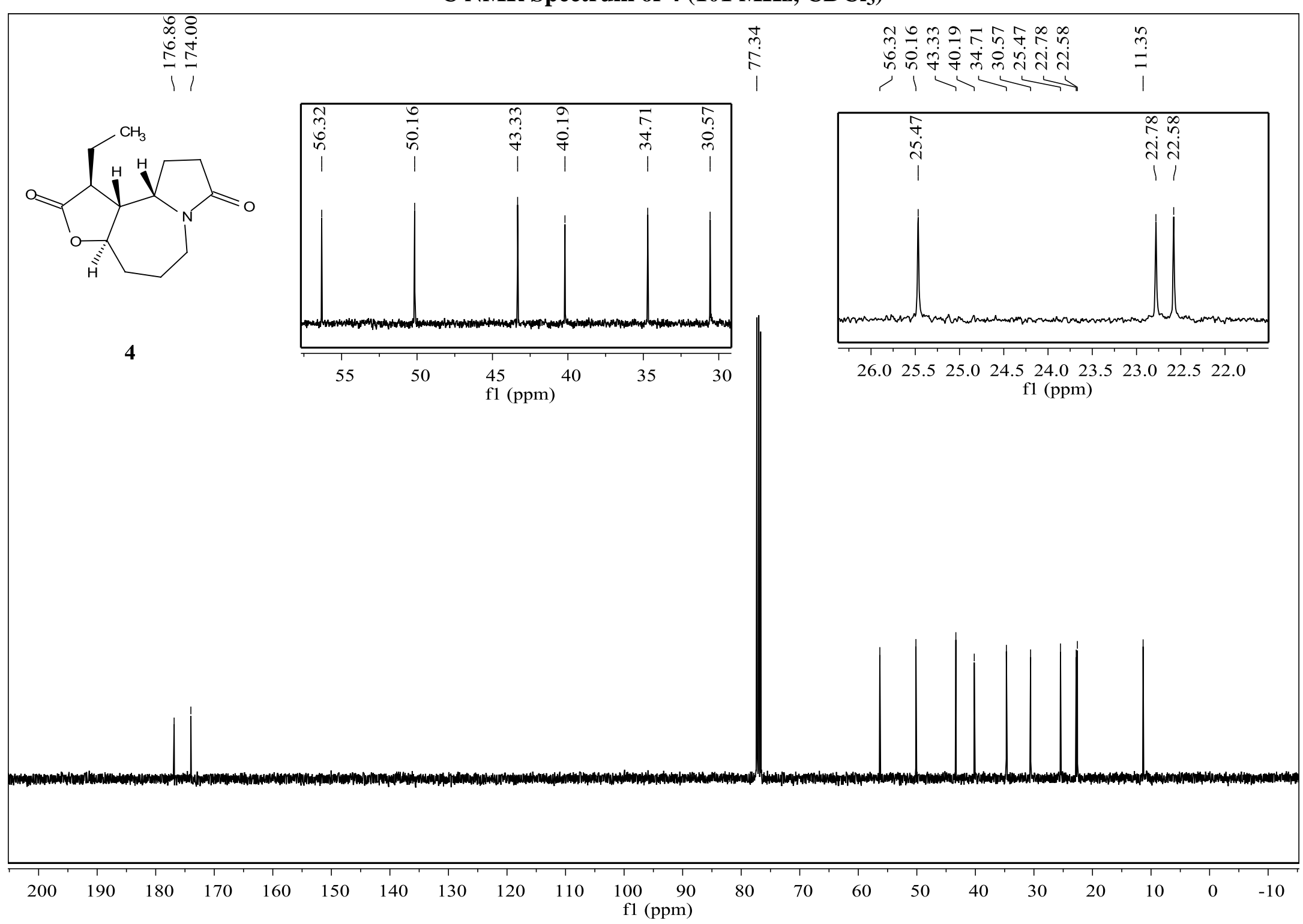


${ }^{1} \mathrm{H}$ NMR Spectrum of $11 \mathrm{a}\left(400 \mathrm{MHz}, \mathrm{CDCl}_{3}\right)$

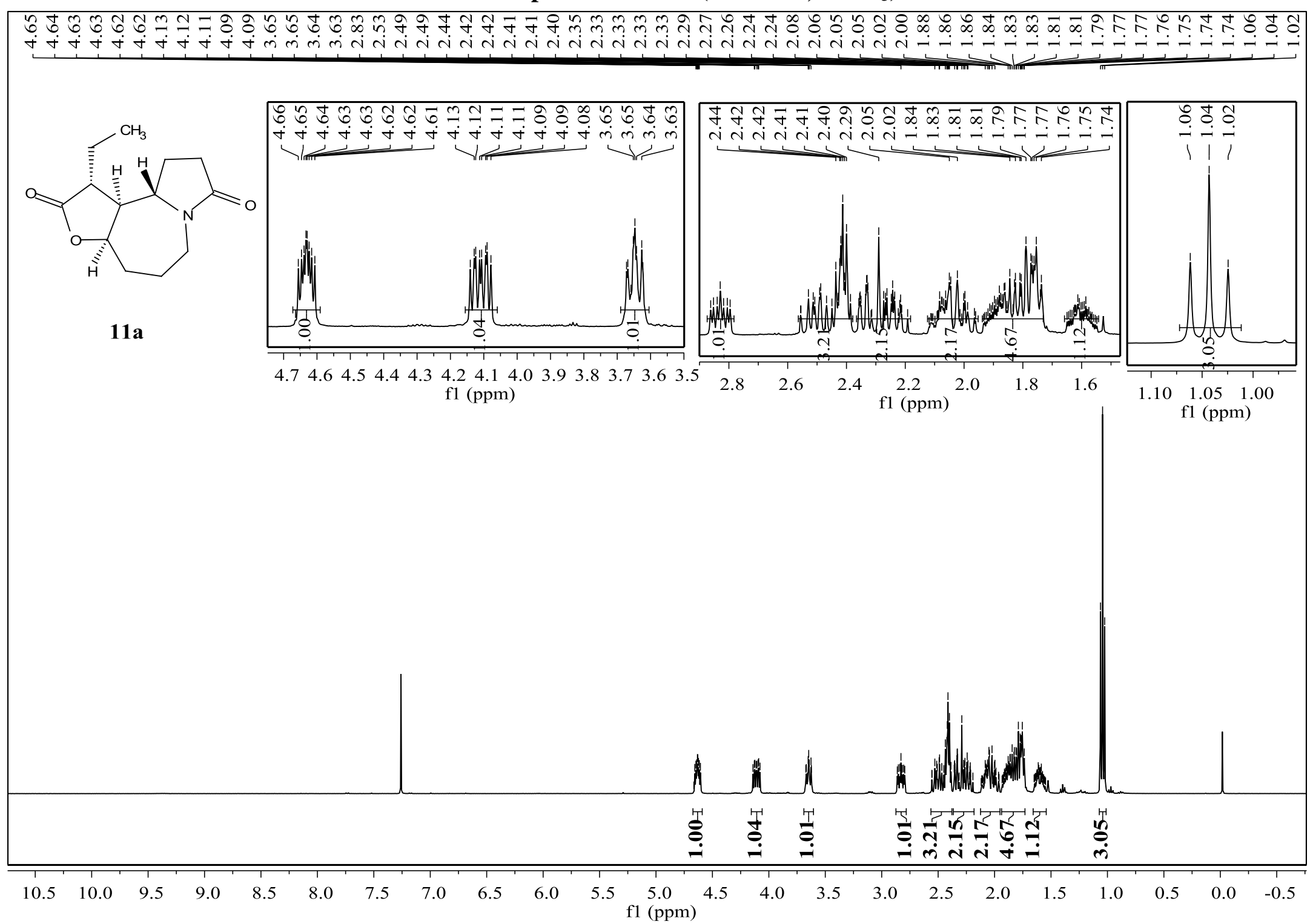


${ }^{13} \mathrm{C}$ NMR Spectrum of $11 \mathrm{a}\left(101 \mathrm{MHz}, \mathrm{CDCl}_{3}\right)$

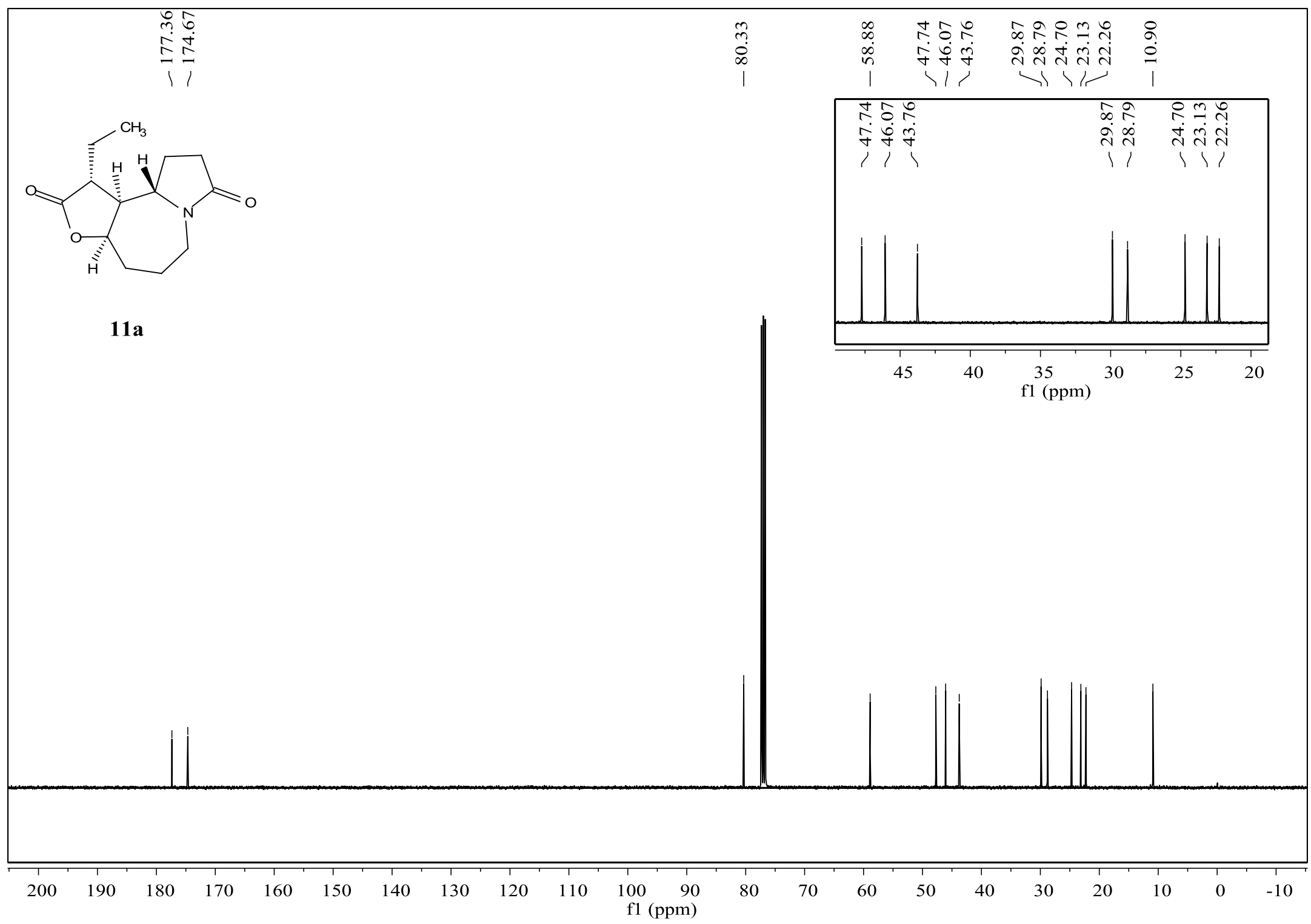


${ }^{1} \mathrm{H}$ NMR Spectrum of $2\left(400 \mathrm{MHz}, \mathrm{CDCl}_{3}\right)$

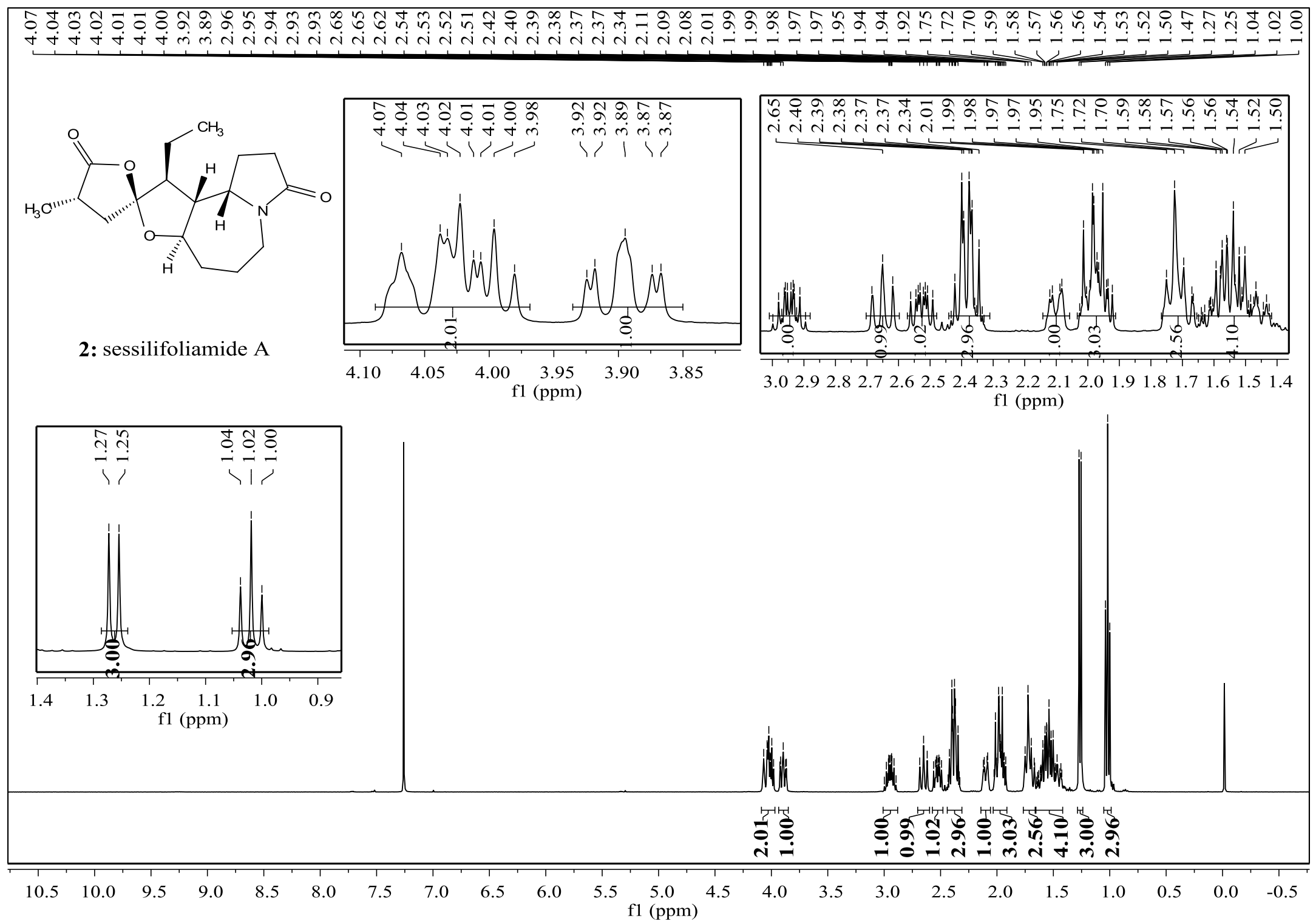


${ }^{13} \mathrm{C}$ NMR Spectrum of $2\left(101 \mathrm{MHz}, \mathrm{CDCl}_{3}\right)$

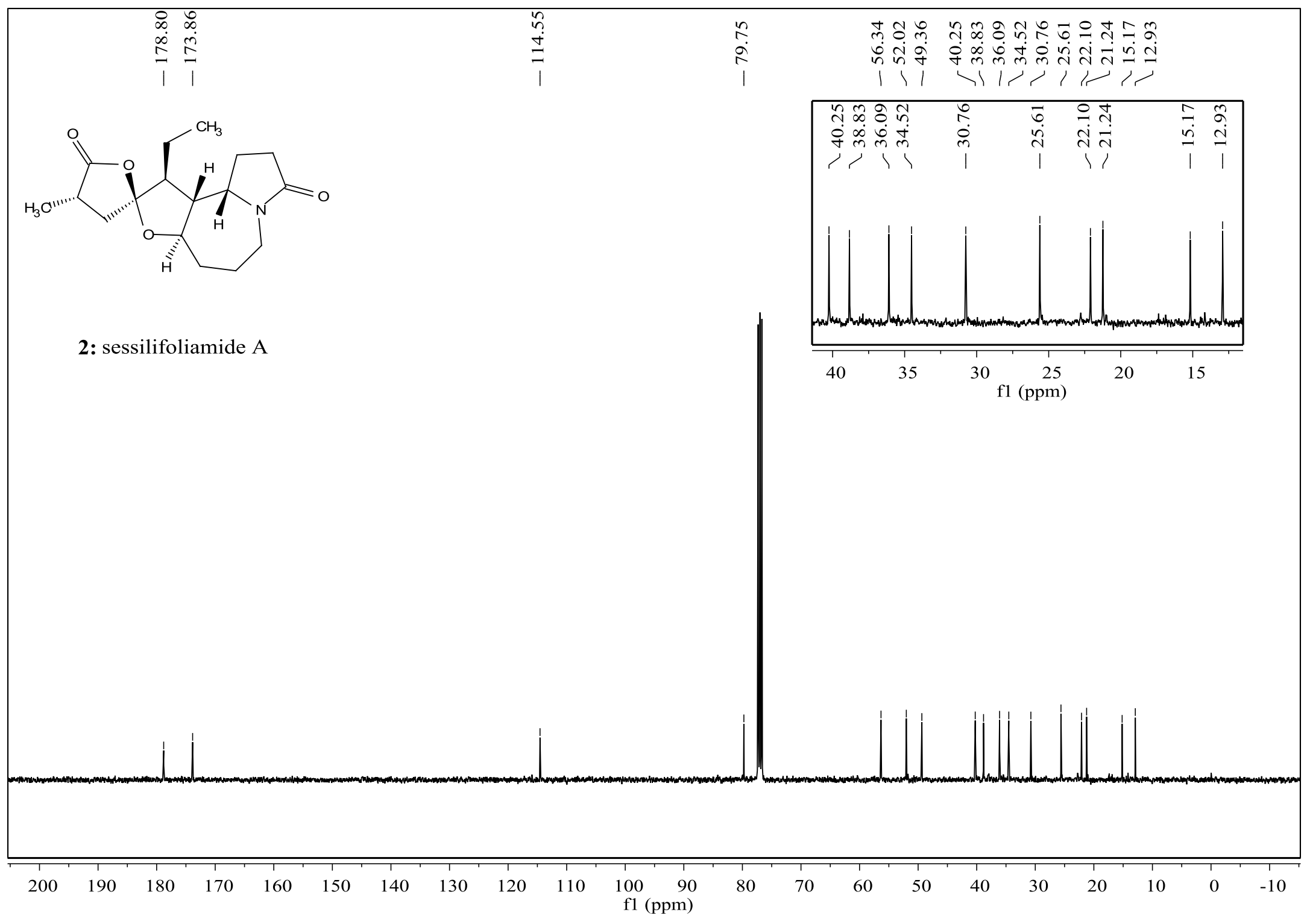


${ }^{1} \mathrm{H}$ NMR Spectrum of $19\left(400 \mathrm{MHz}, \mathrm{CDCl}_{3}\right)$

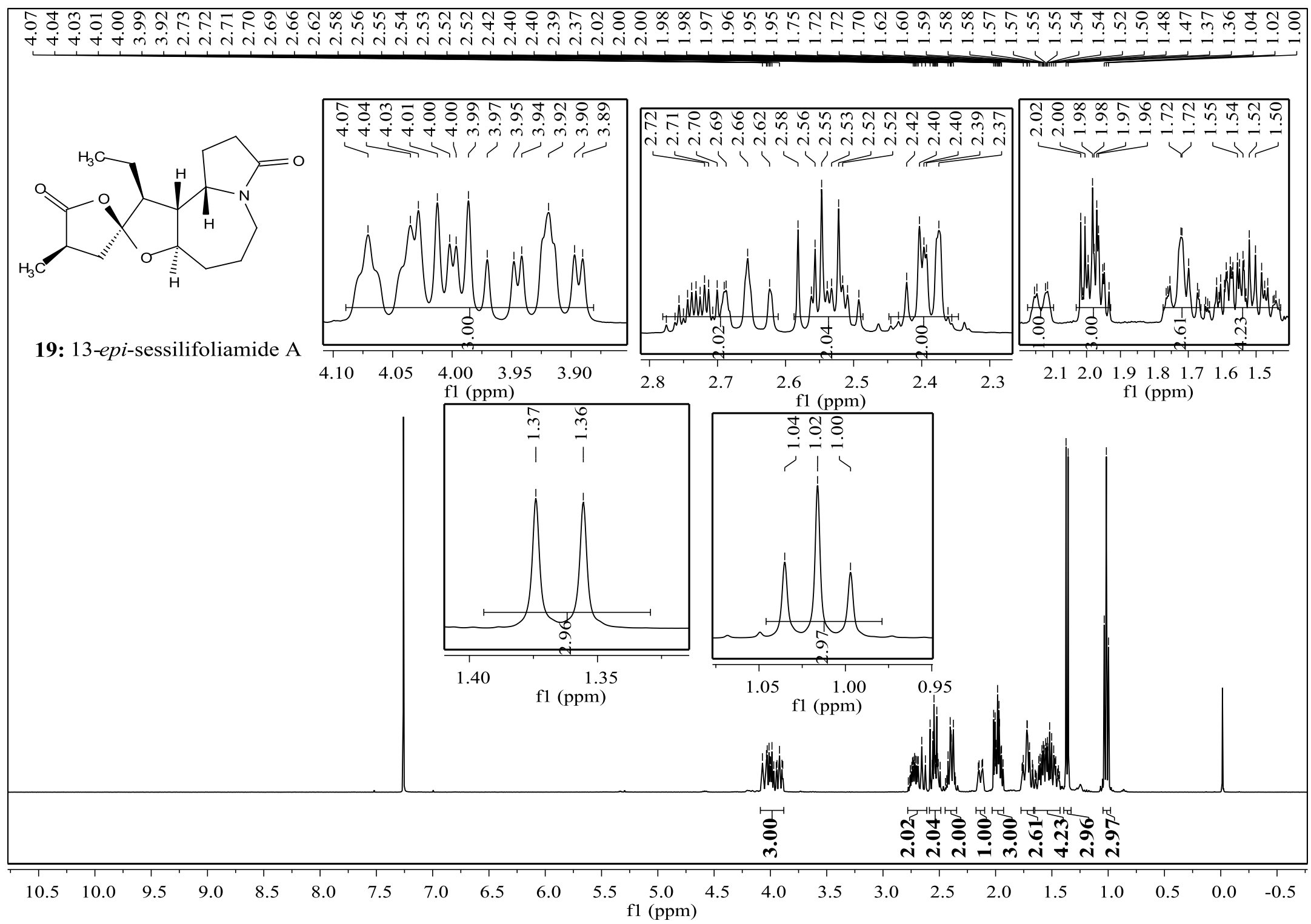


${ }^{13} \mathrm{C}$ NMR Spectrum of 19 (101 $\left.\mathrm{MHz}, \mathrm{CDCl}_{3}\right)$

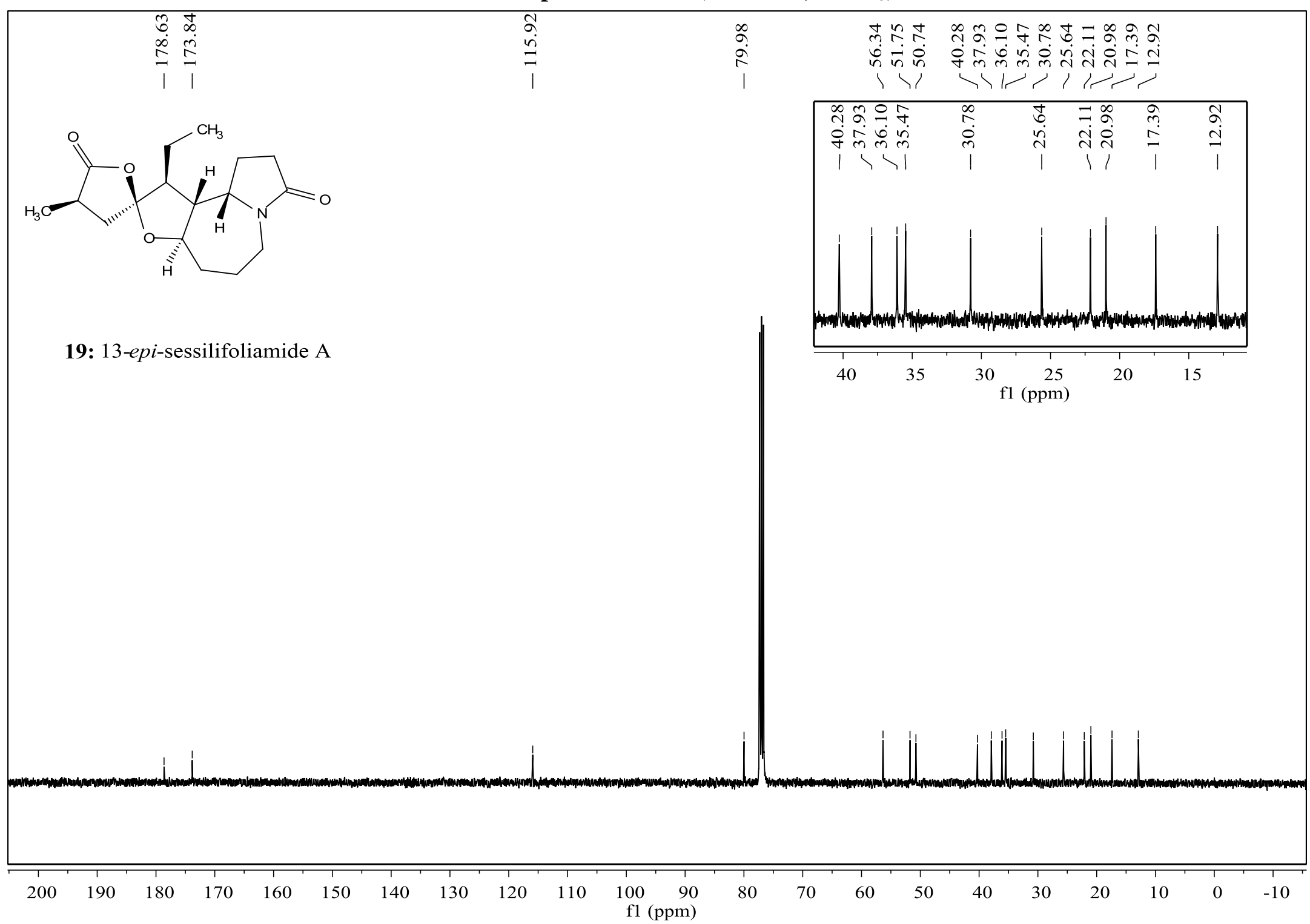


${ }^{1} \mathrm{H}$ NMR Spectrum of $16\left(400 \mathrm{MHz}, \mathrm{CDCl}_{3}\right)$

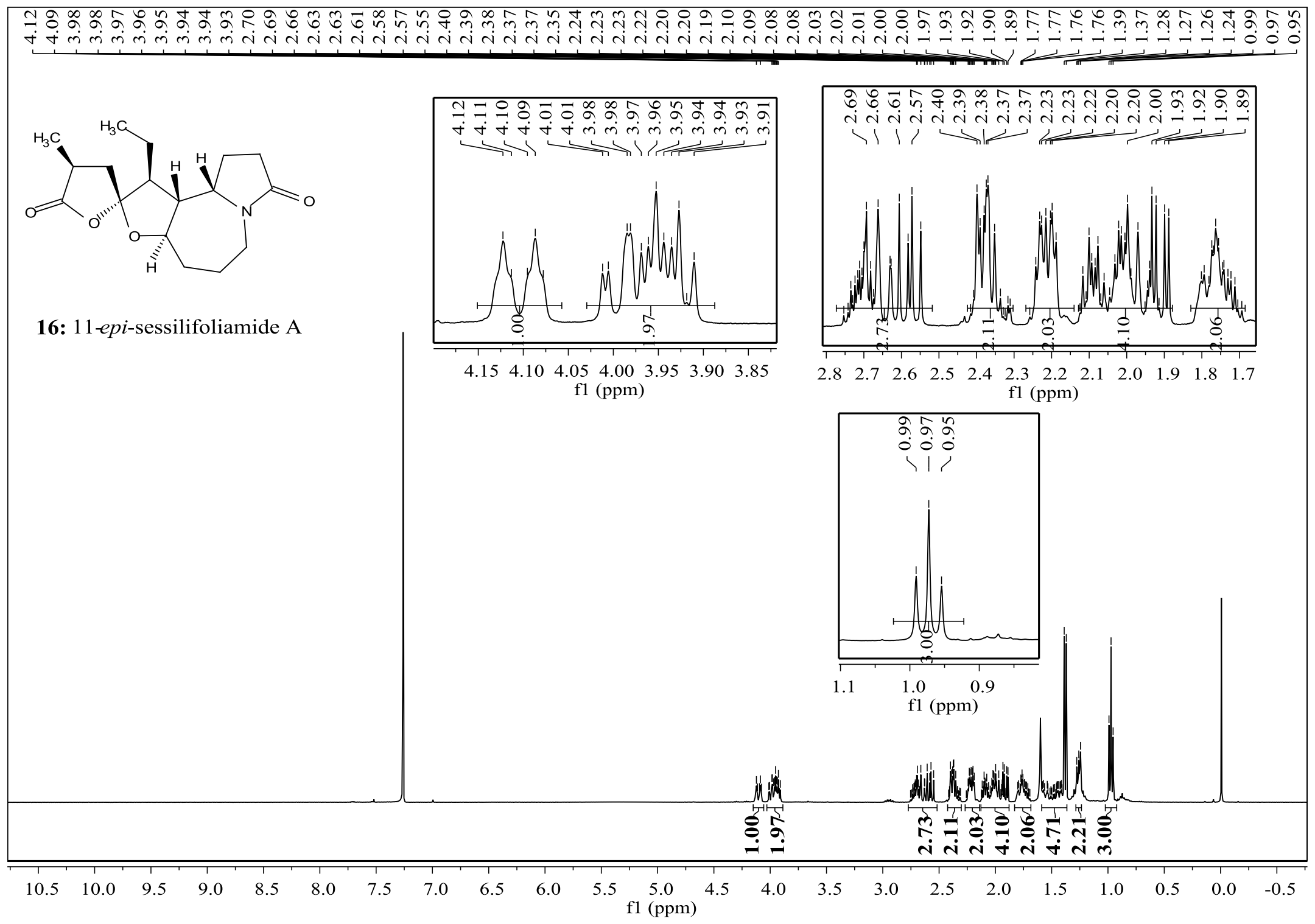


${ }^{13} \mathrm{C}$ NMR Spectrum of $16\left(101 \mathrm{MHz}, \mathrm{CDCl}_{3}\right)$

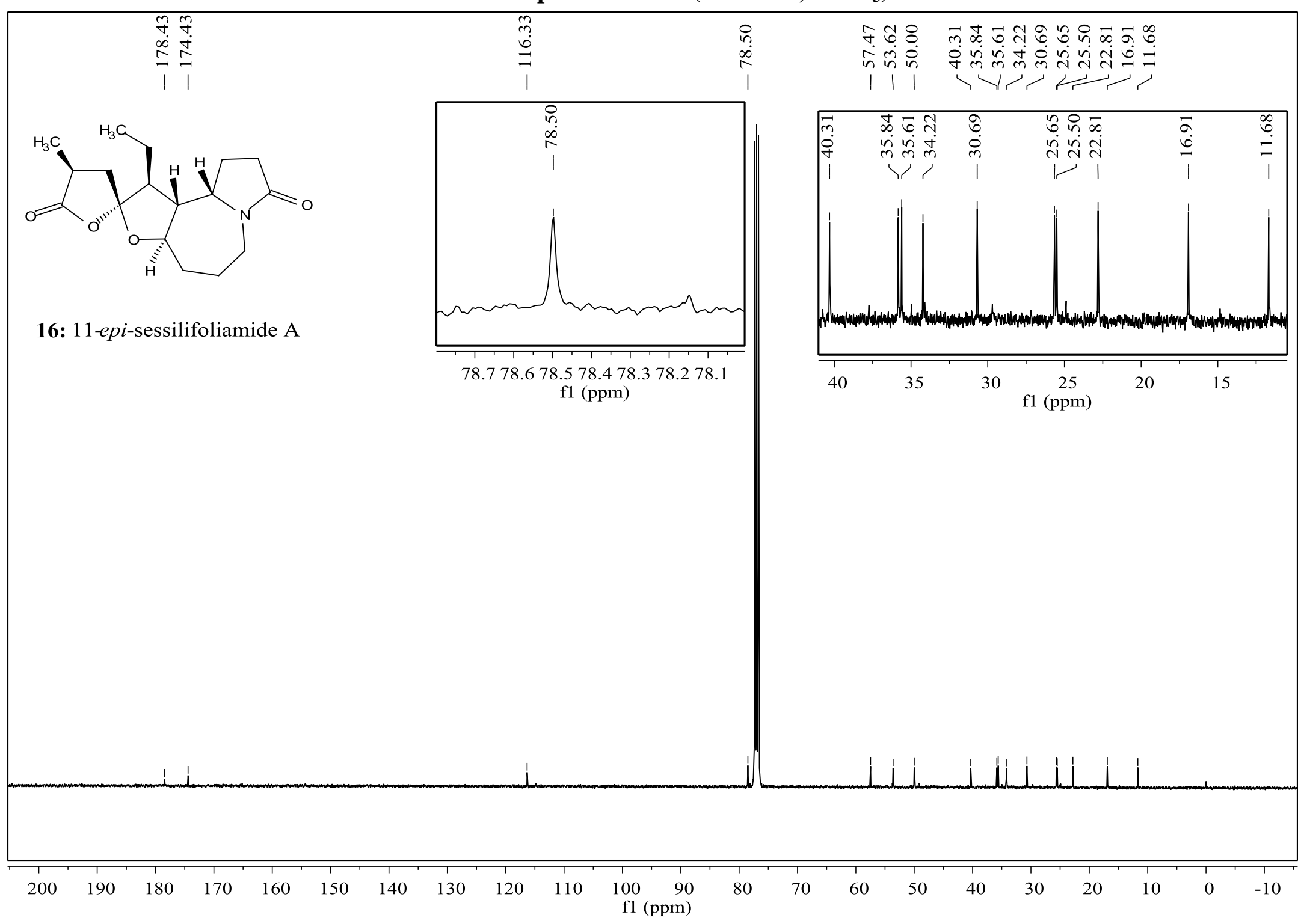


${ }^{1} \mathrm{H}$ NMR Spectrum of $20\left(400 \mathrm{MHz}, \mathrm{CDCl}_{3}\right)$

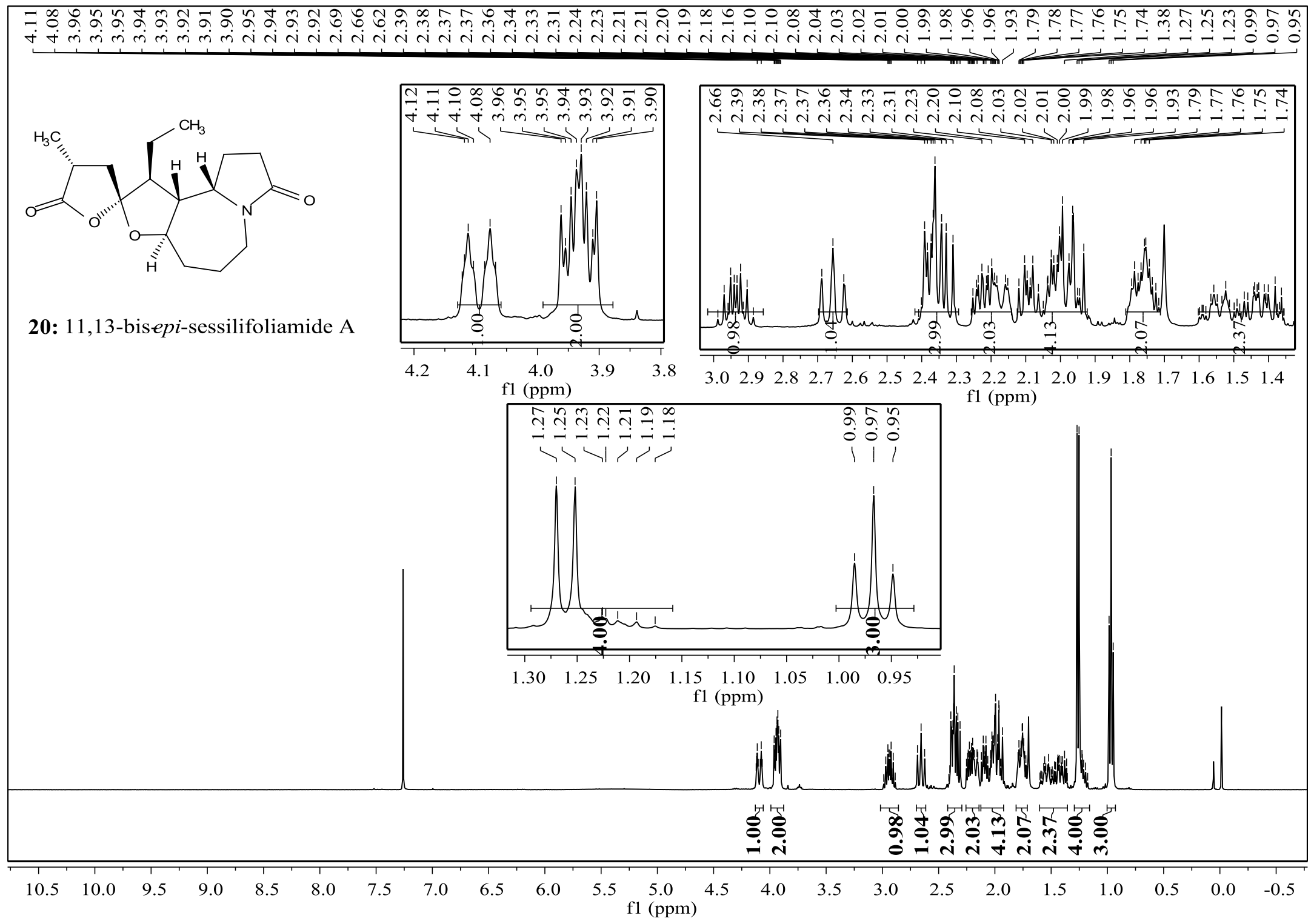


${ }^{13} \mathrm{C}$ NMR Spectrum of $20\left(101 \mathrm{MHz}, \mathrm{CDCl}_{3}\right)$

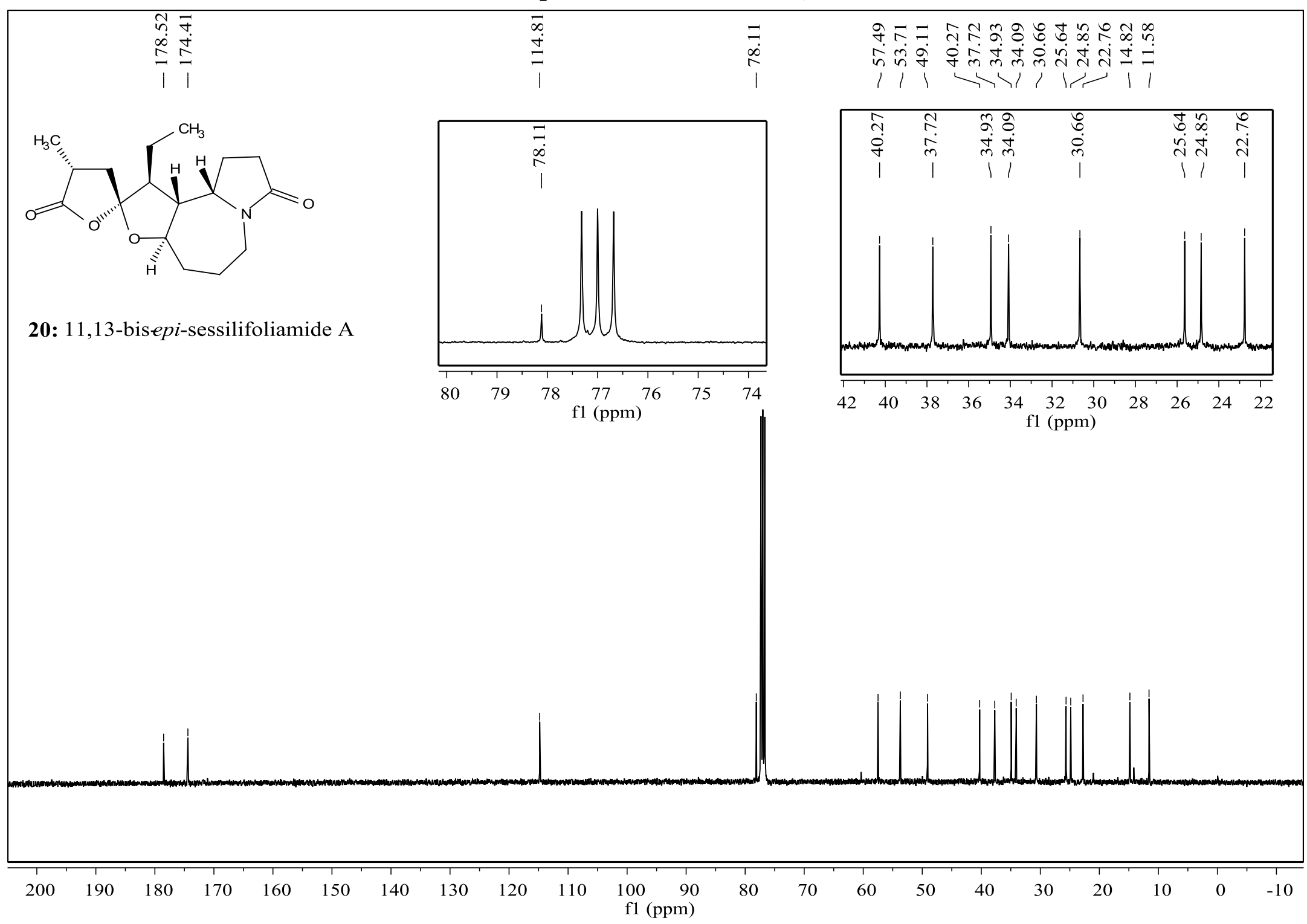


${ }^{1} \mathrm{H}$ NMR Spectrum of 1 (400 $\mathrm{MHz}, \mathrm{CDCl}_{3}$ )

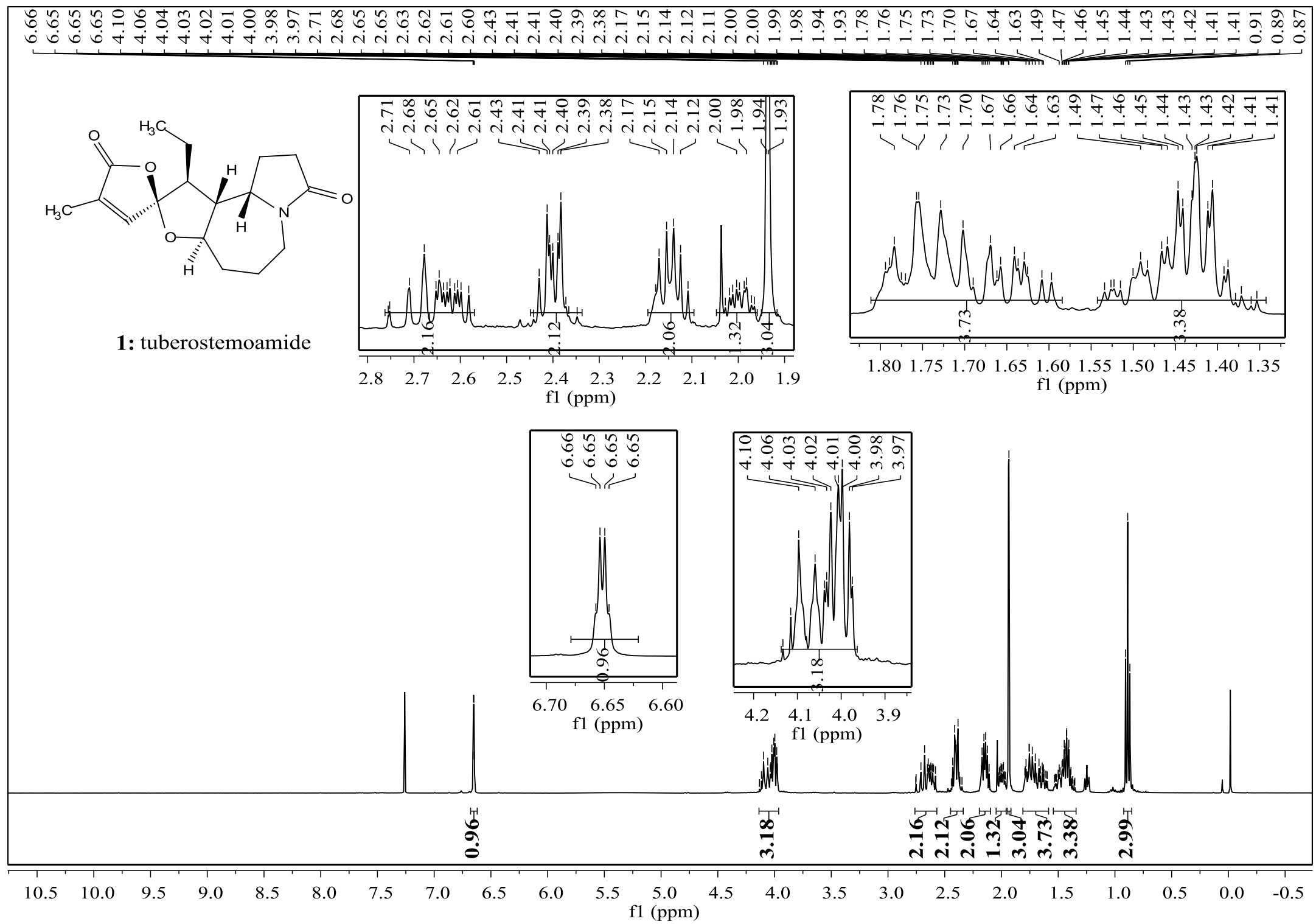


${ }^{13} \mathrm{C}$ NMR Spectrum of $1\left(101 \mathrm{MHz}, \mathrm{CDCl}_{3}\right)$

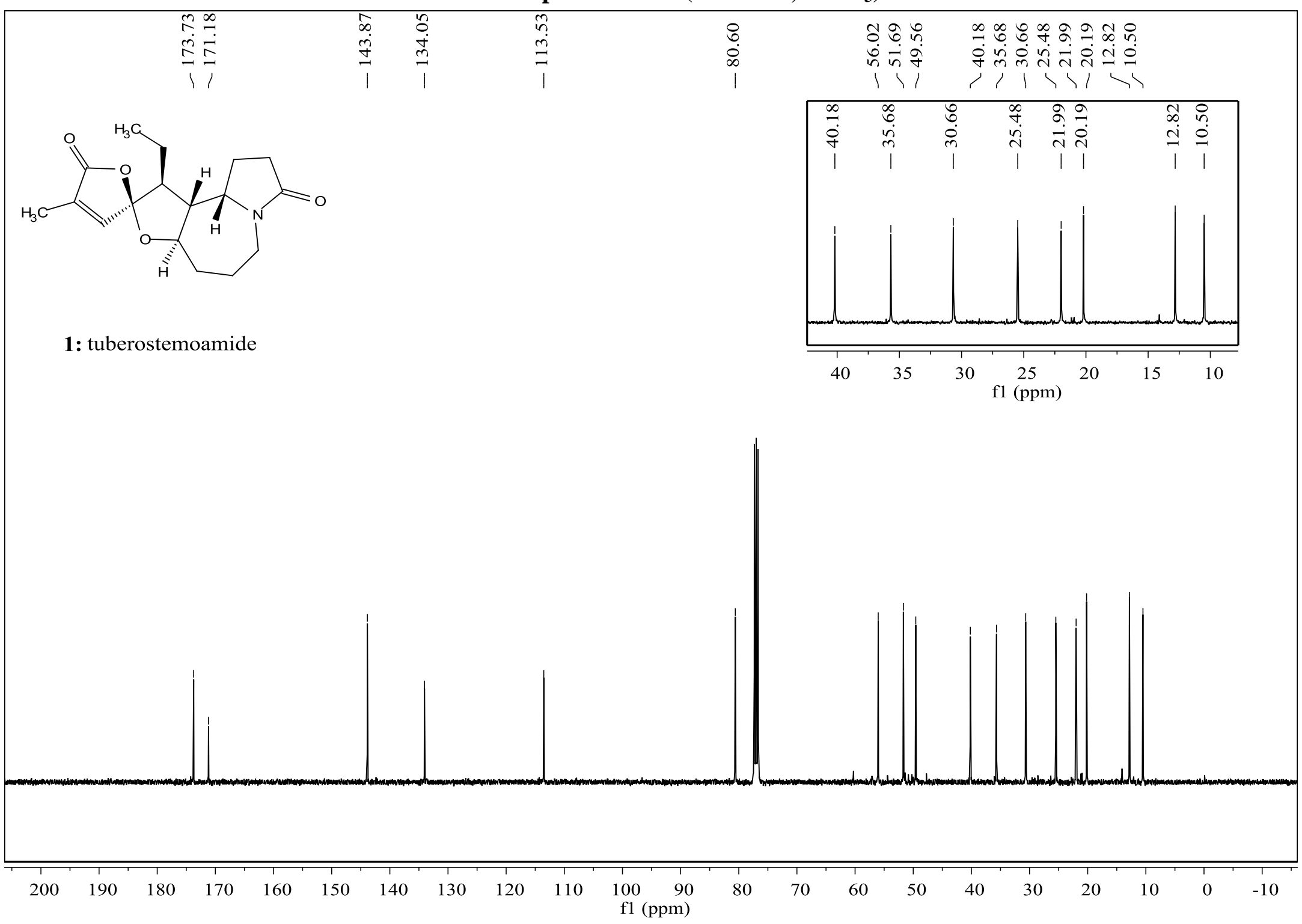


${ }^{1} \mathrm{H}$ NMR Spectrum of $21\left(400 \mathrm{MHz}, \mathrm{CDCl}_{3}\right)$

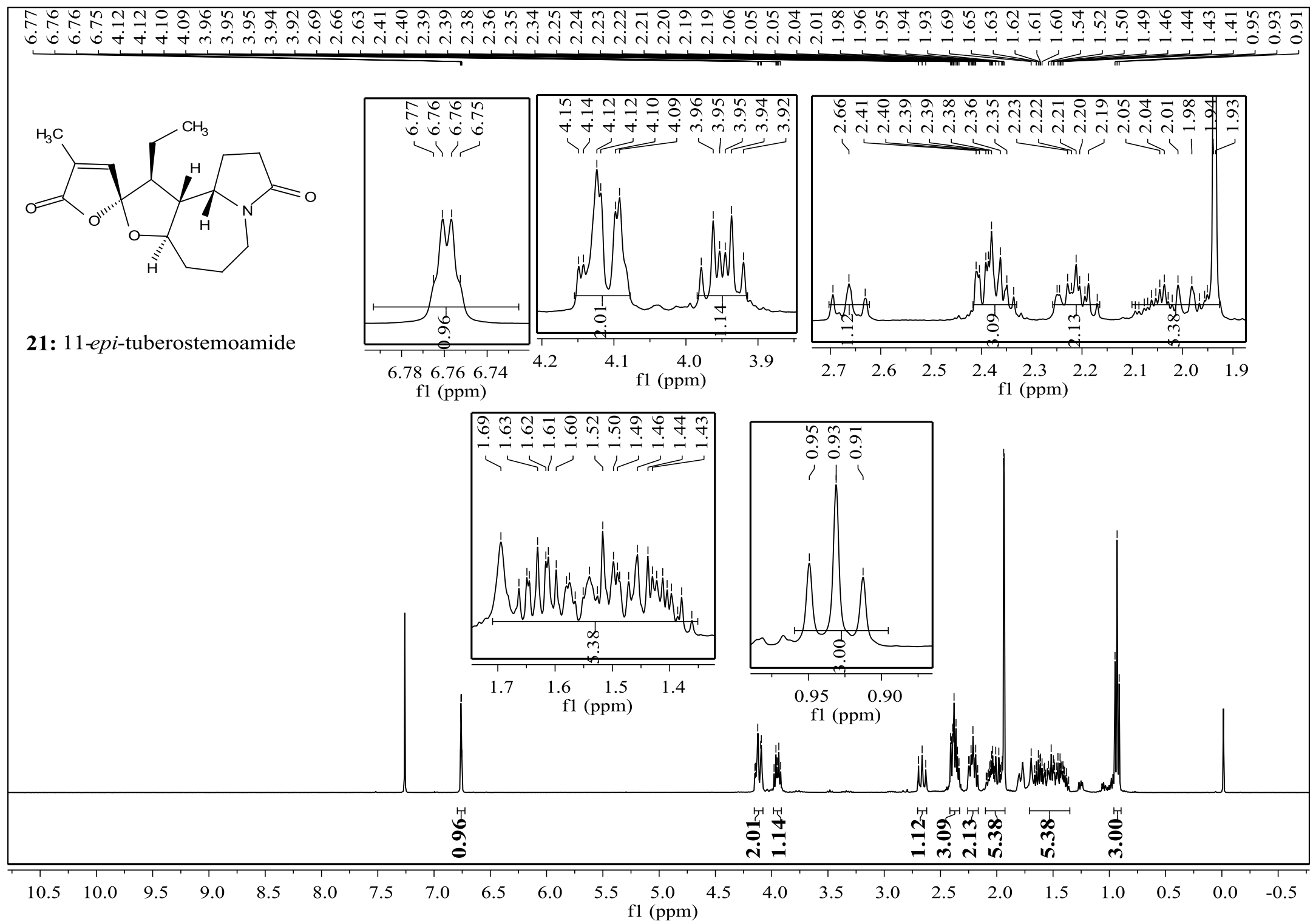




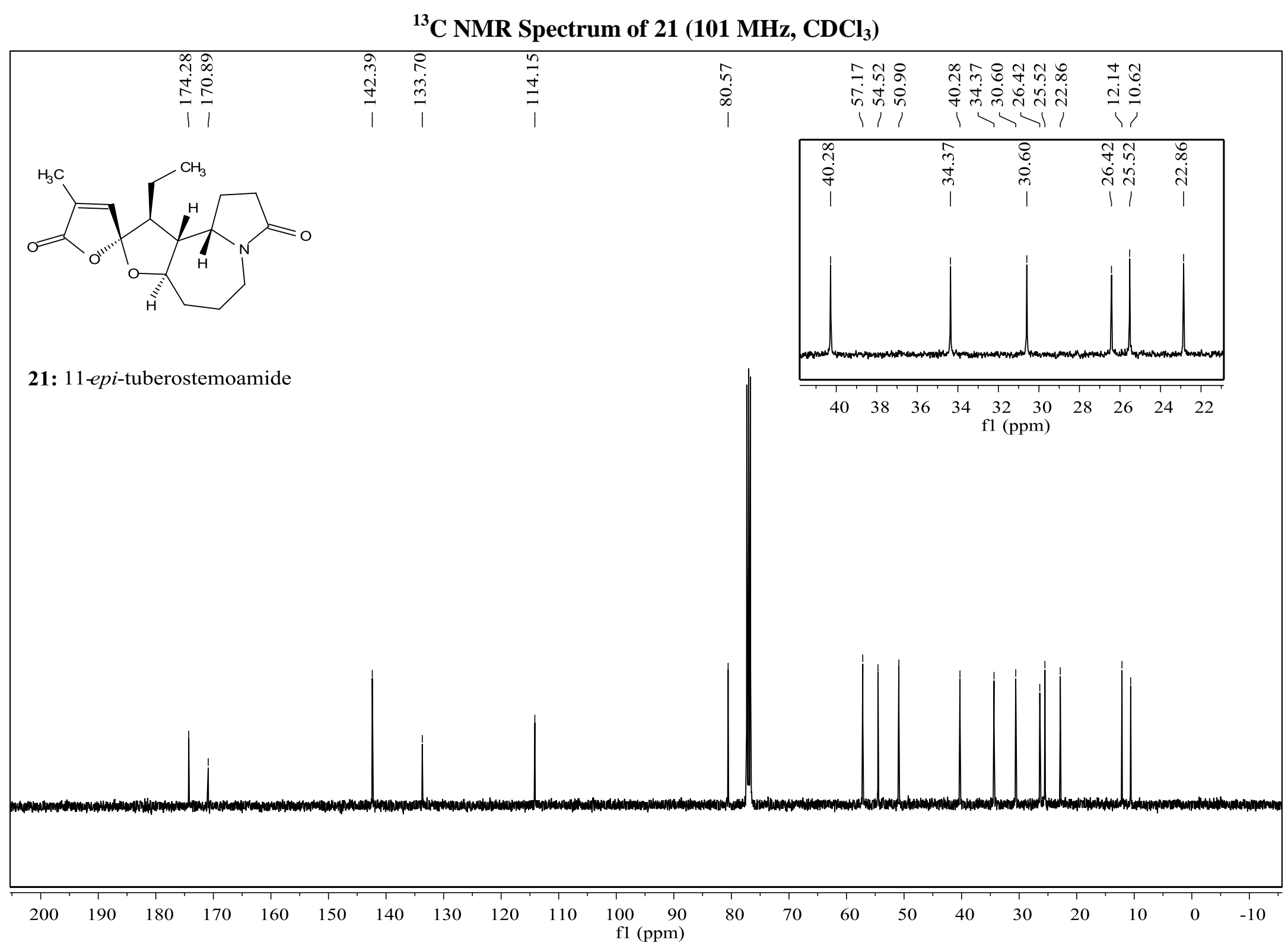




\section{Biological Studies}

Employing the developed synthetic technologies in this research program, we were able to evaluate biological activities of several compounds $(1,2,4,12,11 a, 19,20,21)$ possessed the similar $5 / 7 / 5$ tricycle-skeleton with stemoamide (5).

In Vitro Cytotoxicity Assay.

Anti-proliferative activities against HepG2, SMMC-7721, LoVo, HL-60 and WI38 cell lines were determined by MTT method (Table S8). ${ }^{15}$ Except the compound 20, which exhibited potential anti-proliferative activity on HepG2 cell line $\left(\mathrm{IC}_{50}=99.02 \pm 3.60 \mu \mathrm{M}\right)$, other seven compounds showed nearly no toxicities to all other tumor cell lines and normal cell line (all $\left.\mathrm{IC}_{50}>200 \mu \mathrm{M}\right)$.

Cells were plated in 96 -well microtiter plates at a density of $5 \times 10^{4} /$ well and incubated in a humidified atmosphere with $5 \% \mathrm{CO}_{2}$ at $37{ }^{\circ} \mathrm{C}$ for $24 \mathrm{~h}$. Tested compounds were added onto triplicate wells with different concentrations and $0.1 \%$ DMSO for the control. After they had been incubated for $24 \mathrm{~h}, 10 \mu \mathrm{L}$ of MTT (3-(4,5-dimethylthiazol-2-yl)-2,5-diphenyltetrazolium bromide) solution $(5 \mathrm{mg} / \mathrm{mL})$ was added to each well, and the plate was incubated for an additional $4 \mathrm{~h}$. The formazan was dissolved in $100 \mu \mathrm{L}$ of DMSO. All experiments were performed three times.

Table S8. In vitro antiproliferative activity of selected compounds and DDP.

\begin{tabular}{cccccc}
\hline \multirow{5}{*}{ Compd. } & \multicolumn{5}{c}{$\mathrm{IC}_{50}{ }^{[\mathrm{a}]}(\mu \mathrm{M})$} \\
\cline { 2 - 6 } & HePG2 & SMMC-7721 & LoVo & HL-60 & WI38 \\
\hline 1 & $>200$ & $>200$ & $>200$ & $>200$ & $>200$ \\
2 & $>200$ & $>200$ & $>200$ & $>200$ & $>200$ \\
4 & $>200$ & $>200$ & $>200$ & $>200$ & $>200$ \\
12 & $>200$ & $>200$ & $>200$ & $>200$ & $>200$ \\
$11 \mathrm{a}$ & $>200$ & $>200$ & $>200$ & $>200$ & $>200$ \\
19 & $>200$ & $>200$ & $>200$ & $>200$ & $>200$ \\
20 & $99.02 \pm 3.60$ & $>200$ & $>200$ & $>200$ & $>200$ \\
21 & $>200$ & $>200$ & $>200$ & $>200$ & $>200$ \\
DDP & $25.56 \pm 2.79$ & $20.78 \pm 1.63$ & $39.15 \pm 3.05$ & $41.38 \pm 2.67$ & $42.14 \pm 3.12$ \\
\hline
\end{tabular}

[a] Results expressed as the mean \pm SD deviation of at least three separate determinations. DDP $=$ cis-dichlorodiammine platinum.

\section{Cholinesterase Inhibitory Assays}

In addition of the anti-proliferative activity, Stemonaceae plants also have acetylcholinesterase (AChE) inhibitory activities ${ }^{16-19}$ and anti-inflammatory activities. ${ }^{20}$ Unfortunately, the selected compounds showed no any EeAChE inhibitory activities (all $\mathrm{IC}_{50}>250 \mu \mathrm{M}$ ) (Table S9). Inhibitory activity studies on butyrylcholinesterase (eqBChE) demonstrated that 11,13-bis-epi-sessilifoliamide A (20) showed selective inhibitory activity on eqBChE $\left(\mathrm{IC}_{50}=26.42 \pm 3.43 \mu \mathrm{M}\right)$ (Table S9). Plots of initial velocity versus enzyme concentration (Figure S1) revealed that $\mathbf{2 0}$ may be the reversible inhibitor of eqBChE. Thus, 11,13-bis-epi-sessilifoliamide A $\mathbf{2 0}$ was expected to be a potential drug for treatment of neurodegenerative diseases after further modification. 
Acetylthiocholine iodide, butyrylthiocholine iodide and 5,5-dithiobis-(2-nitrobenzoic) acid (DTNB) were purchased from Sigma Aldrich.EeAChE (E.C. 3.1.1.7, type V-S, purified from E. electricus) and eqBuChE (E.C. 3.1.1.8, purified from equine serum) were diluted in 20 mM HEPES buffer $\mathrm{pH}$ 7.2-7.4, phosphate buffer $\mathrm{pH} 7.4$ such as to have enzyme solution with $0.25 \mathrm{units} / \mathrm{mL}$ enzyme activity. In the procedure, $25 \mu \mathrm{L}$ of compound solution (10xfinal concentration) or $25 \mu \mathrm{L}$ of sodium phosphate buffer ( $\mathrm{pH}$ 7.2-7.4) were added to plate wells containing $10 \mu \mathrm{L}$ of enzyme (0.01-0.05 IU/mL final) and $65 \mu \mathrm{L}$ of sodium phosphate buffer ( $\mathrm{pH}$ 7.2-7.4). After $10 \mathrm{~min}$ of preincubation, $100 \mu \mathrm{L}$ of $0.3 \mathrm{mM}$ DTNB dissolved in phosphate buffer (pH 7.2-7.4) and $50 \mu \mathrm{L}$ of substrate (acetylthiocholine or butyrylthiocholine iodide, $1 \mathrm{mM}$ final) were added and the plate was read at 405 $\mathrm{nm}$ for $10 \mathrm{~min}$. All experiments were run in triplicate and performed at least twice. Tested compounds were dissolved at $0.1 \mathrm{M}$ in DMSO and diluted in phosphate buffer to the required concentrations just before use. Galanthamine was used as reference standard. The final concentrations of DMSO (<0.4\% v.v.) did not affect enzyme activity.

Table S9. Inhibitory activity of all selected compounds on butyrylcholinesterase.

\begin{tabular}{cccc}
\hline Compound & eqBuChEIC $_{50}(\mu \mathrm{M})$ & Compound & EeAChEIC $_{50}(\mu \mathrm{M})$ \\
\hline 1 & $>250$ & 1 & $>250$ \\
2 & $>250$ & 2 & $>250$ \\
4 & $>250$ & 4 & $>250$ \\
12 & $>250$ & 12 & $>250$ \\
$11 \mathrm{a}$ & $>250$ & $11 \mathrm{a}$ & $>250$ \\
19 & $>250$ & 19 & $>250$ \\
20 & $26.42 \pm 3.43$ & 20 & $>250$ \\
21 & $>250$ & 21 & $>250$ \\
Galanthamine & $2.82 \pm 0.03$ & Galanthamine & $0.14 \pm 0.01$ \\
\hline
\end{tabular}

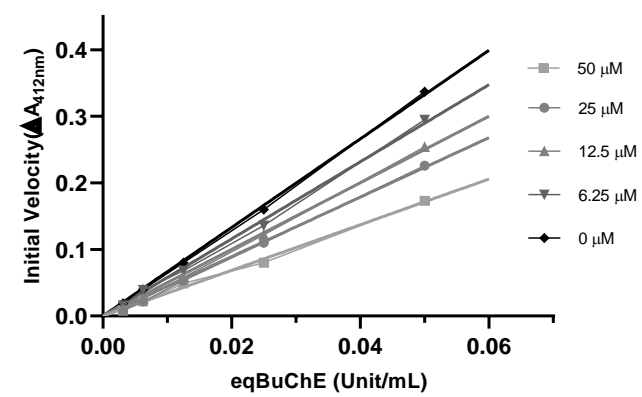

Figure. S1. Plots of initial velocity versus enzyme concentration for the inhibition activity of compound $\mathbf{2 0}$ on the hydrolysis of butyrylcholinesterase

\section{Anti-inflammatory assay}

The inhibitory effects of the synthetic compounds on LPS-induced pro-inflammatory mediators, including NO, TNF- $\alpha$, and IL-6 production in RAW264.7 macrophage were then studied. On the basis of determining the effective concentrations of anti-inflammatory tests, LPS-activated macrophages were applied to evaluate the anti-inflammatory activities. As shown in Figure S2, all tested compounds attenuated the production of 
LPS-induced pro-inflammatory mediators in RAW264.7 macrophage. Among them, compound 2 inhibited the release of NO, TNF- $\alpha$, and IL-6. These results suggested that the anti-inflammation activity in vitro of Stemonaceae plants probably was accomplished by the decreased release of NO, TNF- $\alpha$ and IL- 6 , and the activities of epimers were different from each other and sessilifoliamide A (2) may be a part of the anti-inflammatory substances in Stemonaceae plants.

\section{(1) Cell viability}

In order to obtain more accurate results of anti-inflammatory experiments, eliminate the effects of cell death caused by tested compounds on the results as far as possible, macrophages were exposed for $24 \mathrm{~h}$ to the selected compounds $(12.5,25,50,100$ and $200 \mu \mathrm{M})$, then the cell viability was measured using MTT method. As shown in Figure S3, none of the tested compounds at concentrations ranging from $12.5 \mu \mathrm{M}$ to $200 \mu \mathrm{M}$ had any significant effect on cell viability, this also suggested the compounds at the range of 12.5-50 $\mu \mathrm{M}$ are acceptable and effective in anti-inflammatory tests.
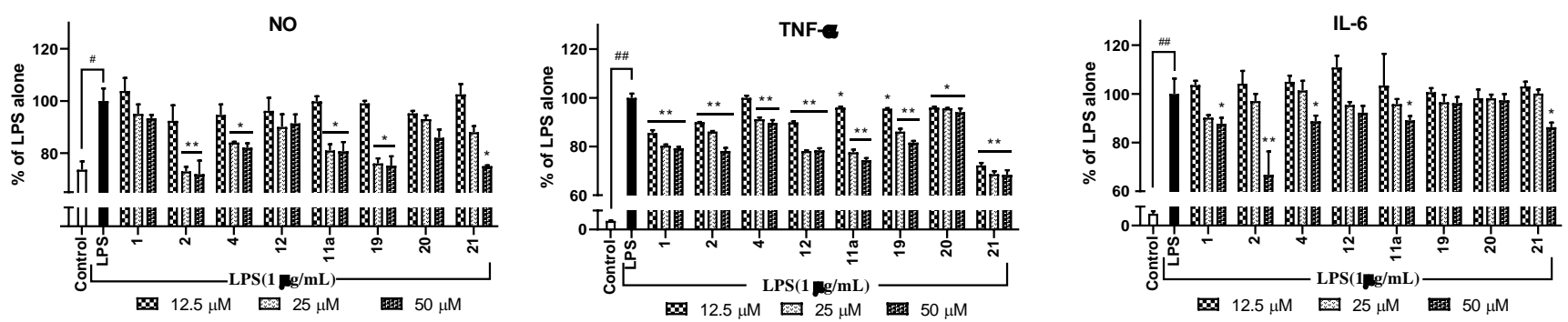

Figure S2. The effect of some selected compounds on lipopolysaccharide (LPS)-induced NO, TNF- $\alpha$, and IL-6 production in RAW264.7 macrophage. Each bar represents the mean \pm SD of three independent experiments. * $\mathrm{p}<0.05,{ }^{\# \#} \mathrm{p}<0.01$ vs. control. * $\mathrm{p}<0.05, * * \mathrm{p}<0.01$, vs. LPS-treated cells.

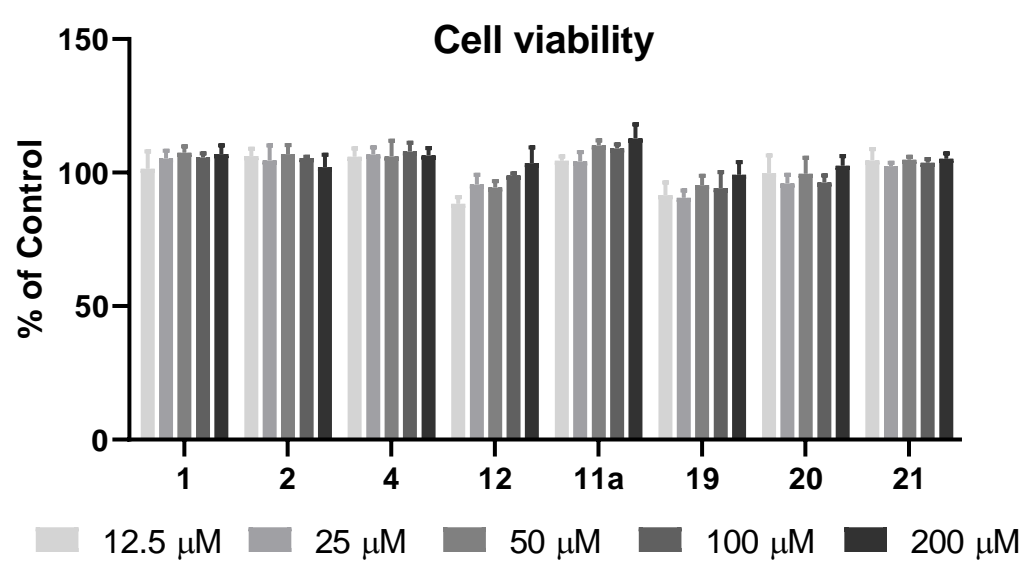

Figure S3. Effect of selected compounds on cell viability. Data represent percent viability as mean \pm SD of 3 replicates per concentration of each compound.

(2) NO production assay

Nitrite level, an index for NO production,was measured in the supernatant of RAW264.7 cells by the Griess method. ${ }^{21}$ RAW264.7 cells were inoculated to 6-well plates at the density of $5 \times 10^{5}$ cells per well and cultured 
for18 h. Different compounds were added to each well, to which was additionally added LPS (1000 ng/mL) and incubated at $37^{\circ} \mathrm{C}$ for $24 \mathrm{~h}$. After stimulated for $24 \mathrm{~h}$ by LPS, the supernatant of the cell culture medium and the same volume of Griess reagent (1\% sulfanilamide and $0.1 \%$ naphthyl ethylenediamine dihydrochloride in $5 \%$ phosphoric acid) were added to a 96-well plate for $10 \mathrm{~min}$, and nitrite was measured at $540 \mathrm{~nm}\left(\mathrm{OD}_{540}\right)$ using a microplate reader (Bio-Rad Laboratories, CA, USA). Meanwhile, the results were evaluated from three independent experiments.

(3) Cytokines Measurement

Production of the pro-inflammatory cytokines was evaluated by an enzyme-linked immunosorbent assay (ELISA). RAW264.7 cells $\left(5 \times 10^{5}\right.$ cells/well) were pretreated with or without compounds in 6-well plates and the cells were stimulated with $1000 \mathrm{ng} / \mathrm{mL}$ LPS at the same time then cultured for $24 \mathrm{~h}$ to assay TNF- $\alpha$ and IL-6 production. The levels of TNF- $\alpha$, IL-6 in cell culture supernatant were measured using a specific ELISA kit (TNF- $\alpha$ : Elabscience, E-EL-M0959c; IL-6: Shanghai Enzyme-linked Biotechnology Co., Ltd, ml063160) according to the manufacturer's instructions, and were read at $450 \mathrm{~nm}\left(\mathrm{OD}_{450}\right)$ in a microplate reader. LPS was used as the positive control in parallel experiments. The results were calculated from two independent experiments. 


\section{Reference}

1 Honda, T.; Matsukawa, T.; Takahashi, K. Org. Biomol. Chem. 2011, 9, 673-675.

2 Kinoshita, A.; Mori, M. J. Org. Chem. 1996, 61, 8356-8357.

3 Kinoshita, A.; Mori, M. Heterocycles 1997, 46, 287-299.

4 Jacobi, P. A.; Lee, K. J. Am. Chem. Soc. 2000, 122, 4295-4303.

5 Mi, X. W.; Wang, Y.; Zhu, L. L.; Wang, R. X.; Hong, R. Synthesis 2012, 44, 3432-3440.

6 Olivo, H. F.; Tovar-Miranda, R.; Barragán, E. J. Org. Chem. 2006, 71, 3287-3290.

7 Sibi, M. P.; Subramanian, T. Synlett 2004, 2004, 1211-1214.

8 Yoritate, M.; Takahashi, Y.; Tajima, H.; Ogihara, C.; Yokoyama, T.; Soda, Y.; Oishi, T.; Sato, T.; Chida, N. J. Am. Chem. Soc. 2017, 139, 18386-18391.

9 Torssell, S.; Wanngren, E.; Somfai, P. J. Org. Chem. 2007, 72, 4246-4249.

10 Williams, D. R.; Reddy, J. P.; Amato, G. S. Tetrahedron Lett. 1994, 35, 6417-6420.

11 Khim, S.-K.; Schultz, A. G. J. Org. Chem. 2004, 69, 7734-7736.

12 Kakuta, D.; Hitotsuyanagi, Y.; Matsuura, N.; Fukaya, H.; Takeya, K. Tetrahedron 2003, 59, 7779-7786.

13 Lin, W. H.; Wang, L.; Qiao, L.; Cai, M. S. Chin. Chem. Lett. 1993, 4, 1067-1070.

14 Lin, W. H.; Ma, L.; Cai, M. S.; Barnes, R. A. Phytochemistry 1994, 36, 1333-1335.

15 Rinner, B.; Siegl, V.; Pürstner, P.; Efferth, T.; Brem, B.; Greger, H.; Pfragner, R. Anticancer Res. 2004, 24, 495-500.

16 Pilli, R. A.; Rosso, G. B.; de Oliveira, M. d. C. F. Nat. Prod. Rep. 2010, 27, 1908-1937.

17 Gao, Y.; Wang, J.; Zhang, C. F.; Xu, X. H.; Zhang, M.; Kong, L. Y. Tetrahedron 2014, 70, 967-974.

18 18. Kongkiatpaiboon, S.; Rojsanga, P.; Pattarajinda, V.; Gritsanapan, W. Pharmacognosy Journal 2013, 5, 56-59.

19 Mungkornasawakul, P.; Chaiyong, S.; Sastraruji, T.; Jatisatienr, A.; Jatisatienr, C.; Pyne, S. G.; Ung, A. T.; Korth, J.; Lie, W. J. Nat. Prod. 2009, 72, 848-851.

20 Wu, Y. X.; He, H. Q.; Nie, Y. J.; Ding, Y. H.; Sun, L.; Qian, F. Acta Pharmacol. Sin. 2018, 39, 85.

21 Foresti, R.; Clark, J. E.; Green, C. J.; Motterlini, R. J. Biol. Chem. 1997, 272, 18411-18417. 


\section{A Map Of Structural relationship of Some Stemona Alkaloids}

After carefully analyzing the structures of stemoamide-group alkaloids, we think there are highly structural correlations among them. Stemoamide and ethylstemoamide may be the main parent molecules of them and may play significant roles in accomplishing possible biotransformations of more stemoamide-group alkaloids.

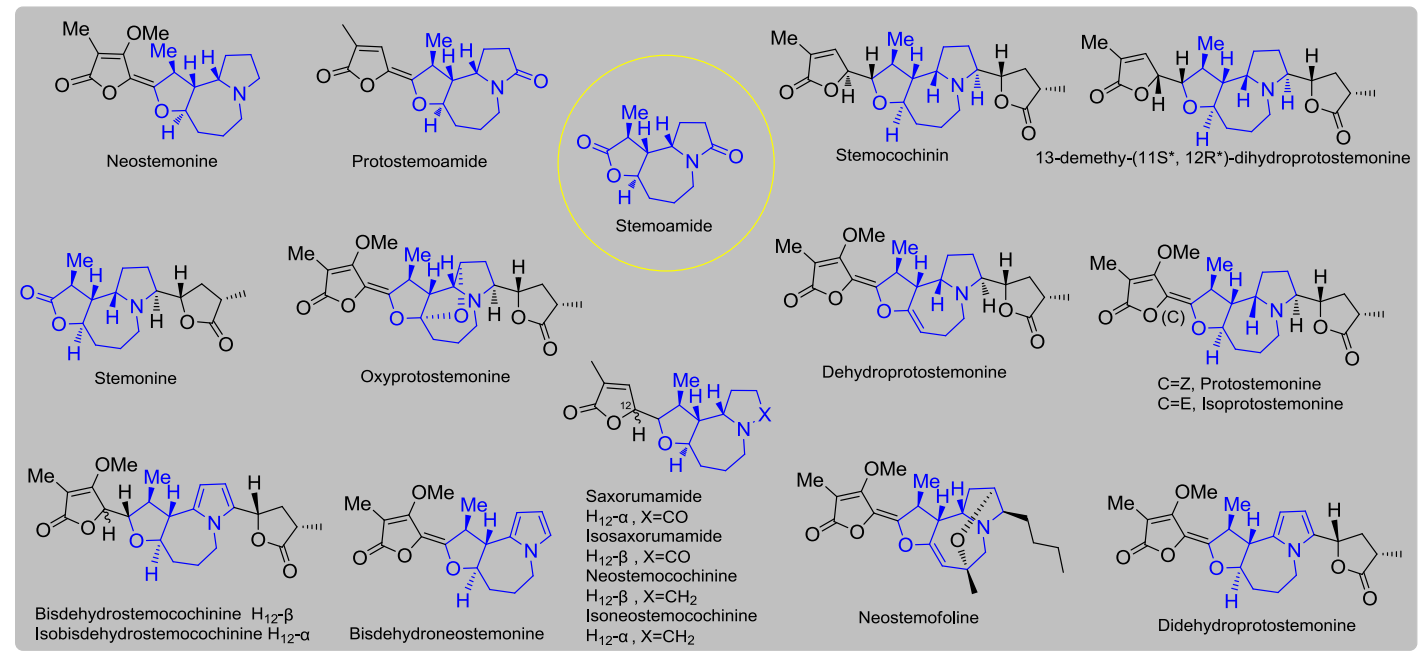

Figure S4. "Stemoamide type" stemoamide-group alkaloids.

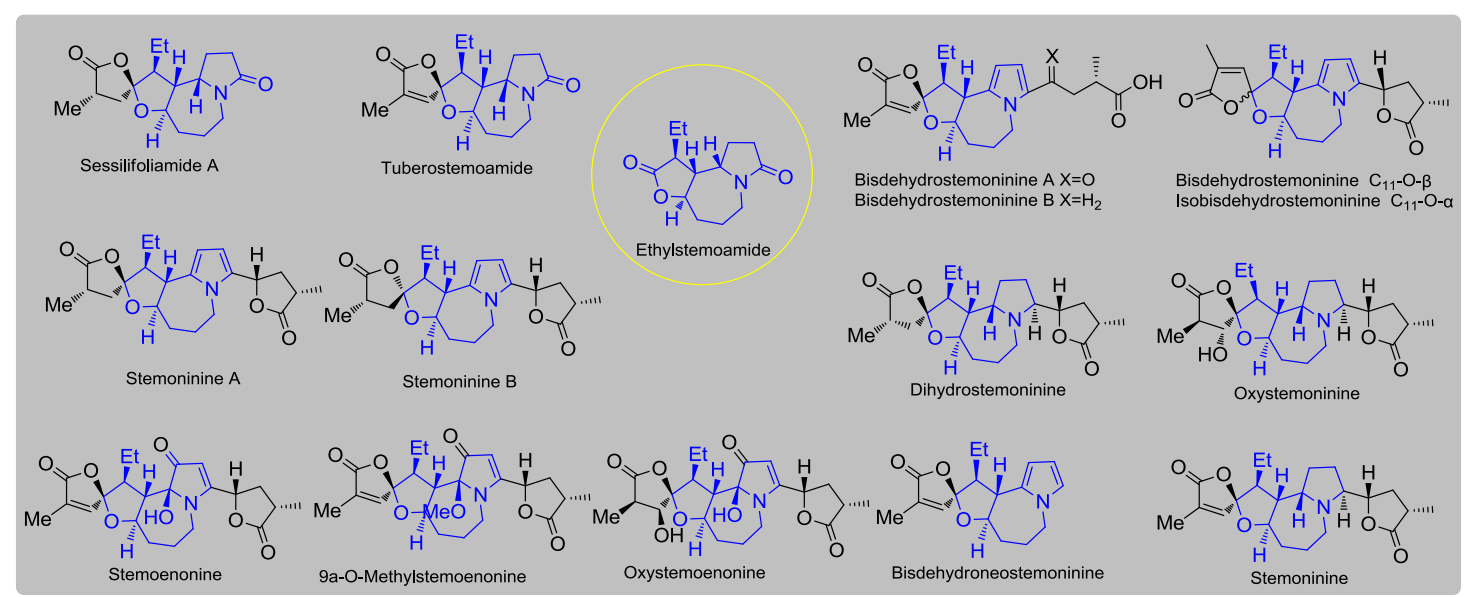

Figure S5. "Ethylstemoamide type" stemoamide-group alkaloids. 


\section{Crystal Data and Cif Check Report for compound 11a/11b \\ (CCDC: 1874368)}
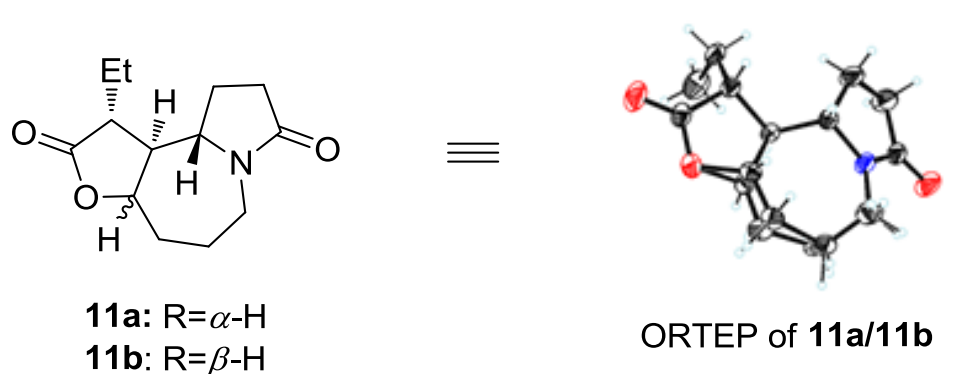


\section{checkCIF/PLATON report}

Structure factors have been supplied for datablock(s) wangzhen-02

THIS REPORT IS FOR GUIDANCE ONLY. IF USED AS PART OF A REVIEW PROCEDURE FOR PUBLICATION, IT SHOULD NOT REPLACE THE EXPERTISE OF AN EXPERIENCED CRYSTALLOGRAPHIC REFEREE.

No syntax errors found. CIF dictionary Interpreting this report

\section{Datablock: wangzhen-02}

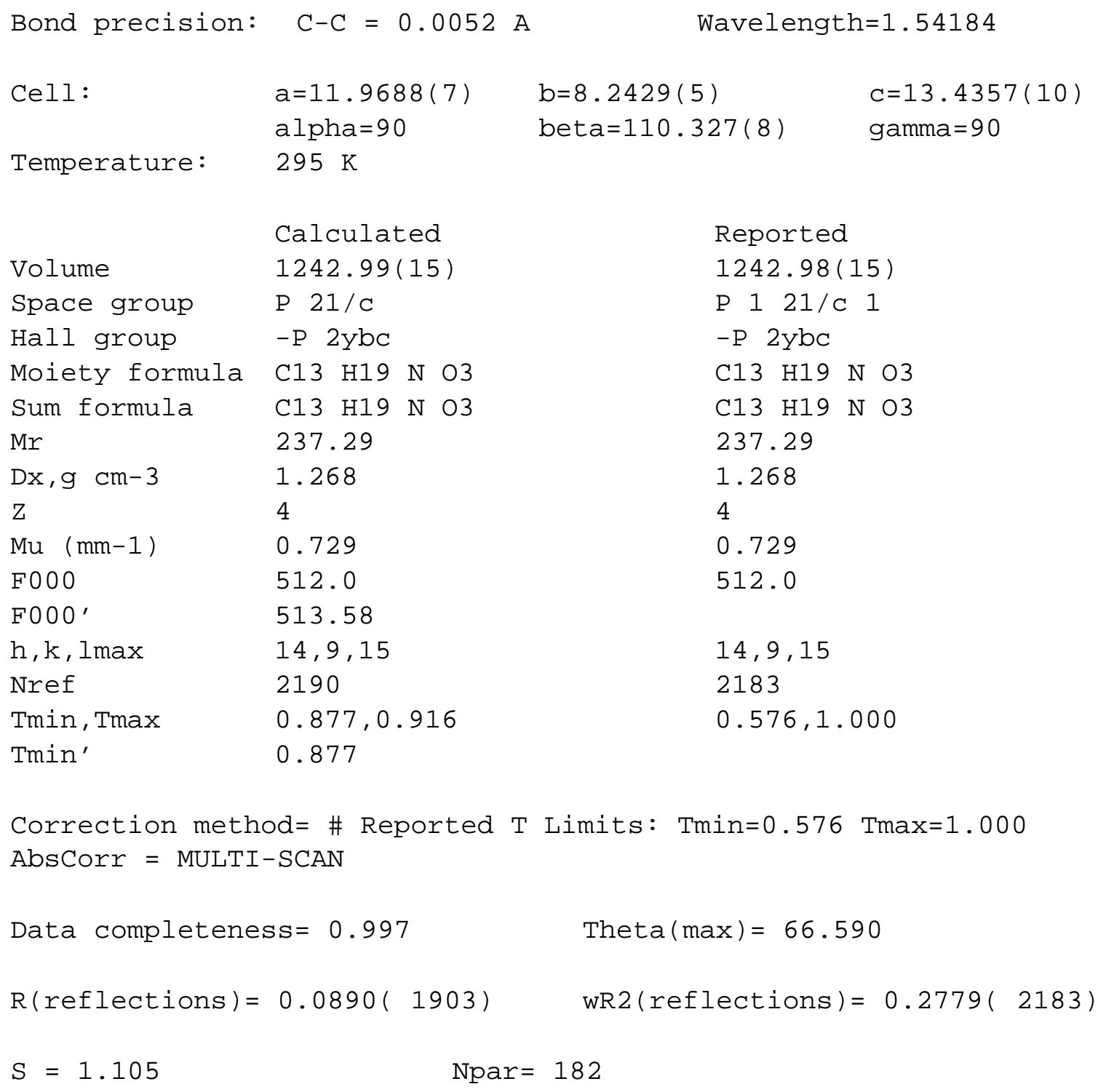


Alert level $\mathrm{C}$

DIFMX02_ALERT_1_C The maximum difference density is $>0.1 *$ ZMAX 0.75

The relevant atom site should be identified.

PLAT084_ALERT_3_C High wR2 Value (i.e. > 0.25) ..............

PLAT097_ALERT_2_C Large Reported Max. (Positive) Residual Density

PLAT234_ALERT_4_C

PLAT241_ALERT_2_C

Large Hirshfeld Difference C1 -

High 'MainMol' Ueq as Compared to Neighbors of

PLAT241_ALERT_2_C High 'MainMol' Ueq as Compared to Neighbors of

PLAT241_ALERT_2_C High 'MainMol' Ueq as Compared to Neighbors of

PLAT242_ALERT_2_C Low 'MainMol' Ueq as Compared to Neighbors of

PLAT242_ALERT_2_C Low 'MainMol' Ueq as Compared to Neighbors of

PLAT242_ALERT_2_C Low 'MainMol' Ueq as Compared to Neighbors of

PLAT260_ALERT_2_C Large Average Ueq of Residue Including 01

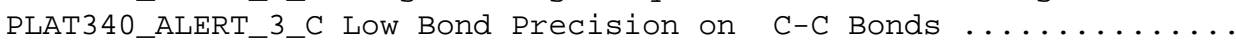

PLAT360_ALERT_2_C

Short $\mathrm{C}(\mathrm{sp} 3)-\mathrm{C}(\mathrm{sp} 3)$ Bond $\mathrm{C} 7 \quad-\mathrm{C} 8$.

PLAT 411_ALERT_2_C

Short Inter H...H Contact H2BA $\ldots \mathrm{H} 8 \mathrm{~A}$

$\mathrm{x},-1 / 2-\mathrm{y}, 1 / 2+\mathrm{z}=$

PLAT790_ALERT_4_C Centre of Gravity not Within Unit Cell: Resd. \# C13 H19 $\mathrm{N} O 3$

PLAT906_ALERT_3_C Large $K$ Value in the Analysis of Variance ......

PLAT911_ALERT_3_C Missing FCF Refl Between Thmin \& STh/L= 0.595

PLAT913_ALERT_3_C Missing \# of Very Strong Reflections in FCF ....
0.28 Report
0.71 eA-3
0.16 Ang.
O2 Check
C1 Check
C7 Check
C6 Check
C9 Check
C11 Check
0.082 Check
0.00525 Ang.
1.40 Ang.
2.02 Ang.
4_556 Check
1 Note
3.405 Check
7 Report
5 Note

\section{Alert level G}

PLAT003_ALERT_2_G Number of Uiso or Uij Restrained non-H Atoms ... PLAT072_ALERT_2_G SHELXL First Parameter in WGHT Unusually Large PLAT186_ALERT_4_G The CIF-Embedded .res File Contains ISOR Records

PLAT230_ALERT_2_G

PLAT230_ALERT_2_G

PLAT300_ALERT_4_G

PLAT300_ALERT_4_G Hirshfeld Test Diff for

$\mathrm{O} 2$

Hirshfeld Test Diff for C1

Atom Site Occupancy of C2

PLAT300_ALERT_4_G Atom Site Occupancy of C3

PLAT300_ALERT_4_G Atom Site Occupancy of C3B

PLAT300_ALERT_4_G Atom Site Occupancy of C4

PLAT300_ALERT_4_G Atom Site Occupancy of C4B

PLAT300_ALERT_4_G Atom Site Occupancy of H1AA

PLAT300_ALERT_4_G Atom Site Occupancy of H1AB

PLAT300_ALERT_4_G Atom Site Occupancy of H2A

PLAT300_ALERT_4_G Atom Site Occupancy of H2B

PLAT300_ALERT_4_G Atom Site Occupancy of H1BC

PLAT300_ALERT_4_G Atom Site Occupancy of H3A

PLAT300_ALERT_4_G Atom Site Occupancy of H3B

PLAT300_ALERT_4_G Atom Site Occupancy of H4

PLAT300_ALERT_4_G Atom Site Occupancy of H1BD

PLAT300_ALERT_4_G Atom Site Occupancy of H3BA

PLAT300_ALERT_4_G Atom Site Occupancy of H5A

PLAT300_ALERT_4_G Atom Site Occupancy of H3BB

PLAT300_ALERT_4_G Atom Site Occupancy of H2BA

PLAT300_ALERT_4_G Atom Site Occupancy of H2BB

PLAT300_ALERT_4_G Atom Site Occupancy of H4B

PLAT300_ALERT_4_G Atom Site Occupancy of H5B

PLAT301_ALERT_3_G

PLAT720 ALERT 4 G

PLAT793_ALERT_4_G

PLAT793_ALERT_4_G

PLAT793_ALERT_4_G

PLAT793_ALERT_4_G

PLAT 860_ALERT_3_G

PLAT 909_ALERT_3_G

PLAT910_ALERT_3_G
Main Residue Disorder ............ (Resd 1)

Number of Unusual/Non-Standard Labels ........

Model has Chirality at C4 (Centro SPGR)

Model has Chirality at C6 (Centro SPGR)

Model has Chirality at C10 (Centro SPGR)

Model has Chirality at C4B (Centro SPGR)

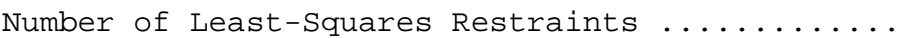

Percentage of I>2sig(I) Data at Theta(Max) Still Missing \# of FCF Reflection(s) Below Theta(Min).
5 Report

0.16 Report

1 Report

$5.2 \mathrm{~s} . \mathrm{u}$.

$6.3 \mathrm{s.u}$.

0.5 Check

0.5 Check

0.5 Check

0.5 Check

0.55 Check

0.45 Check

0.5 Check

0.5 Check

0.5 Check

0.5 Check

0.5 Check

0.5 Check

0.5 Check

0.55 Check

0.5 Check

0.5 Check

0.55 Check

0.5 Check

0.5 Check

0.5 Check

0.45 Check

0.45 Check

18\% Note

8 Note

R Verify

$S$ Verify

$R$ Verify

S Verify

30 Note

$72 \%$ Note

1 Note 


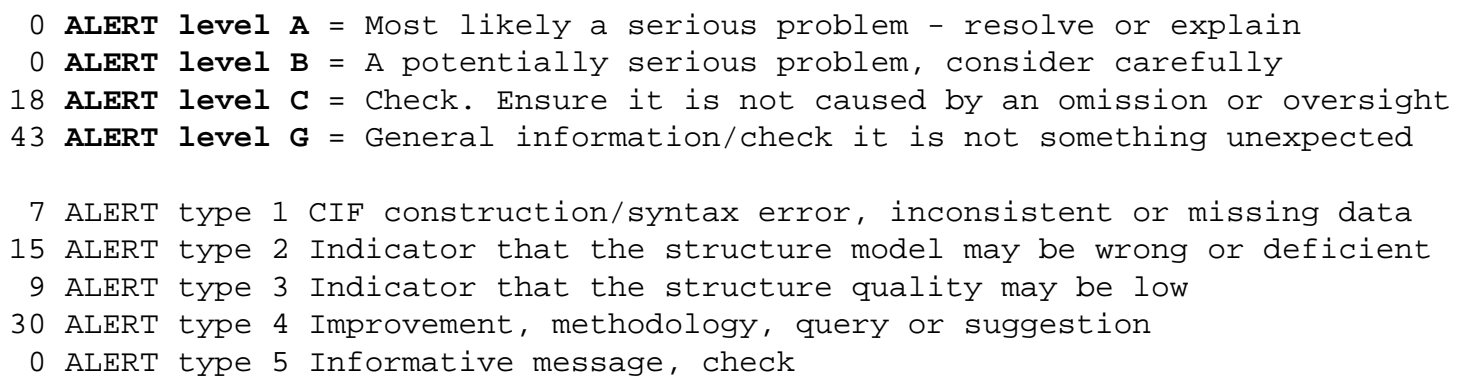

It is advisable to attempt to resolve as many as possible of the alerts in all categories. Often the minor alerts point to easily fixed oversights, errors and omissions in your CIF or refinement strategy, so attention to these fine details can be worthwhile. In order to resolve some of the more serious problems it may be necessary to carry out additional measurements or structure refinements. However, the purpose of your study may justify the reported deviations and the more serious of these should normally be commented upon in the discussion or experimental section of a paper or in the "special_details" fields of the CIF. checkCIF was carefully designed to identify outliers and unusual parameters, but every test has its limitations and alerts that are not important in a particular case may appear. Conversely, the absence of alerts does not guarantee there are no aspects of the results needing attention. It is up to the individual to critically assess their own results and, if necessary, seek expert advice.

\section{Publication of your CIF in IUCr journals}

A basic structural check has been run on your CIF. These basic checks will be run on all CIFs submitted for publication in IUCr journals (Acta Crystallographica, Journal of Applied Crystallography, Journal of Synchrotron Radiation); however, if you intend to submit to Acta Crystallographica Section $C$ or $E$ or IUCrData, you should make sure that full publication checks are run on the final version of your CIF prior to submission.

\section{Publication of your CIF in other journals}

Please refer to the Notes for Authors of the relevant journal for any special instructions relating to CIF submission.

\section{PLATON version of 06/01/2019; check.def file version of 19/12/2018}


Datablock wangzhen-02 - ellipsoid plot

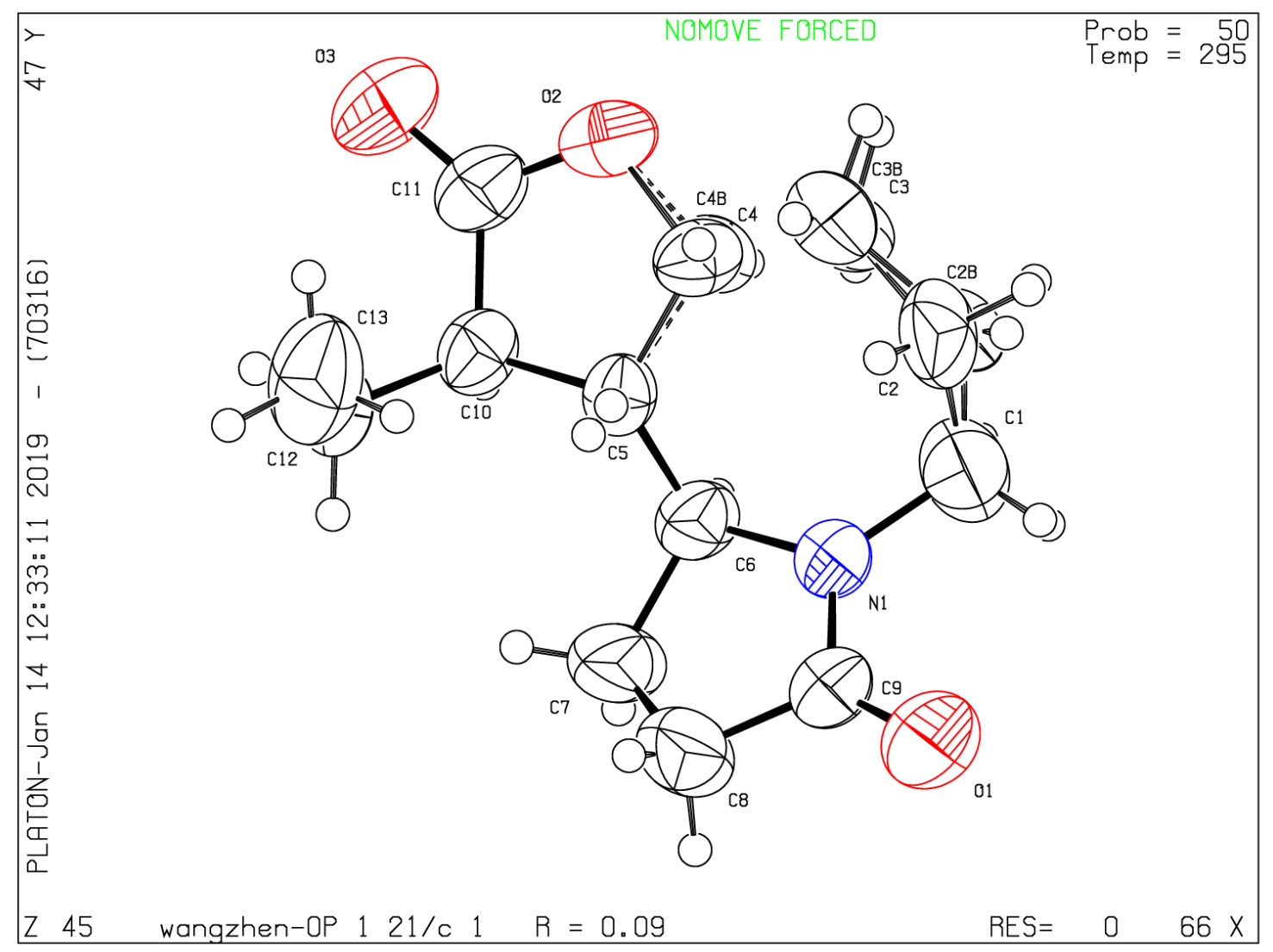




\section{Crystal Data and Cif Check Report for Compound 12 (CCDC: 1874370)}

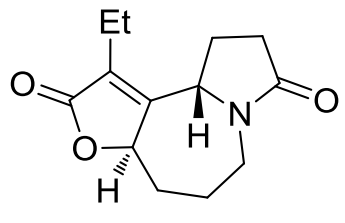

12

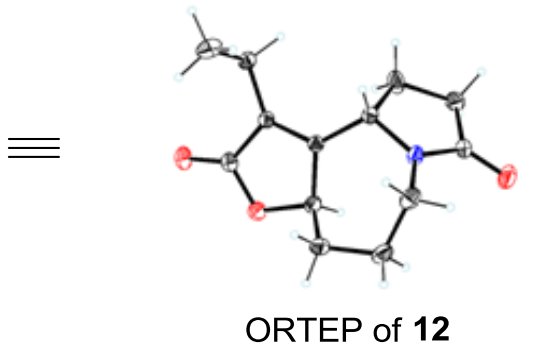




\section{checkCIF/PLATON report}

Structure factors have been supplied for datablock(s) wangzhen-04

THIS REPORT IS FOR GUIDANCE ONLY. IF USED AS PART OF A REVIEW PROCEDURE FOR PUBLICATION, IT SHOULD NOT REPLACE THE EXPERTISE OF AN EXPERIENCED CRYSTALLOGRAPHIC REFEREE.

No syntax errors found. CIF dictionary Interpreting this report

\section{Datablock: wangzhen-04}

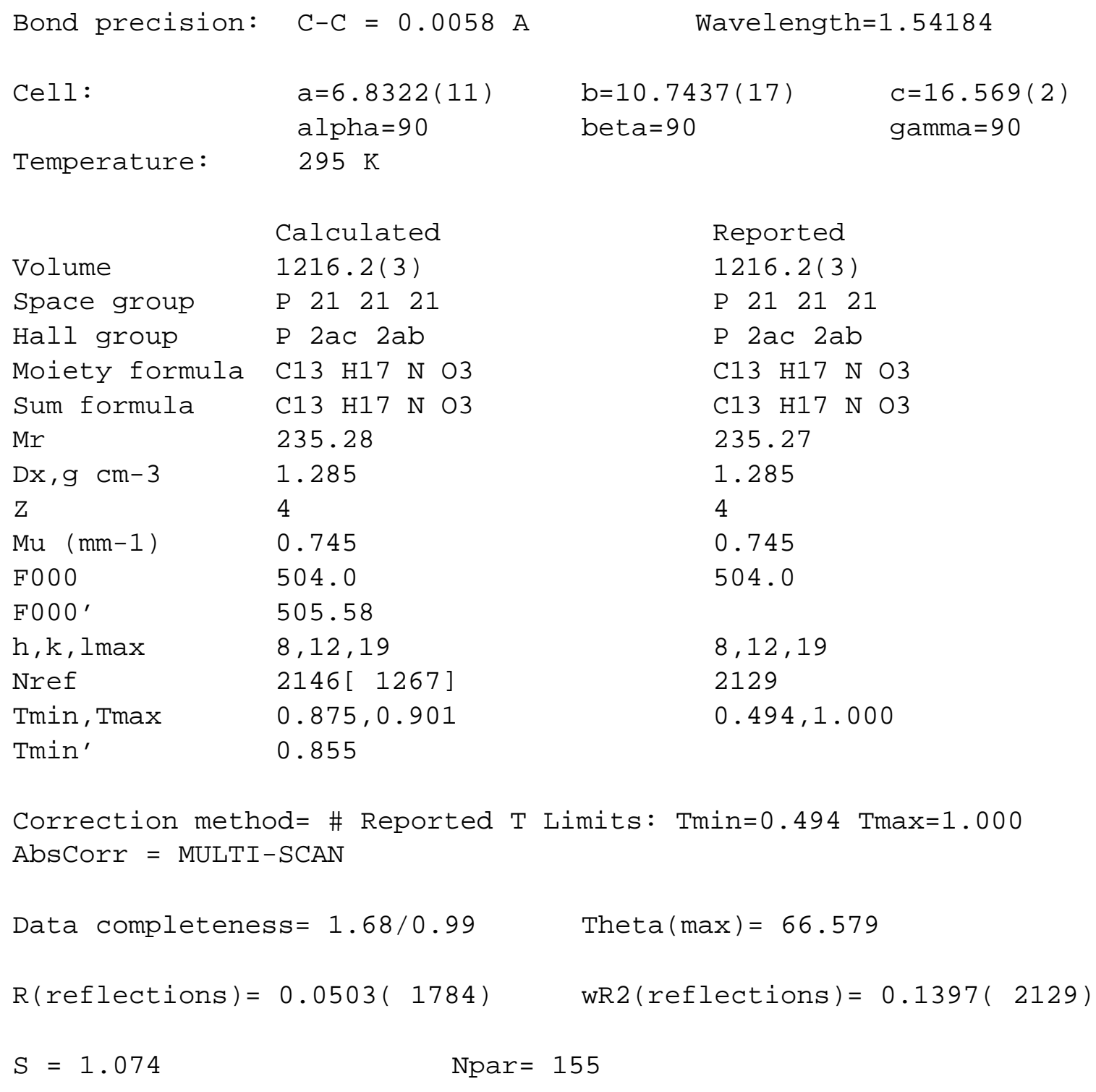


Alert level $\mathrm{C}$

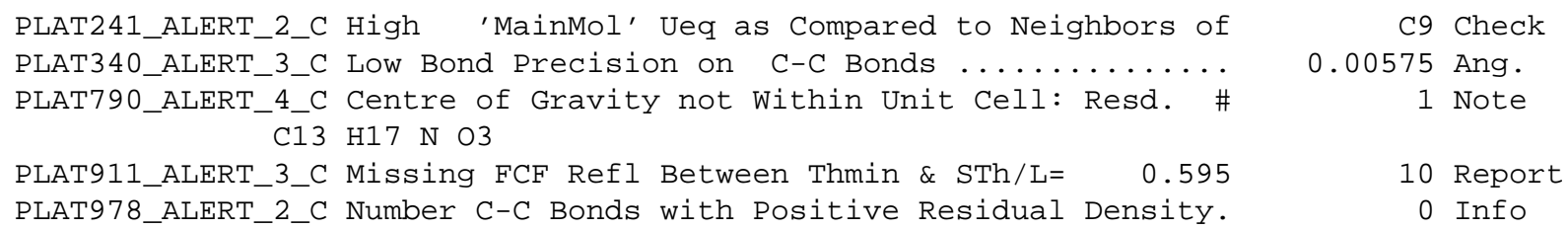

Alert level G

\begin{tabular}{|c|c|c|c|}
\hline PLAT032_ALERT_4_G & Std. Uncertainty on Flack Parameter Value High & 0.300 & Report \\
\hline PLAT398_ALERT_2_G & Angle From 120 for 02 & 109.3 & \\
\hline PLAT791_ALERT_4_G & Model has Chirality at $\mathrm{C} 4$ & $\mathrm{~S}$ & ver \\
\hline PLAT791_ALERT_4_G & Model has Chirality at $\mathrm{C} 8$ & $\mathrm{R}$ & $V \epsilon$ \\
\hline PLAT909_ALERT_3_G & Percentage of I>2sig(I) Da & $58 \%$ & Note \\
\hline PLAT916_ALERT_2_G & Hooft y and Flack x Parameter Values Differ by & 0.15 & Chec \\
\hline PLAT933_ALERT_2_G & Number of OMIT Records in Embedded .res File & & \\
\hline
\end{tabular}

0 ALERT level $\mathbf{A}=$ Most likely a serious problem - resolve or explain

0 ALERT level $\mathbf{B}=\mathrm{A}$ potentially serious problem, consider carefully

5 ALERT level $\mathbf{C}=$ Check. Ensure it is not caused by an omission or oversight

7 ALERT level $\mathbf{G}=$ General information/check it is not something unexpected

0 ALERT type 1 CIF construction/syntax error, inconsistent or missing data

5 ALERT type 2 Indicator that the structure model may be wrong or deficient

3 ALERT type 3 Indicator that the structure quality may be low

4 ALERT type 4 Improvement, methodology, query or suggestion

0 ALERT type 5 Informative message, check

It is advisable to attempt to resolve as many as possible of the alerts in all categories. Often the minor alerts point to easily fixed oversights, errors and omissions in your CIF or refinement strategy, so attention to these fine details can be worthwhile. In order to resolve some of the more serious problems it may be necessary to carry out additional measurements or structure refinements. However, the purpose of your study may justify the reported deviations and the more serious of these should normally be commented upon in the discussion or experimental section of a paper or in the "special_details" fields of the CIF. checkCIF was carefully designed to identify outliers and unusual parameters, but every test has its limitations and alerts that are not important in a particular case may appear. Conversely, the absence of alerts does not guarantee there are no aspects of the results needing attention. It is up to the individual to critically assess their own results and, if necessary, seek expert advice.

\section{Publication of your CIF in IUCr journals}

A basic structural check has been run on your CIF. These basic checks will be run on all CIFs submitted for publication in IUCr journals (Acta Crystallographica, Journal of Applied

Crystallography, Journal of Synchrotron Radiation); however, if you intend to submit to Acta Crystallographica Section C or E or IUCrData, you should make sure that full publication checks are run on the final version of your CIF prior to submission.

\section{Publication of your CIF in other journals}

Please refer to the Notes for Authors of the relevant journal for any special instructions relating to CIF submission. 
PLATON version of 06/01/2019; check.def file version of 19/12/2018

Datablock wangzhen-04 - ellipsoid plot

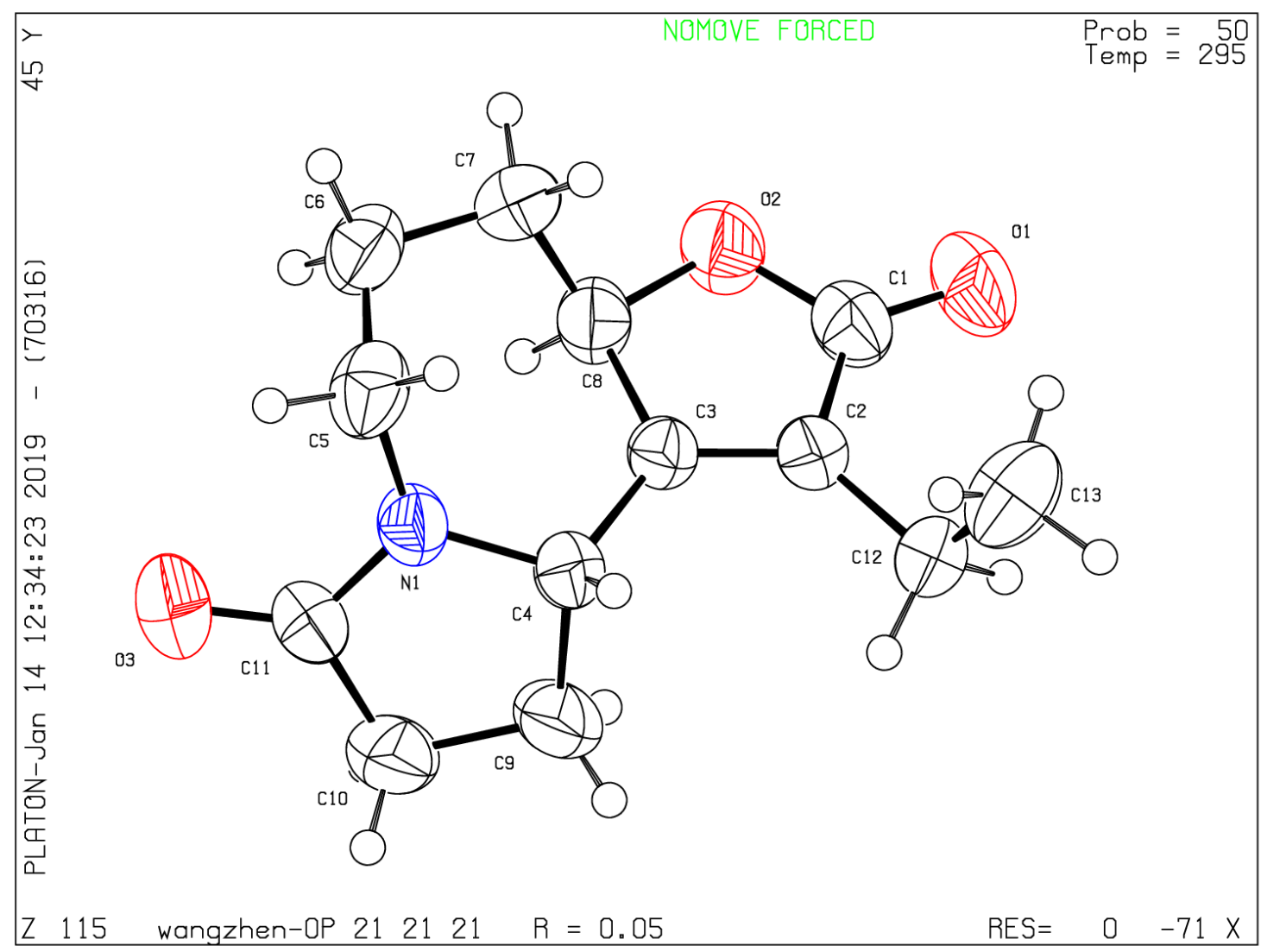




\section{Crystal Data and Cif Check Report for ethylstemoamide \\ (CCDC: 1883782)}

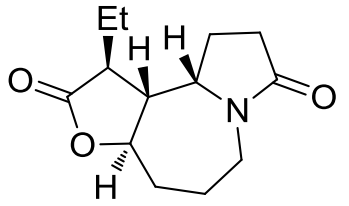

4: ethylstemoamide

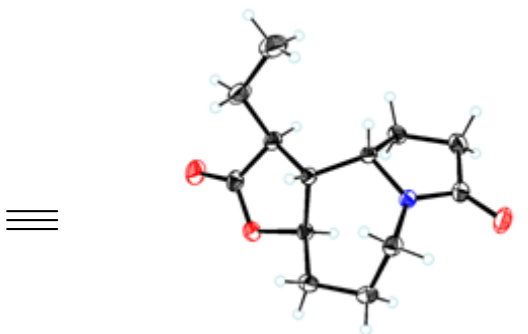

ORTEP of 4 


\section{checkCIF/PLATON report}

Structure factors have been supplied for datablock(s) 20181123_houysh_chon01_0m_a

THIS REPORT IS FOR GUIDANCE ONLY. IF USED AS PART OF A REVIEW PROCEDURE FOR PUBLICATION, IT SHOULD NOT REPLACE THE EXPERTISE OF AN EXPERIENCED CRYSTALLOGRAPHIC REFEREE.

No syntax errors found. CIF dictionary Interpreting this report

\section{Datablock: 20181123_houysh_chon01_0m_a}

\begin{tabular}{|c|c|c|}
\hline Bond precision: & $\mathrm{C}-\mathrm{C}=0.0017 \mathrm{~A}$ & Wavelength $=1.54178$ \\
\hline Cell: & $a=7.7654(2)$ & $b=12.3880(3)$ \\
\hline & alpha $=90$ & gamma $=90$ \\
\hline Temperature: & $150 \mathrm{~K}$ & \\
\hline & Calculated & Reported \\
\hline Volume & $2346.91(11)$ & $2346.91(11)$ \\
\hline Space group & $\mathrm{P} \quad \mathrm{b} \quad \mathrm{c} \quad \mathrm{a}$ & $\mathrm{P} \quad \mathrm{b} \quad \mathrm{c}$ a \\
\hline Hall group & $-\mathrm{P} 2 \mathrm{ac} 2 \mathrm{ab}$ & $-\mathrm{P} 2 \mathrm{ac} 2 \mathrm{ab}$ \\
\hline Moiety formula & C13 H19 N O3 & C13 H19 N O3 \\
\hline Sum formula & C13 H19 N O3 & C13 H19 N O3 \\
\hline $\mathrm{Mr}$ & 237.29 & 237.29 \\
\hline $\mathrm{Dx}, \mathrm{g} \mathrm{cm-3}$ & 1.343 & 1.343 \\
\hline $\mathrm{Z}$ & 8 & 8 \\
\hline $\mathrm{Mu} \quad(\mathrm{mm}-1)$ & 0.772 & 0.772 \\
\hline $\mathrm{F} 000$ & 1024.0 & 1024.0 \\
\hline $\mathrm{F} 000^{\prime}$ & 1027.17 & \\
\hline$h, k, l \max$ & $9,14,29$ & $9,14,29$ \\
\hline Nref & 2084 & 2083 \\
\hline $\operatorname{Tmin}, \operatorname{Tmax}$ & $0.877,0.898$ & $0.695,0.753$ \\
\hline Tmin' & 0.877 & \\
\hline $\begin{array}{l}\text { Correction meth } \\
\text { AbsCorr = MULTI }\end{array}$ & $\begin{array}{l}\text { od=\# Reported } \mathrm{T} \\
\text {-SCAN }\end{array}$ & Limits: $\operatorname{Tmin}=0.695$ Tmax $=0.753$ \\
\hline Data completene & $S S=1.000$ & Theta $(\max )=66.586$ \\
\hline$R($ reflections $)=$ & $0.0337(1957)$ & $\mathrm{wR} 2($ reflections $)=0.0836(2083)$ \\
\hline $\mathrm{S}=1.054$ & Npar $=$ & 155 \\
\hline
\end{tabular}

The following ALERTS were generated. Each ALERT has the format test-name_ALERT_alert-type_alert-level.

Click on the hyperlinks for more details of the test. 
Alert level $\mathbf{G}$

\begin{tabular}{|c|c|c|c|c|}
\hline SLAT793_ALERT_4_G & Model has Chirality at $\mathrm{C} 4$ & (Centro SPGR) & & Jerify \\
\hline PLAT793_ALERT_4_G & Model has Chirality at C5 & (Centro SPGR) & $\mathrm{R}$ & Jerify \\
\hline PLAT793_ALERT_4_G & Model has Chirality at $\mathrm{C} 6$ & (Centro SPGR) & S & \\
\hline PLAT793_ALERT_4_G & Model has Chirality at $\mathrm{C} 8$ & (Centro SPGR) & $\mathrm{R}$ & \\
\hline PLAT909_ALERT_3_G & Percentage of I>2sig(I) Data at The & ta(Max) Still & $92 \%$ & ote \\
\hline PLAT913_ALERT_3_G & Missing \# of Very Strong Reflection & $\mathrm{s}$ in $\mathrm{FCF}$ & 1 & e \\
\hline PLAT955_ALERT_1_G & Reported (CIF) and Actual (FCF) Lma & $x$ Differ by . & 1 & Un. \\
\hline SLAT978_ALERT_2_G & Number $\mathrm{C}-\mathrm{C}$ Bonds with Positive Resi & dual Density. & 10 & \\
\hline
\end{tabular}

0 ALERT level $\mathbf{A}=$ Most likely a serious problem - resolve or explain

0 ALERT level $\mathbf{B}=\mathrm{A}$ potentially serious problem, consider carefully

0 ALERT level $\mathbf{C}=$ Check. Ensure it is not caused by an omission or oversight

8 ALERT level $\mathbf{G}=$ General information/check it is not something unexpected

1 ALERT type 1 CIF construction/syntax error, inconsistent or missing data

1 ALERT type 2 Indicator that the structure model may be wrong or deficient

2 ALERT type 3 Indicator that the structure quality may be low

4 ALERT type 4 Improvement, methodology, query or suggestion

0 ALERT type 5 Informative message, check

It is advisable to attempt to resolve as many as possible of the alerts in all categories. Often the minor alerts point to easily fixed oversights, errors and omissions in your CIF or refinement strategy, so attention to these fine details can be worthwhile. In order to resolve some of the more serious problems it may be necessary to carry out additional measurements or structure refinements. However, the purpose of your study may justify the reported deviations and the more serious of these should normally be commented upon in the discussion or experimental section of a paper or in the "special_details" fields of the CIF. checkCIF was carefully designed to identify outliers and unusual parameters, but every test has its limitations and alerts that are not important in a particular case may appear. Conversely, the absence of alerts does not guarantee there are no aspects of the results needing attention. It is up to the individual to critically assess their own results and, if necessary, seek expert advice.

\section{Publication of your CIF in IUCr journals}

A basic structural check has been run on your CIF. These basic checks will be run on all CIFs submitted for publication in IUCr journals (Acta Crystallographica, Journal of Applied Crystallography, Journal of Synchrotron Radiation); however, if you intend to submit to Acta Crystallographica Section $C$ or $E$ or IUCrData, you should make sure that full publication checks are run on the final version of your CIF prior to submission.

\section{Publication of your CIF in other journals}

Please refer to the Notes for Authors of the relevant journal for any special instructions relating to CIF submission.

\section{PLATON version of 06/01/2019; check.def file version of 19/12/2018}


Datablock 20181123_houysh_chon01_0m_a - ellipsoid plot

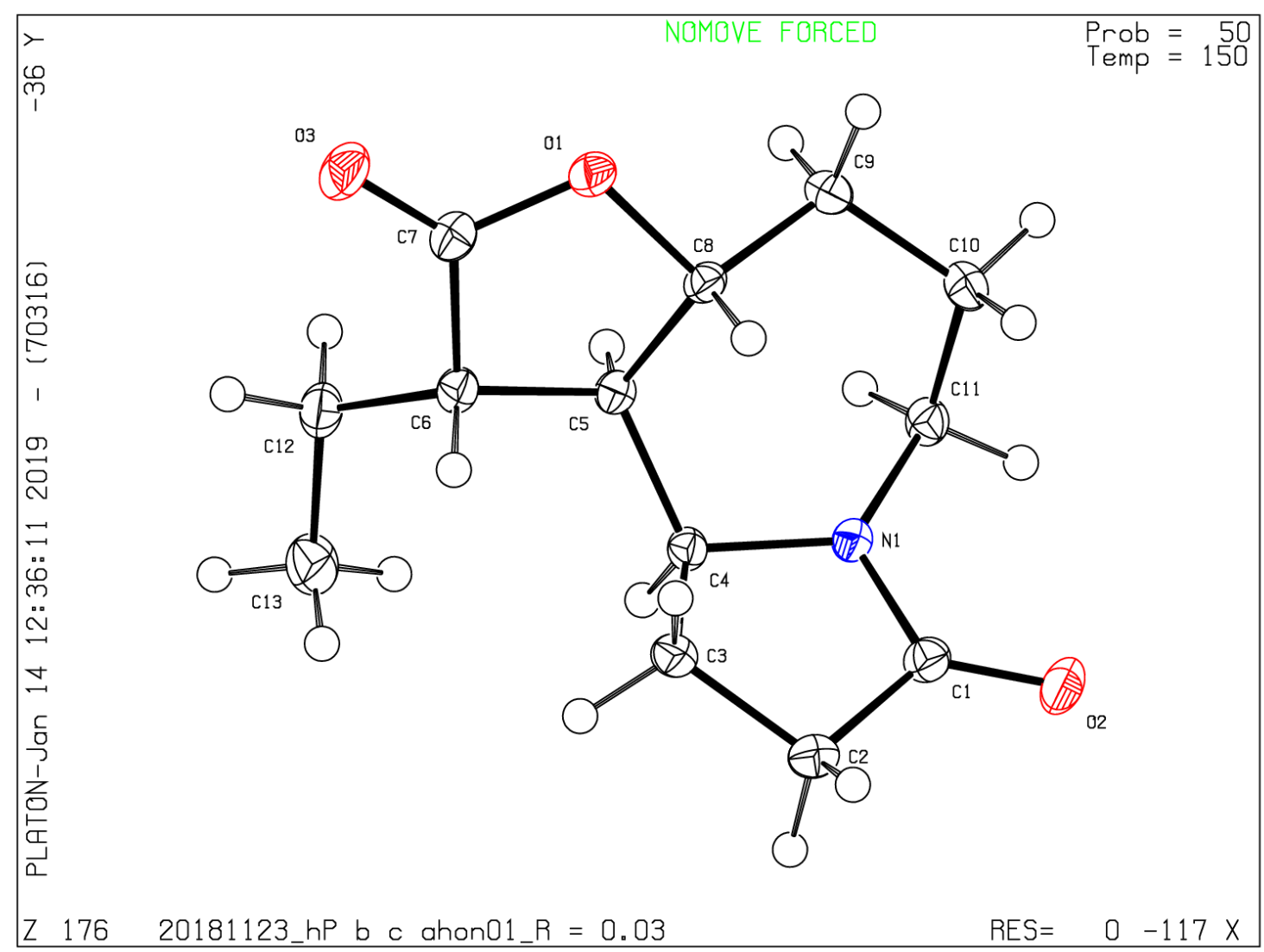




\section{Crystal Data and Cif Check Report for 9,10-bis-epi-ethylstemoamide (11a) (CCDC: 1883803)}

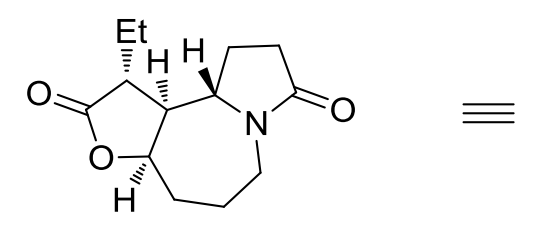

11a: 9,10-bis-epi-ethylstemoamide

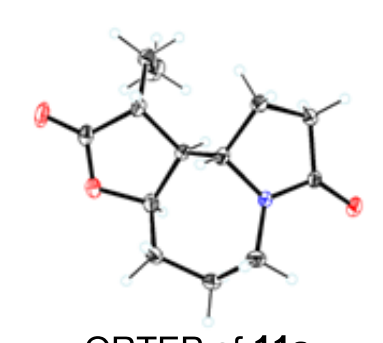

ORTEP of 11a 


\section{checkCIF/PLATON report}

Structure factors have been supplied for datablock(s) 20181122_houysh_chon07_0m_a

THIS REPORT IS FOR GUIDANCE ONLY. IF USED AS PART OF A REVIEW PROCEDURE FOR PUBLICATION, IT SHOULD NOT REPLACE THE EXPERTISE OF AN EXPERIENCED CRYSTALLOGRAPHIC REFEREE.

No syntax errors found. CIF dictionary Interpreting this report

\section{Datablock: 20181122_houysh_chon07_0m_a}

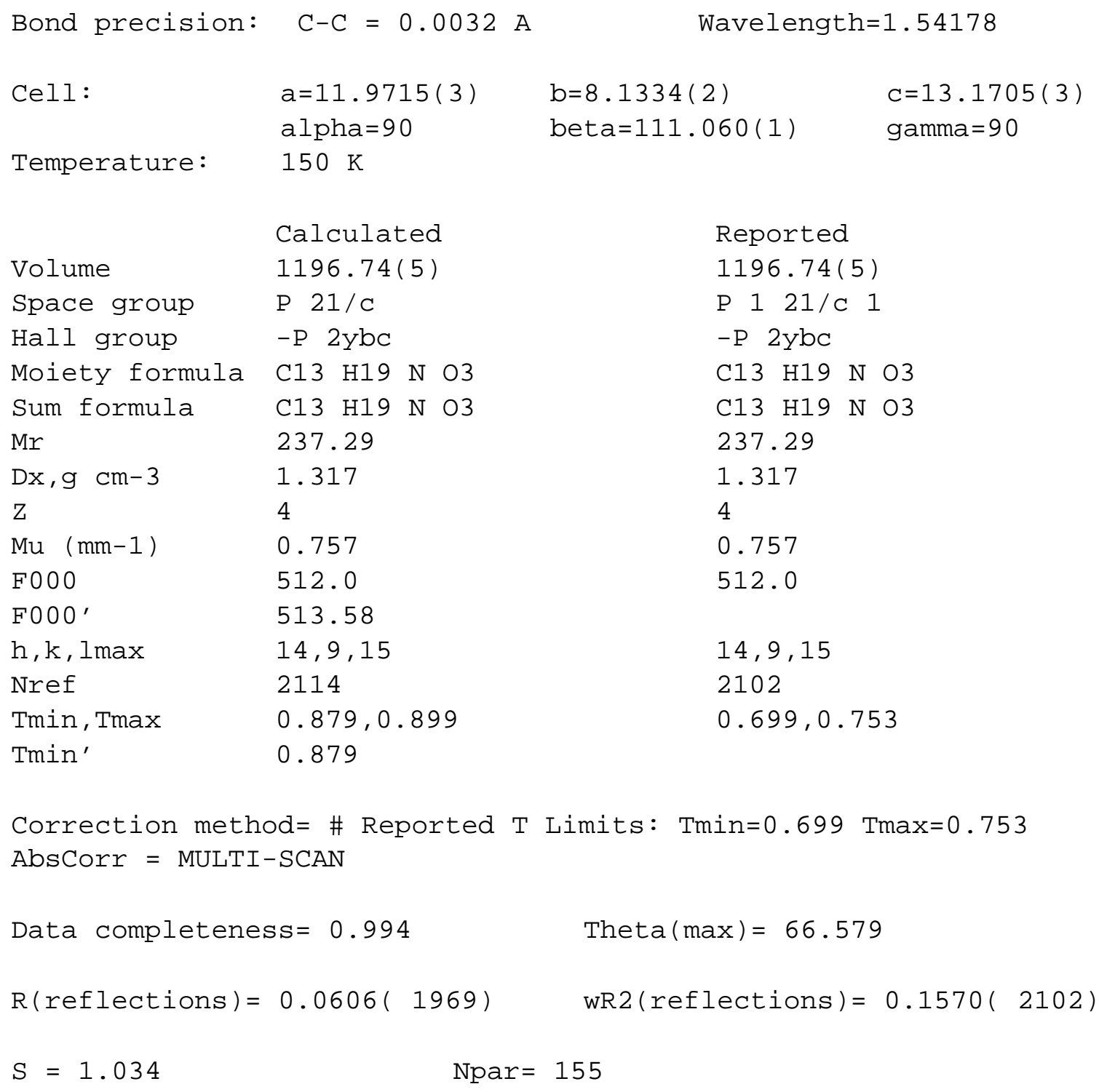


Alert level $\mathrm{C}$

DIFMX02_ALERT_1_C The maximum difference density is $>0.1 *$ ZMAX*0.75

The relevant atom site should be identified.

PLAT094_ALERT_2_C Ratio of Maximum / Minimum Residual Density ....

PLAT097_ALERT_2_C Large Reported Max. (Positive) Residual Density

PLAT906_ALERT_3_C Large $\mathrm{K}$ Value in the Analysis of Variance ......

PLAT911_ALERT_3_C Missing FCF Refl Between Thmin \& STh/L= 0.595

PLAT913_ALERT_3_C Missing \# of Very Strong Reflections in FCF ....

$$
\begin{aligned}
3.01 & \text { Report } \\
0.70 & \text { eA-3 } \\
2.635 & \text { Check } \\
12 & \text { Report } \\
7 & \text { Note }
\end{aligned}
$$

Alert level $\mathbf{G}$

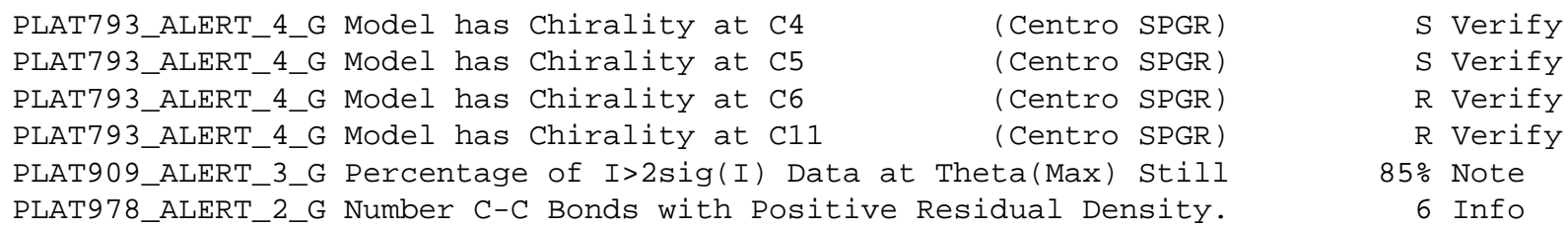

0 ALERT level $\mathbf{A}=$ Most likely a serious problem - resolve or explain

0 ALERT level B = A potentially serious problem, consider carefully

6 ALERT level $\mathbf{C}=$ Check. Ensure it is not caused by an omission or oversight

6 ALERT level $\mathbf{G}=$ General information/check it is not something unexpected

1 ALERT type 1 CIF construction/syntax error, inconsistent or missing data

3 ALERT type 2 Indicator that the structure model may be wrong or deficient

4 ALERT type 3 Indicator that the structure quality may be low

4 ALERT type 4 Improvement, methodology, query or suggestion

0 ALERT type 5 Informative message, check

It is advisable to attempt to resolve as many as possible of the alerts in all categories. Often the minor alerts point to easily fixed oversights, errors and omissions in your CIF or refinement strategy, so attention to these fine details can be worthwhile. In order to resolve some of the more serious problems it may be necessary to carry out additional measurements or structure refinements. However, the purpose of your study may justify the reported deviations and the more serious of these should normally be commented upon in the discussion or experimental section of a paper or in the "special_details" fields of the CIF. checkCIF was carefully designed to identify outliers and unusual parameters, but every test has its limitations and alerts that are not important in a particular case may appear. Conversely, the absence of alerts does not guarantee there are no aspects of the results needing attention. It is up to the individual to critically assess their own results and, if necessary, seek expert advice.

\section{Publication of your CIF in IUCr journals}

A basic structural check has been run on your CIF. These basic checks will be run on all CIFs submitted for publication in IUCr journals (Acta Crystallographica, Journal of Applied

Crystallography, Journal of Synchrotron Radiation); however, if you intend to submit to Acta Crystallographica Section C or E or IUCrData, you should make sure that full publication checks are run on the final version of your CIF prior to submission.

\section{Publication of your CIF in other journals}

Please refer to the Notes for Authors of the relevant journal for any special instructions relating to CIF submission. 
PLATON version of 06/01/2019; check.def file version of 19/12/2018

Datablock 20181122_houysh_chon07_0m_a - ellipsoid plot

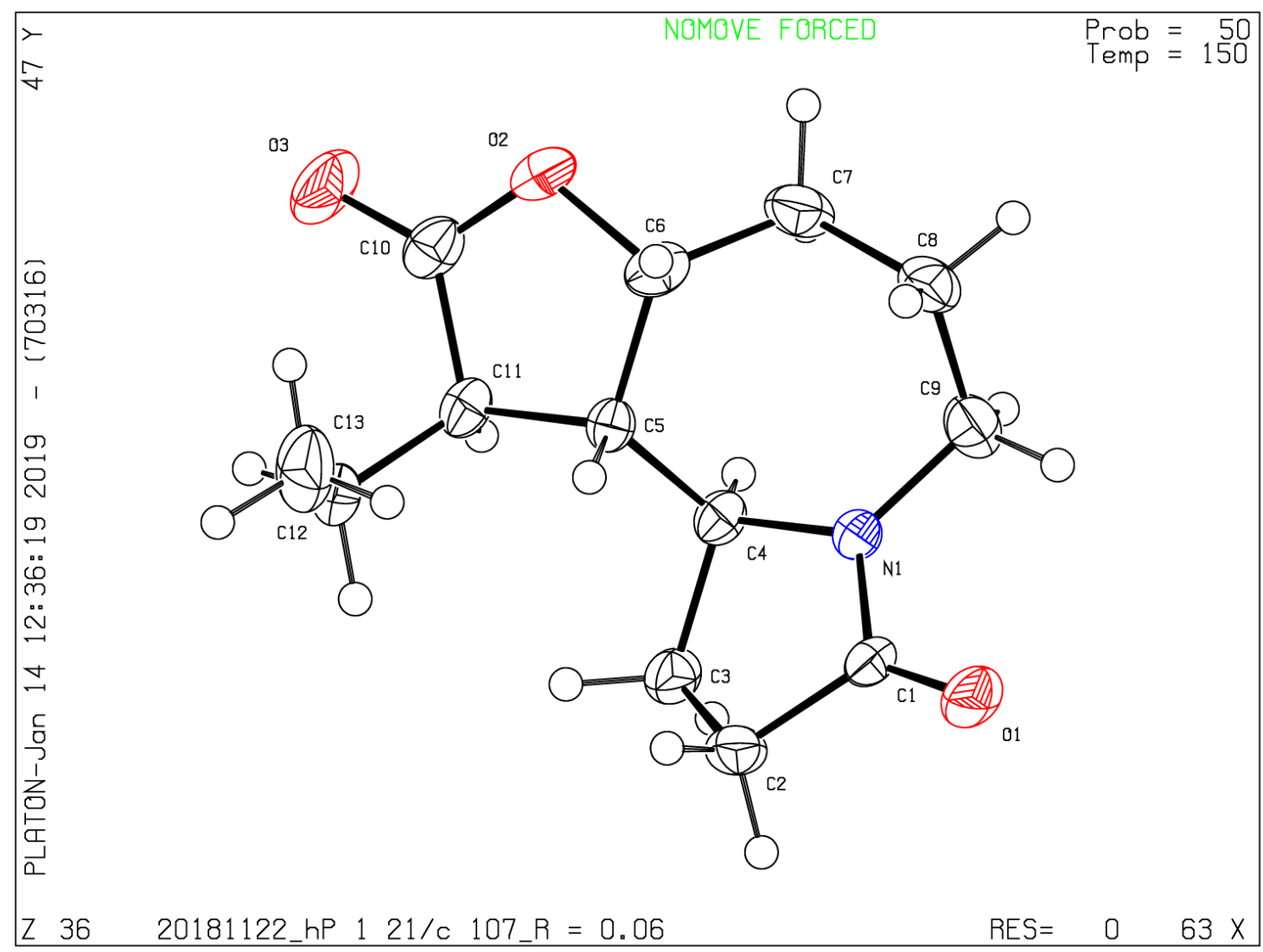




\section{Crystal Data and Cif Check Report for sessilifoliamide A (2) \\ (CCDC: 1883815)}

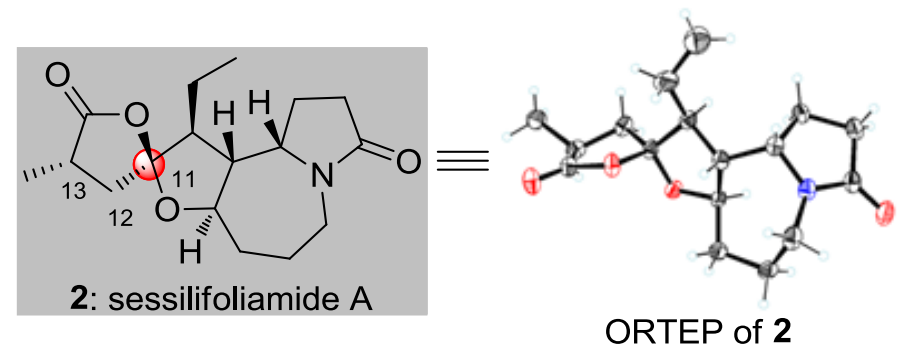




\section{checkCIF/PLATON report}

Structure factors have been supplied for datablock(s) 20181126_houysh_chon11_0m_a

THIS REPORT IS FOR GUIDANCE ONLY. IF USED AS PART OF A REVIEW PROCEDURE FOR PUBLICATION, IT SHOULD NOT REPLACE THE EXPERTISE OF AN EXPERIENCED CRYSTALLOGRAPHIC REFEREE.

No syntax errors found. CIF dictionary Interpreting this report

\section{Datablock: 20181126_houysh_chon11_0m_a}

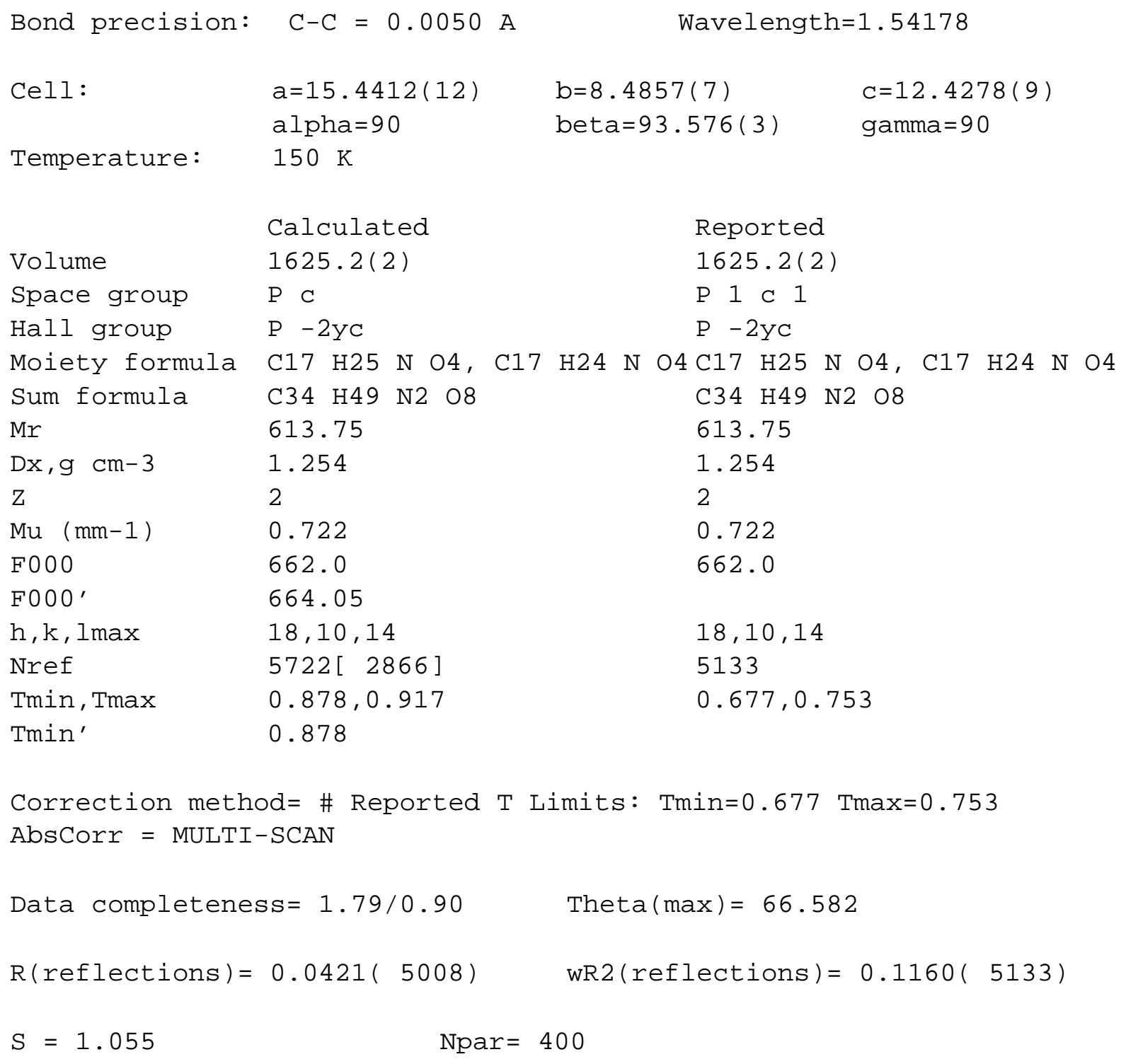

The following ALERTS were generated. Each ALERT has the format test-name_ALERT_alert-type_alert-level.

Click on the hyperlinks for more details of the test. 
Alert level $\mathrm{C}$

DIFMX02_ALERT_1_C The maximum difference density is > 0.1 \#MAX*0.75

The relevant atom site should be identified.

PLAT089_ALERT_3_C Poor Data / Parameter Ratio (Zmax < 18) ...... 7.14 Note

PLAT094_ALERT_2_C Ratio of Maximum / Minimum Residual Density ....

PLAT097_ALERT_2_C Large Reported Max. (Positive) Residual Density

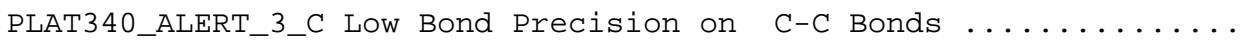

PLAT362_ALERT_2_C Short C (sp3)-C(sp2) Bond C15' - C16'

PLAT411_ALERT_2_C Short Inter H...H Contact H2B ..H9'A .

$-1+\mathrm{x}, 2-\mathrm{y}, 1 / 2+\mathrm{z}=$
PLAT911_ALERT_3_C Missing FCF Refl Between Thmin \& STh/L= 0.595

PLAT915_ALERT_3_C No Flack x Check Done: Low Friedel Pair Coverage

2.87 Report

$0.73 \mathrm{eA}-3$

0.005 Ang.

1.41 Ang.

2.14 Ang.

2_475 Check

8 Report

$80 \div$

\section{Alert level G}

PLAT720_ALERT_4_G Number of Unusual/Non-Standard Labels ......................

PLAT792 ALERT 1 G Model has Chirality at C4

PLAT792 ALERT 1 G Model has Chirality at $\mathrm{C}^{\prime}$ ' (Polar SPGR)

PLAT792_ALERT_1_G Model has Chirality at C5 (Polar SPGR)

PLAT792_ALERT_1_G Model has Chirality at C5'

(Polar SPGR)

PLAT792_ALERT_1_G Model has Chirality at C6

(Polar SPGR)

PLAT792_ALERT_1_G Model has Chirality at C6'

(Polar SPGR)

(Polar SPGR)

PLAT792_ALERT_1_G Model has Chirality at C10

(Polar SPGR)

PLAT792_ALERT_1_G Model has Chirality at C10'

(Polar SPGR)

PLAT792 ALERT $1 \mathrm{G}$ Model has Chirality at C11

(Polar SPGR)

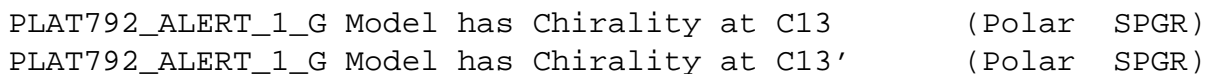

PLAT792_ALERT_1_G Model has Chirality at C13' (Polar SPGR)

PLAT913_ALERT_3_G Missing \# of Very Strong Reflections in FCF ....

PLAT933_ALERT_2_G Number of OMIT Records in Embedded.res File...

PLAT978_ALERT_2_G Number C-C Bonds with Positive Residual Density.
10 Note
S Verify
S Verify
R Verify
R Verify
R Verify
R Verify
S Verify
S Verify
S Verify
S Verify
S Verify
S Verify
93\% Note
1 Note
3 Note
5 Info

0 ALERT level $\mathbf{A}=$ Most likely a serious problem - resolve or explain

0 ALERT level $\mathbf{B}=\mathrm{A}$ potentially serious problem, consider carefully

9 ALERT level $\mathbf{C}=$ Check. Ensure it is not caused by an omission or oversight

17 ALERT level $\mathbf{G}=$ General information/check it is not something unexpected

13 ALERT type 1 CIF construction/syntax error, inconsistent or missing data

6 ALERT type 2 Indicator that the structure model may be wrong or deficient

6 ALERT type 3 Indicator that the structure quality may be low

1 ALERT type 4 Improvement, methodology, query or suggestion

0 ALERT type 5 Informative message, check 
It is advisable to attempt to resolve as many as possible of the alerts in all categories. Often the minor alerts point to easily fixed oversights, errors and omissions in your CIF or refinement strategy, so attention to these fine details can be worthwhile. In order to resolve some of the more serious problems it may be necessary to carry out additional measurements or structure refinements. However, the purpose of your study may justify the reported deviations and the more serious of these should normally be commented upon in the discussion or experimental section of a paper or in the "special_details" fields of the CIF. checkCIF was carefully designed to identify outliers and unusual parameters, but every test has its limitations and alerts that are not important in a particular case may appear. Conversely, the absence of alerts does not guarantee there are no aspects of the results needing attention. It is up to the individual to critically assess their own results and, if necessary, seek expert advice.

\section{Publication of your CIF in IUCr journals}

A basic structural check has been run on your CIF. These basic checks will be run on all CIFs submitted for publication in IUCr journals (Acta Crystallographica, Journal of Applied Crystallography, Journal of Synchrotron Radiation); however, if you intend to submit to Acta Crystallographica Section C or E or IUCrData, you should make sure that full publication checks are run on the final version of your CIF prior to submission.

\section{Publication of your CIF in other journals}

Please refer to the Notes for Authors of the relevant journal for any special instructions relating to CIF submission.

\section{PLATON version of 06/01/2019; check.def file version of 19/12/2018}


Datablock 20181126_houysh_chon11_0m_a - ellipsoid plot

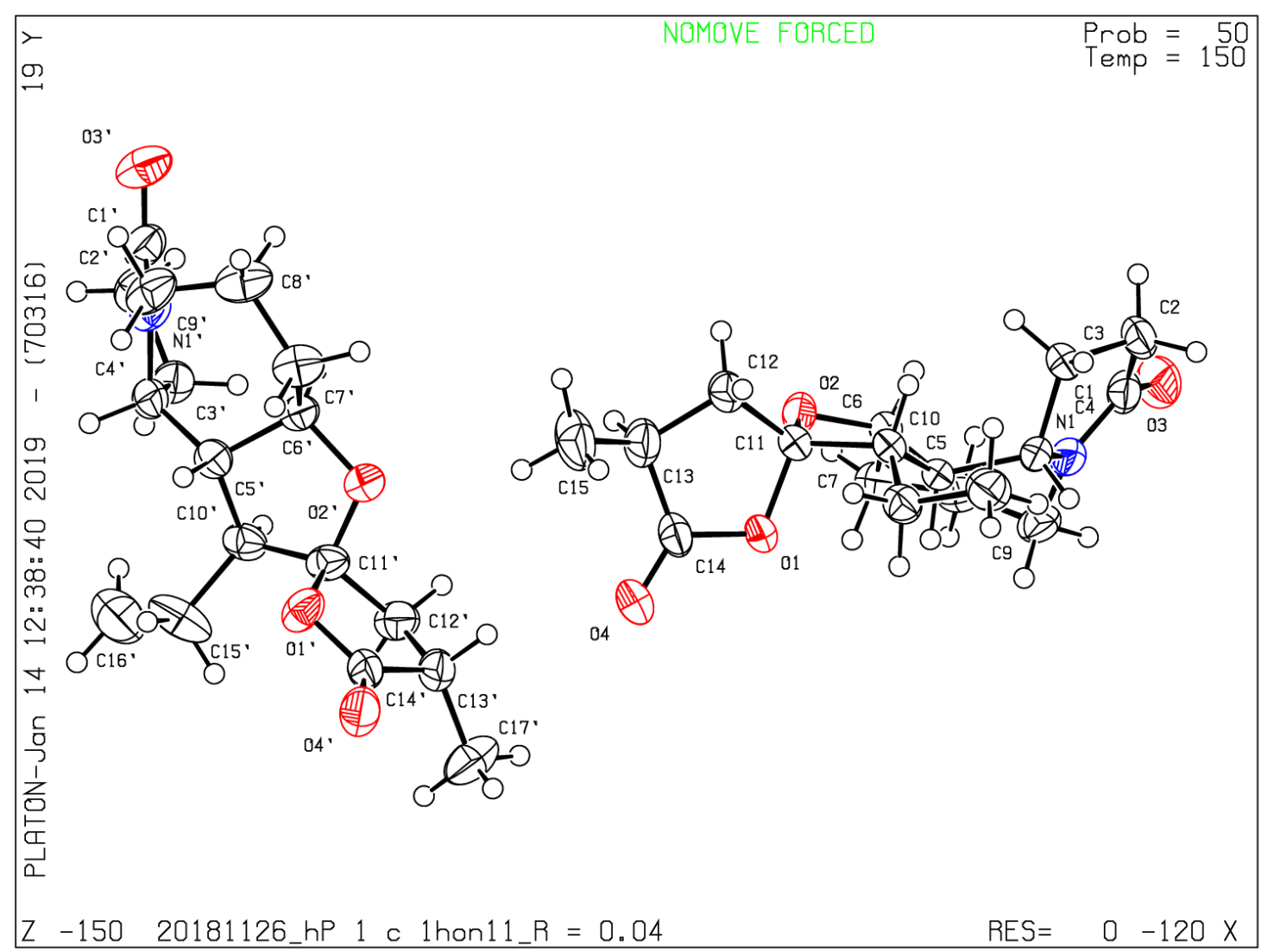




\section{Crystal Data and Cif Check Report for}

13-epi-sessilifoliamide A （19） (CCDC: 1883806)

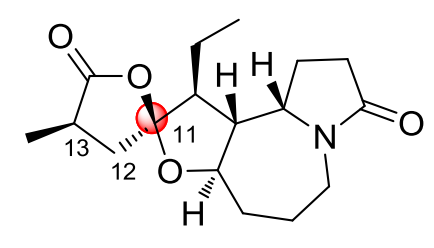

19: 13-epi-sessilifoliamide A

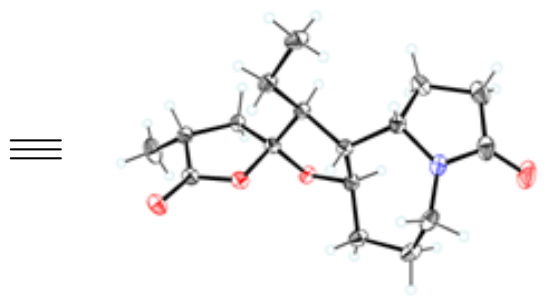

ORTEP of 19 


\section{checkCIF/PLATON report}

Structure factors have been supplied for datablock(s) 20181119houysh_chon_0m_a

THIS REPORT IS FOR GUIDANCE ONLY. IF USED AS PART OF A REVIEW PROCEDURE FOR PUBLICATION, IT SHOULD NOT REPLACE THE EXPERTISE OF AN EXPERIENCED CRYSTALLOGRAPHIC REFEREE.

No syntax errors found. CIF dictionary Interpreting this report

\section{Datablock: 20181119houysh_chon_0m_a}

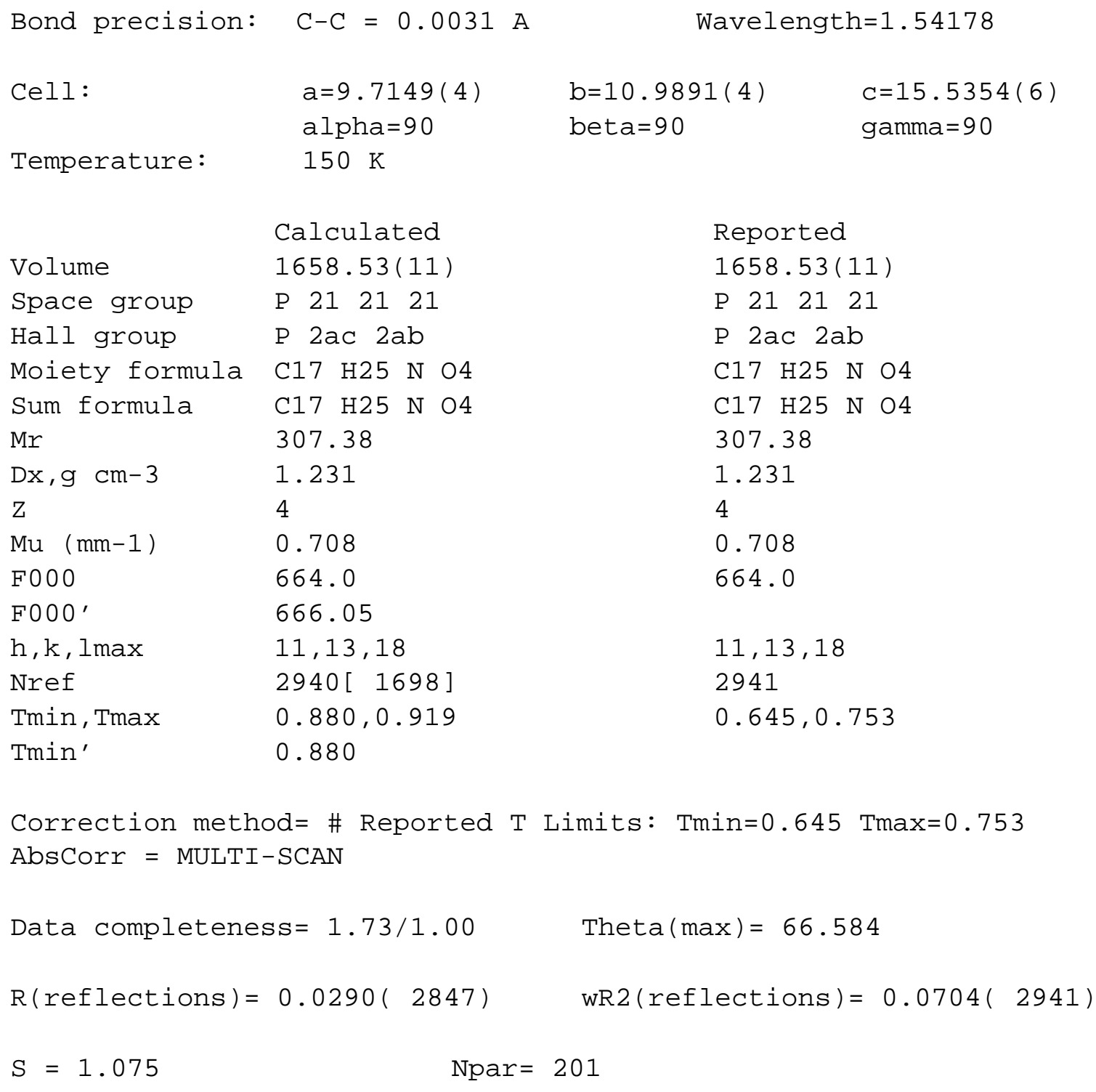


Alert level $G$

\begin{tabular}{|c|c|c|c|c|}
\hline PLAT398_ALERT_2_G & Deviating & Angle From 120 & for 02 & \\
\hline PLAT791_ALERT_4_G & Model has Chirality & at $\mathrm{C} 7$ & (Chiral & SPGR) \\
\hline PLAT791_ALERT_4_G & Model has Chirality & at $\mathrm{C} 8$ & (Chiral & SPGR) \\
\hline PLAT791_ALERT_4_G & Model has Chirality & at $\mathrm{C} 9$ & (Chiral & SPGR) \\
\hline PLAT791_ALERT_4_G & Model has Chirality & at $\mathrm{C} 10$ & (Chiral & SPGR) \\
\hline PLAT791_ALERT_4_G & Model has Chirality & at $\mathrm{C} 11$ & (Chiral & SPGR) \\
\hline PLAT791_ALERT_4_G & Model has Chirality & at $\mathrm{C} 13$ & (Chiral & SPGR) \\
\hline PLAT850_ALERT_4_G & Paramet & aryat d & d & s.u. \\
\hline PLAT909_ALERT_3_G & $\mathrm{If}>2 \mathrm{si}$ & & & Still \\
\hline$A T 978 \quad A T$ & & & & \\
\hline
\end{tabular}
109.9 Degree
$R$ Verify
R Verify
S Verify
S Verify
S Verify
R Verify
0.08 Check
95\% Note
4 Info

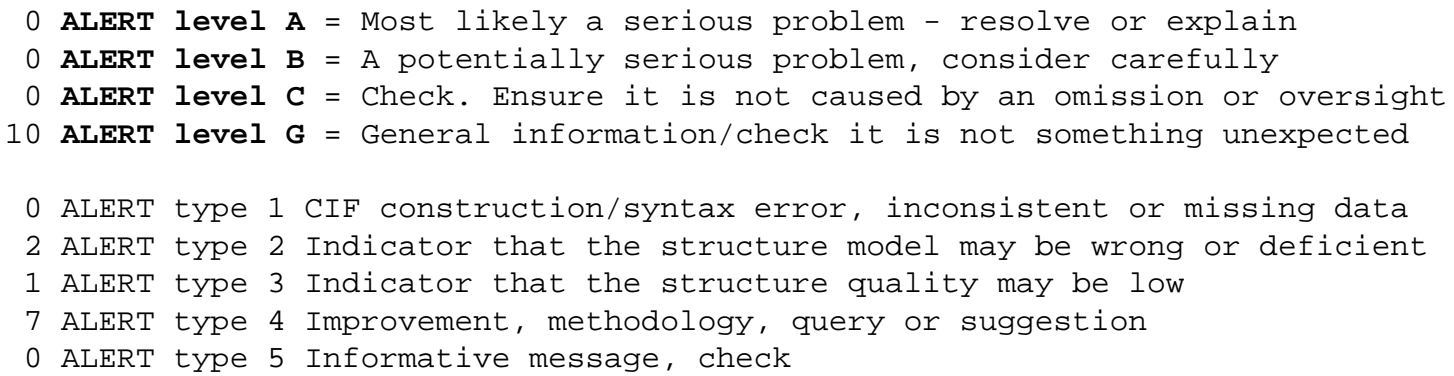

It is advisable to attempt to resolve as many as possible of the alerts in all categories. Often the minor alerts point to easily fixed oversights, errors and omissions in your CIF or refinement strategy, so attention to these fine details can be worthwhile. In order to resolve some of the more serious problems it may be necessary to carry out additional measurements or structure refinements. However, the purpose of your study may justify the reported deviations and the more serious of these should normally be commented upon in the discussion or experimental section of a paper or in the "special_details" fields of the CIF. checkCIF was carefully designed to identify outliers and unusual parameters, but every test has its limitations and alerts that are not important in a particular case may appear. Conversely, the absence of alerts does not guarantee there are no aspects of the results needing attention. It is up to the individual to critically assess their own results and, if necessary, seek expert advice.

\section{Publication of your CIF in IUCr journals}

A basic structural check has been run on your CIF. These basic checks will be run on all CIFs submitted for publication in IUCr journals (Acta Crystallographica, Journal of Applied Crystallography, Journal of Synchrotron Radiation); however, if you intend to submit to Acta Crystallographica Section C or E or IUCrData, you should make sure that full publication checks are run on the final version of your CIF prior to submission.

\section{Publication of your CIF in other journals}

Please refer to the Notes for Authors of the relevant journal for any special instructions relating to CIF submission.

\section{PLATON version of 06/01/2019; check.def file version of 19/12/2018}


Datablock 20181119houysh_chon_0m_a - ellipsoid plot

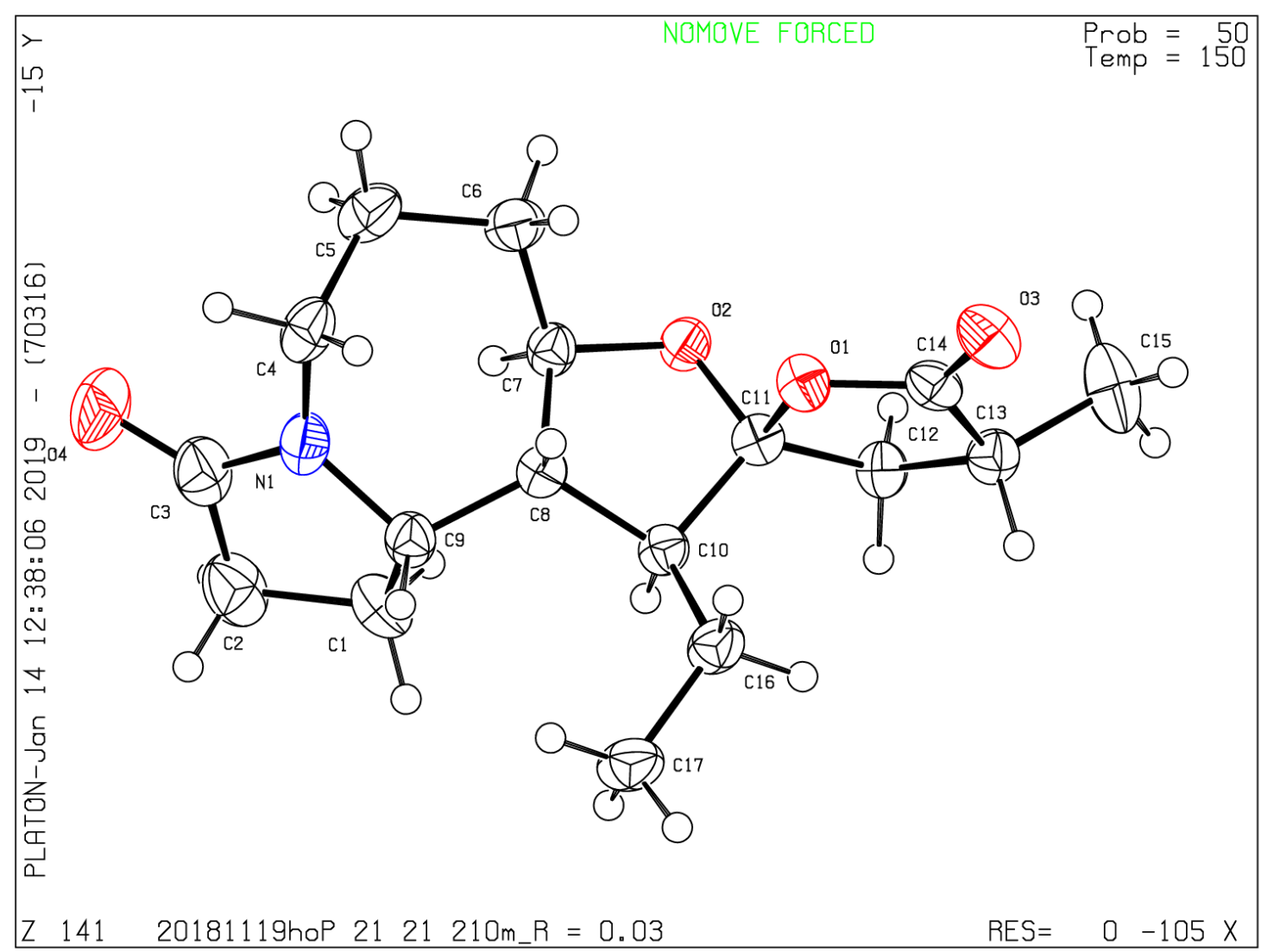




\section{Crystal Data and Cif Check Report for 11,13-bis-epi-sessilifoliamide A (20) (CCDC: 1883804)}

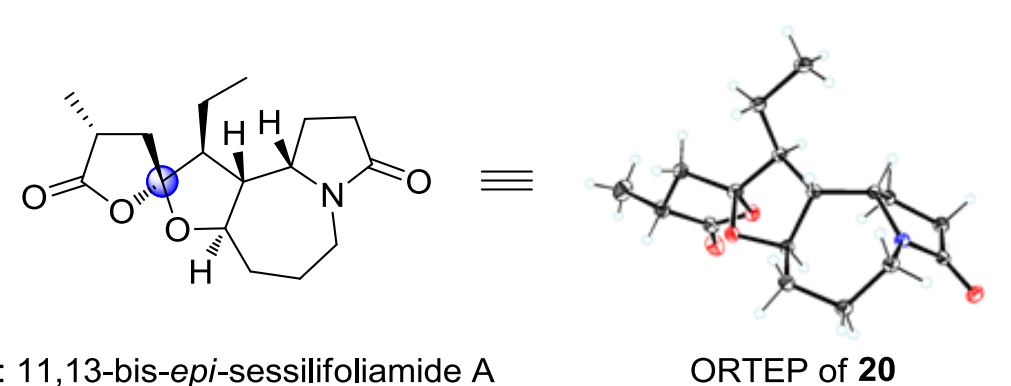

20: 11,13-bis-epi-sessilifoliamide A 


\section{checkCIF/PLATON report}

Structure factors have been supplied for datablock(s) 201811222_houysh_chon08_0m_a

THIS REPORT IS FOR GUIDANCE ONLY. IF USED AS PART OF A REVIEW PROCEDURE FOR PUBLICATION, IT SHOULD NOT REPLACE THE EXPERTISE OF AN EXPERIENCED CRYSTALLOGRAPHIC REFEREE.

No syntax errors found. CIF dictionary Interpreting this report

\section{Datablock: 201811222_houysh_chon08_0m_a}

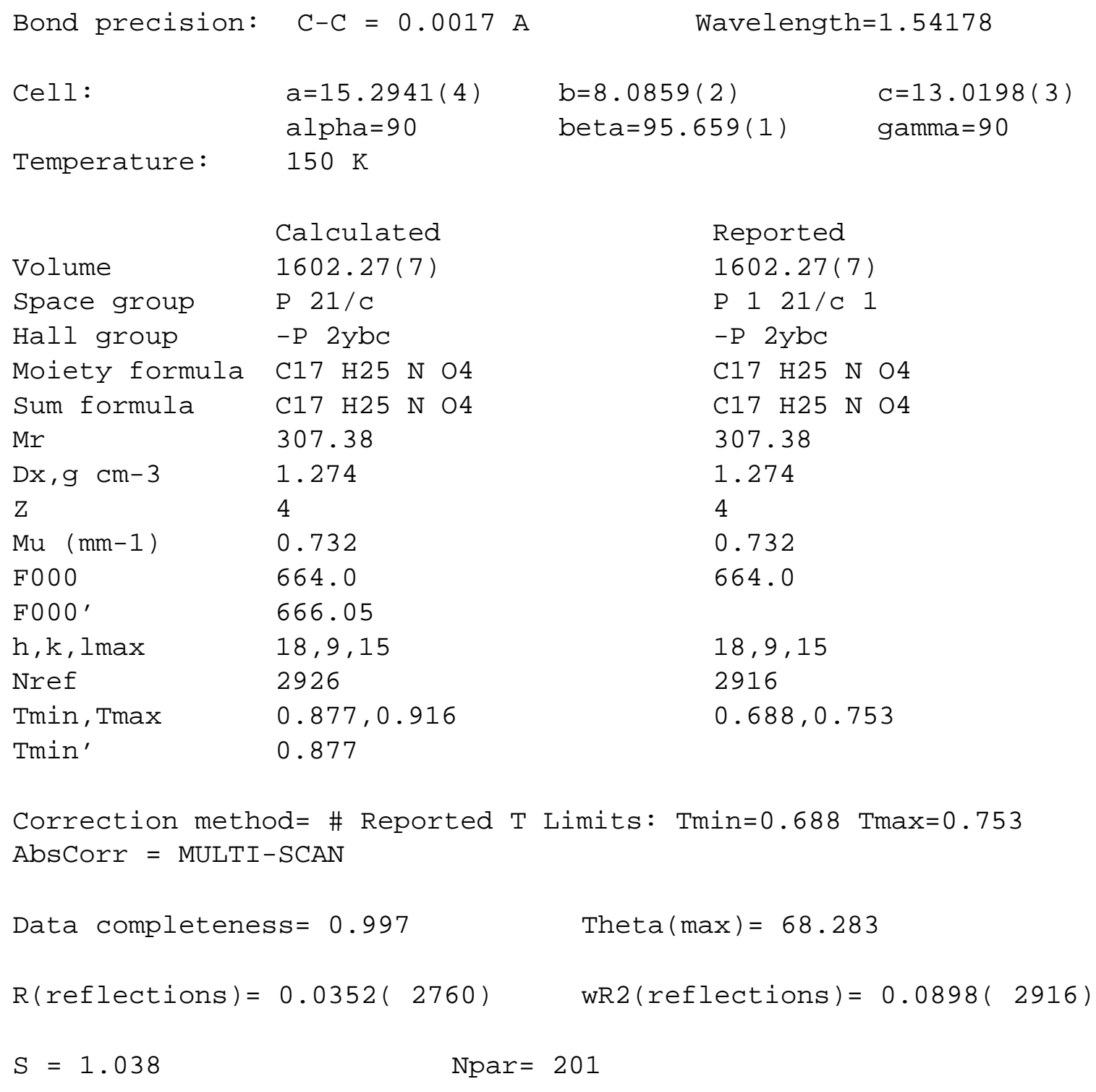


Alert level C

PLAT906_ALERT_3_C Large $K$ Value in the Analysis of Variance ......

2. 020 Check

PLAT911_ALERT_3_C Missing FCF Refl Between Thmin \& STh/L= 0.600

10 Report

Alert level G

\begin{tabular}{|c|c|c|c|c|c|}
\hline PLAT398_ALERT_2_G & Deviating & Angle From 120 & for 01 & 106.7 & Degree \\
\hline PLAT398_ALERT_2_G & Deviating & Angle From 120 & for 02 & 109.4 & Degree \\
\hline PLAT793_ALERT_4_G & Model has Chirality & at $\mathrm{C} 4$ & (Centro SPGR) & S & Verify \\
\hline PLAT793_ALERT_4_G & Model has Chirality & at $\mathrm{C} 5$ & (Centro SPGR) & $\mathrm{R}$ & Verif \\
\hline PLAT793_ALERT_4_G & Model has Chirality & at $\mathrm{C} 6$ & (Centro SPGR) & R & Verify \\
\hline PLAT793_ALERT_4_G & Model has Chirality & at $\mathrm{C} 10$ & (Centro SPGR) & S & Ver \\
\hline PLAT793_ALERT_4_G & Model has Chirality & at $\mathrm{C} 11$ & (Centro SPGR) & $\mathrm{R}$ & Ver \\
\hline PLAT793_ALERT_4_G & Model has Chirality & at $\mathrm{C} 13$ & (Centro SPGR) & $\mathrm{R}$ & Veri \\
\hline PLAT913_ALERT_3_G & \# of Very & cor & in $\mathrm{FCF}$ & 1 & Note \\
\hline LAT978_ALERT_2_G & Bonds & & & & \\
\hline
\end{tabular}

0 ALERT level $\mathbf{A}=$ Most likely a serious problem - resolve or explain

0 ALERT level $\mathbf{B}=A$ potentially serious problem, consider carefully

2 ALERT level $\mathbf{C}=$ Check. Ensure it is not caused by an omission or oversight

10 ALERT level $\mathbf{G}=$ General information/check it is not something unexpected

0 ALERT type 1 CIF construction/syntax error, inconsistent or missing data

3 ALERT type 2 Indicator that the structure model may be wrong or deficient

3 ALERT type 3 Indicator that the structure quality may be low

6 ALERT type 4 Improvement, methodology, query or suggestion

0 ALERT type 5 Informative message, check

It is advisable to attempt to resolve as many as possible of the alerts in all categories. Often the minor alerts point to easily fixed oversights, errors and omissions in your CIF or refinement strategy, so attention to these fine details can be worthwhile. In order to resolve some of the more serious problems it may be necessary to carry out additional measurements or structure refinements. However, the purpose of your study may justify the reported deviations and the more serious of these should normally be commented upon in the discussion or experimental section of a paper or in the "special_details" fields of the CIF. checkCIF was carefully designed to identify outliers and unusual parameters, but every test has its limitations and alerts that are not important in a particular case may appear. Conversely, the absence of alerts does not guarantee there are no aspects of the results needing attention. It is up to the individual to critically assess their own results and, if necessary, seek expert advice.

\section{Publication of your CIF in IUCr journals}

A basic structural check has been run on your CIF. These basic checks will be run on all CIFs submitted for publication in IUCr journals (Acta Crystallographica, Journal of Applied Crystallography, Journal of Synchrotron Radiation); however, if you intend to submit to Acta Crystallographica Section C or E or IUCrData, you should make sure that full publication checks are run on the final version of your CIF prior to submission.

\section{Publication of your CIF in other journals}

Please refer to the Notes for Authors of the relevant journal for any special instructions relating to CIF submission. 
PLATON version of 06/01/2019; check.def file version of 19/12/2018

Datablock 201811222_houysh_chon08_0m_a - ellipsoid plot

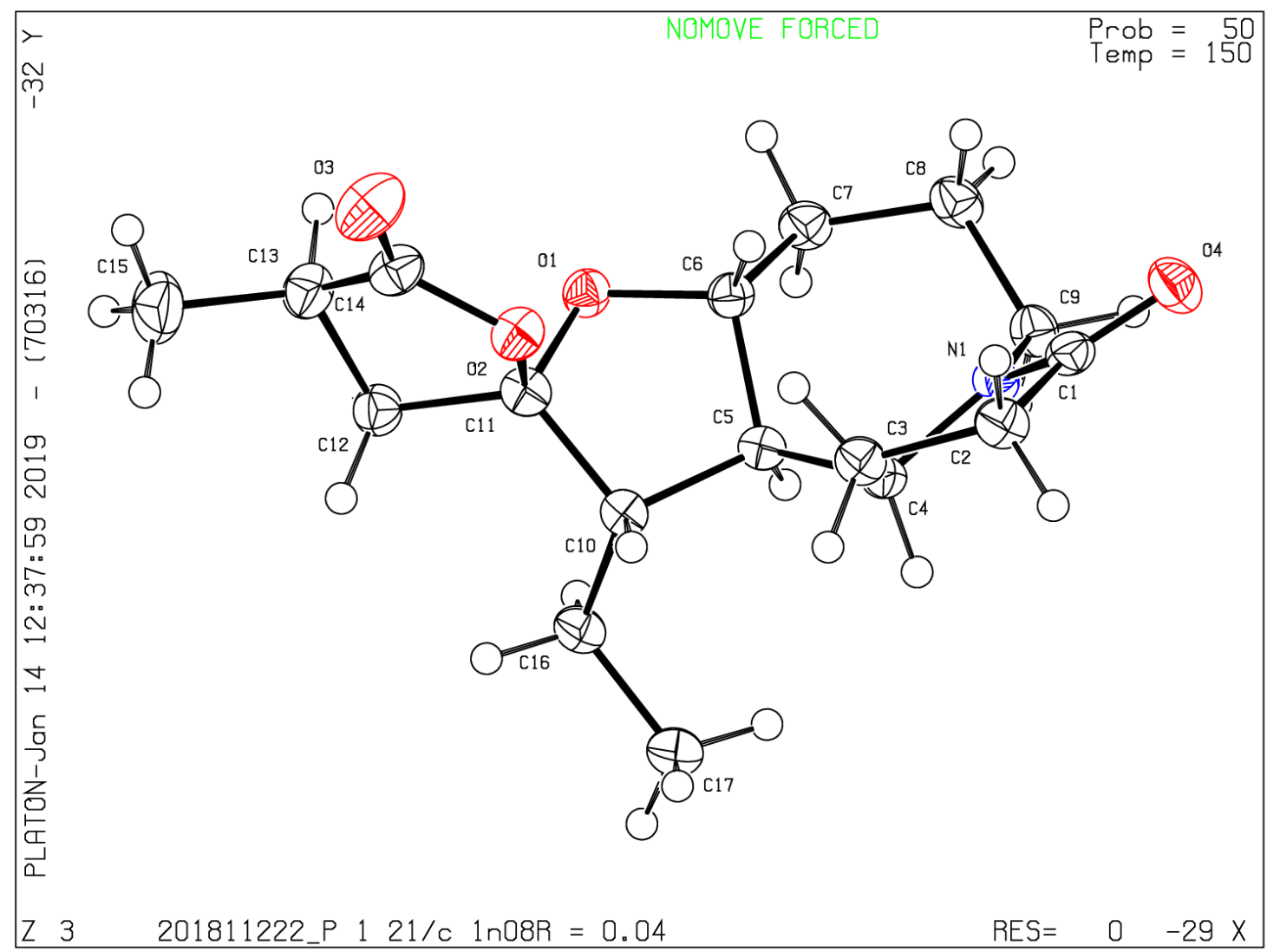




\section{Crystal Data and Cif Check Report for tuberostemoamide (1) \\ (CCDC: 1874369)}

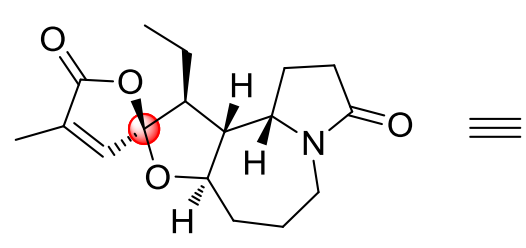

1: tuberostemoamide

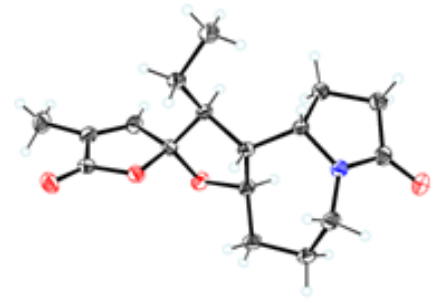

ORTEP of 1 


\section{checkCIF/PLATON report}

Structure factors have been supplied for datablock(s) houysh_0723

THIS REPORT IS FOR GUIDANCE ONLY. IF USED AS PART OF A REVIEW PROCEDURE FOR PUBLICATION, IT SHOULD NOT REPLACE THE EXPERTISE OF AN EXPERIENCED CRYSTALLOGRAPHIC REFEREE.

No syntax errors found. CIF dictionary Interpreting this report

\section{Datablock: houysh_0723}

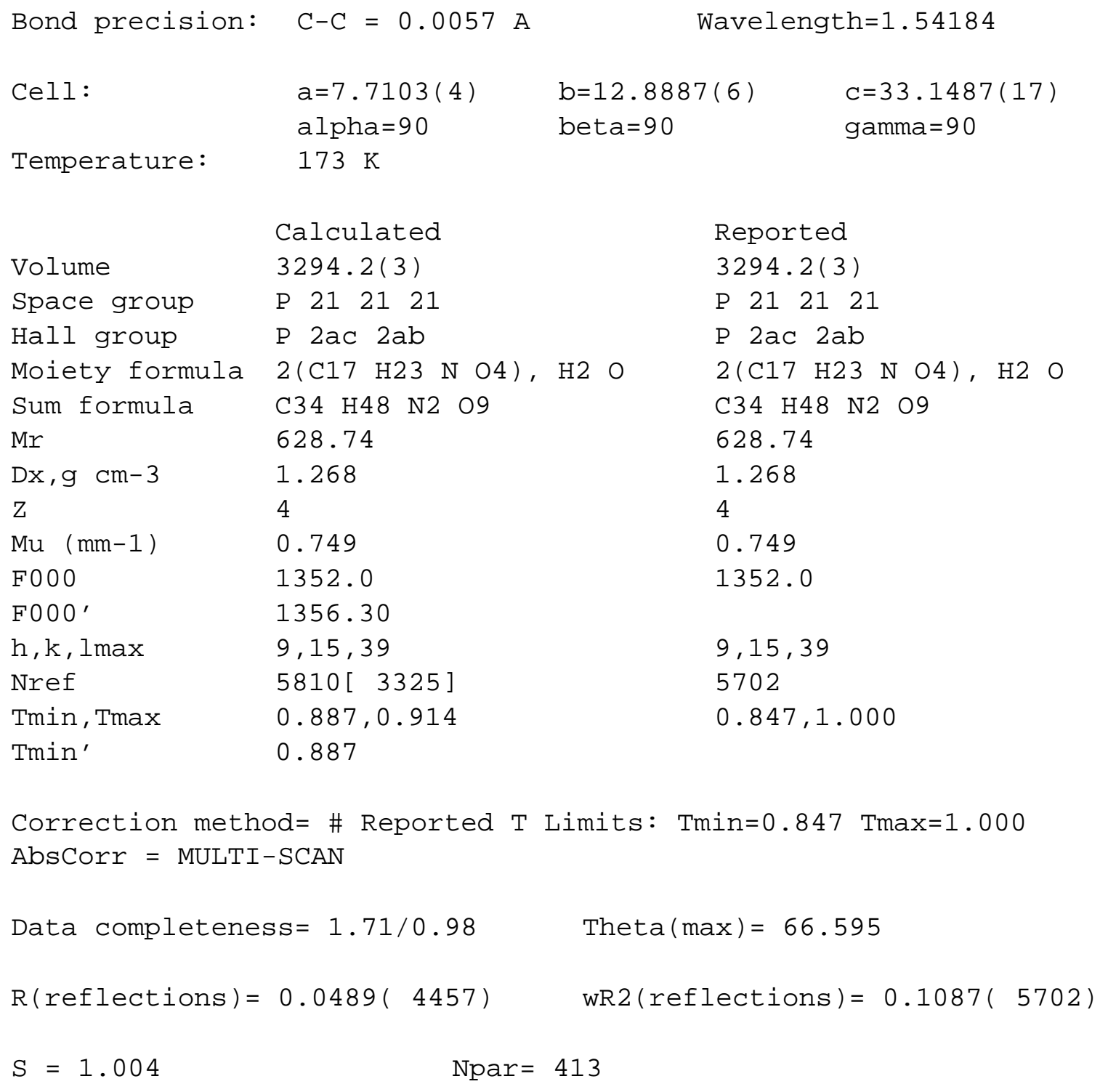


Alert level $\mathrm{C}$

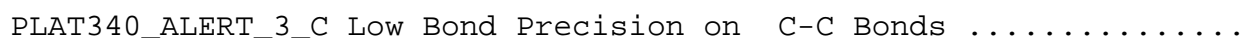

0.00572 Ang.

PLAT790_ALERT_4_C Centre of Gravity not Within Unit Cell: Resd. \#

1 Note

C17 H23 N O4

PLAT911_ALERT_3_C Missing FCF Refl Between Thmin \& STh/L= $0.595 \quad 21$ Report

\section{Alert level G}

PLAT007_ALERT_5_G Number of Unrefined Donor-H Atoms ...........

PLAT398_ALERT_2_G Deviating C-O-C Angle From 120 for O2BA

PLAT398_ALERT_2_G Deviating C-O-C Angle From 120 for O0BA

PLAT398_ALERT_2_G Deviating C-O-C Angle From 120 for 039

PLAT720_ALERT_4_G Number of Unusual/Non-Standard Labels ........

PLAT790_ALERT_4_G Centre of Gravity not Within Unit Cell: Resd. \# C17 H23 N 04

PLAT790_ALERT_4_G Centre of Gravity not Within Unit Cell: Resd. \# $\mathrm{H} 2 \mathrm{O}$

PLAT791_ALERT_4_G Model has Chirality at C5BA

(Chiral SPGR)

PLAT791_ALERT_4_G Model has Chirality at C7BA

(Chiral SPGR)

PLAT791_ALERT_4_G Model has Chirality at C1AA

(Chiral SPGR)

PLAT791_ALERT_4_G Model has Chirality at C9

(Chiral SPGR)

PLAT791_ALERT_4_G Model has Chirality at C9AA

(Chiral SPGR)

PLAT791_ALERT_4_G Model has Chirality at C18

(Chiral SPGR)

PLAT791_ALERT_4_G Model has Chirality at C29

(Chiral SPGR)

PLAT791_ALERT_4_G Model has Chirality at C32

(Chiral SPGR)

PLAT791_ALERT_4_G Model has Chirality at C40

(Chiral SPGR)

PLAT791_ALERT_4_G Model has Chirality at C45 (Chiral SPGR)

PLAT909_ALERT_3_G Percentage of I>2sig(I) Data at Theta(Max) Still

PLAT910_ALERT_3_G Missing \# of FCF Reflection(s) Below Theta(Min).

PLAT916_ALERT_2_G Hooft y and Flack x Parameter Values Differ by.

PLAT933_ALERT_2_G Number of OMIT Records in Embedded.res File...

PLAT978_ALERT_2_G Number C-C Bonds with Positive Residual Density.

2 Report

109.5 Degree

109.0 Degree

109.8 Degree

24 Note

2 Note

3 Note

S Verify

S Verify

S Verify

$R$ Verify

$R$ Verify

S Verify

S Verify

$S$ Verify

$R$ Verify

$R$ Verify

56\% Note

1 Note

0.25 Check

2 Note

1 Info

0 ALERT level $\mathbf{A}=$ Most likely a serious problem - resolve or explain

0 ALERT level $\mathbf{B}=A$ potentially serious problem, consider carefully

3 ALERT level $\mathbf{C}=$ Check. Ensure it is not caused by an omission or oversight

22 ALERT level $\mathbf{G}=$ General information/check it is not something unexpected

0 ALERT type 1 CIF construction/syntax error, inconsistent or missing data

6 ALERT type 2 Indicator that the structure model may be wrong or deficient

4 ALERT type 3 Indicator that the structure quality may be low

14 ALERT type 4 Improvement, methodology, query or suggestion

1 ALERT type 5 Informative message, check 
It is advisable to attempt to resolve as many as possible of the alerts in all categories. Often the minor alerts point to easily fixed oversights, errors and omissions in your CIF or refinement strategy, so attention to these fine details can be worthwhile. In order to resolve some of the more serious problems it may be necessary to carry out additional measurements or structure refinements. However, the purpose of your study may justify the reported deviations and the more serious of these should normally be commented upon in the discussion or experimental section of a paper or in the "special_details" fields of the CIF. checkCIF was carefully designed to identify outliers and unusual parameters, but every test has its limitations and alerts that are not important in a particular case may appear. Conversely, the absence of alerts does not guarantee there are no aspects of the results needing attention. It is up to the individual to critically assess their own results and, if necessary, seek expert advice.

\section{Publication of your CIF in IUCr journals}

A basic structural check has been run on your CIF. These basic checks will be run on all CIFs submitted for publication in IUCr journals (Acta Crystallographica, Journal of Applied Crystallography, Journal of Synchrotron Radiation); however, if you intend to submit to Acta Crystallographica Section C or E or IUCrData, you should make sure that full publication checks are run on the final version of your CIF prior to submission.

\section{Publication of your CIF in other journals}

Please refer to the Notes for Authors of the relevant journal for any special instructions relating to CIF submission.

\section{PLATON version of 06/01/2019; check.def file version of 19/12/2018}


Datablock houysh_0723 - ellipsoid plot

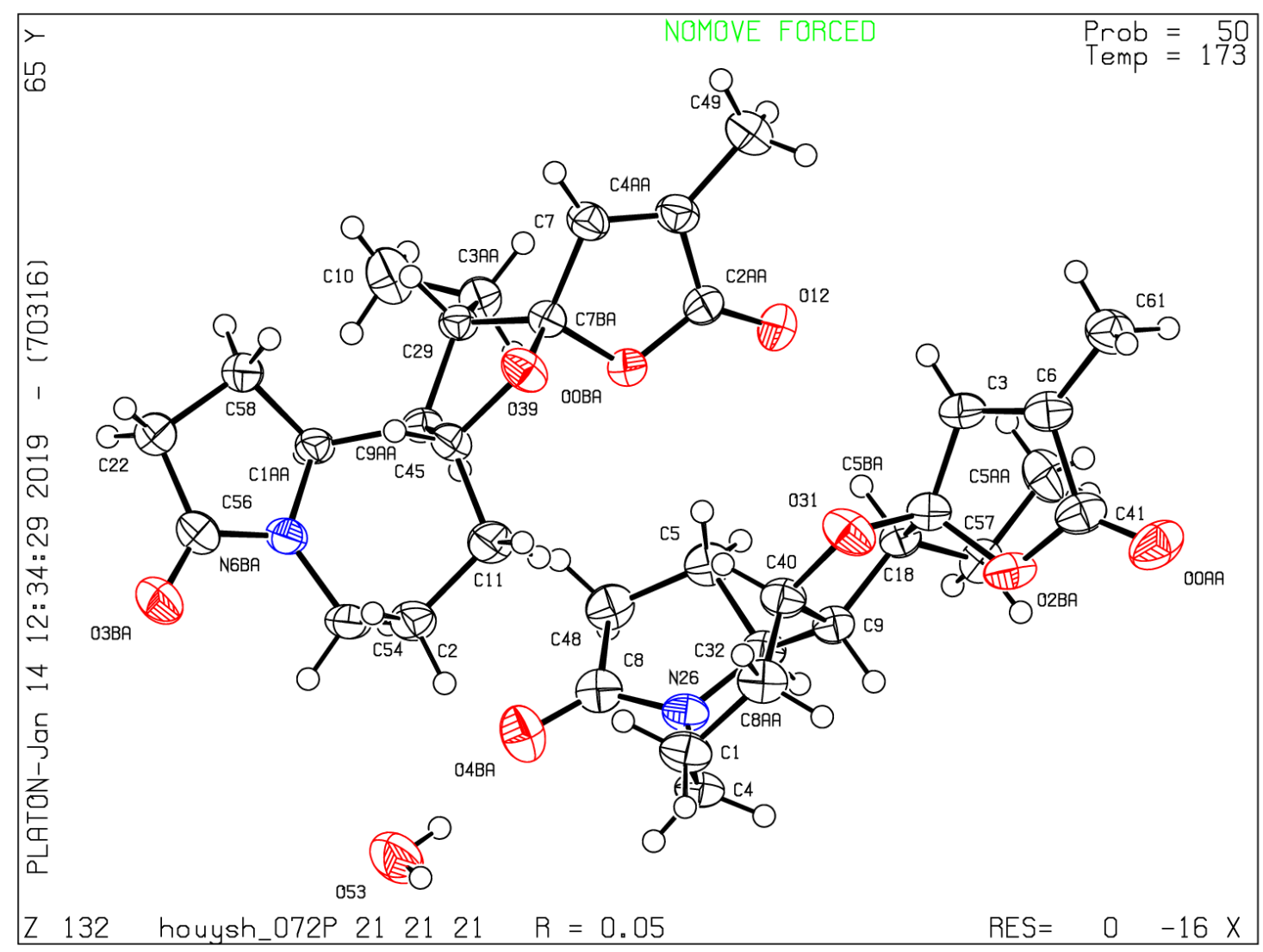




\section{Crystal Data and Cif Check Report for 11-epi-tuberostemoamide (21) (CCDC: 1883814)}

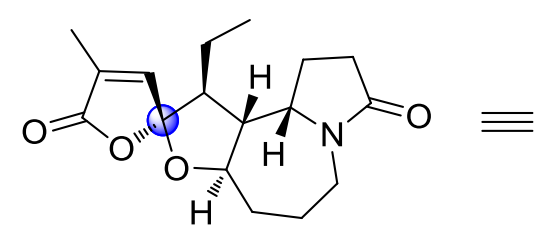

21: 11-epi-tuberostemoamide

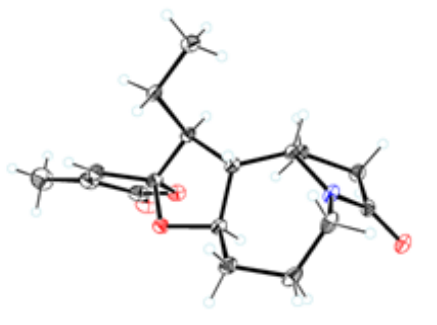

ORTEP of $\mathbf{2 1}$ 


\section{checkCIF/PLATON report}

Structure factors have been supplied for datablock(s) 20181123houysh_chon09_0m_a

THIS REPORT IS FOR GUIDANCE ONLY. IF USED AS PART OF A REVIEW PROCEDURE FOR PUBLICATION, IT SHOULD NOT REPLACE THE EXPERTISE OF AN EXPERIENCED CRYSTALLOGRAPHIC REFEREE.

No syntax errors found. CIF dictionary Interpreting this report

\section{Datablock: 20181123houysh_chon09_0m_a}

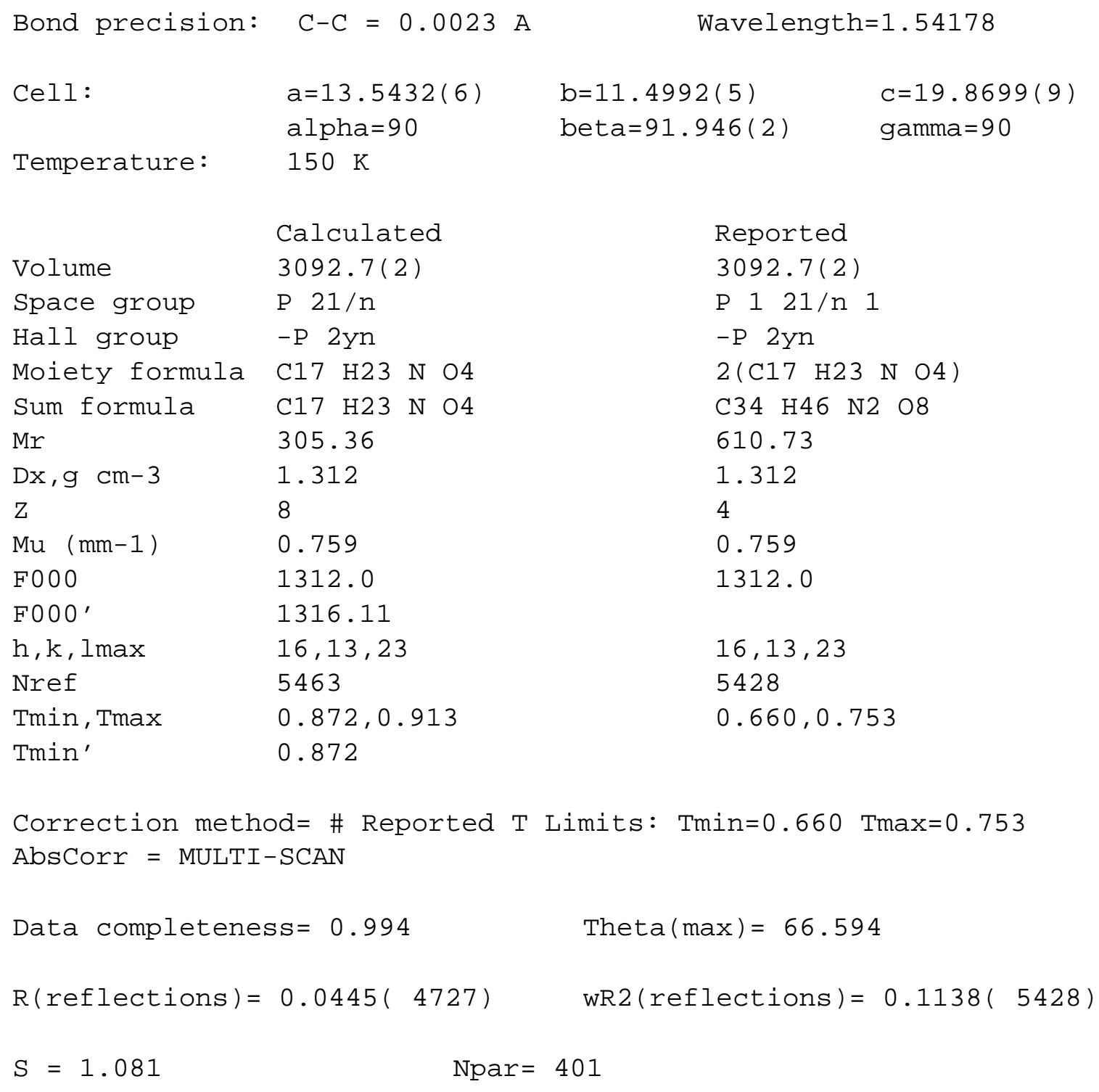


Alert level $\mathrm{C}$

PLAT906_ALERT_3_C Large $K$ Value in the Analysis of Variance ......

PLAT911_ALERT_3_C Missing FCF Refl Between Thmin \& STh/L= 0.595

PLAT934_ALERT_3_C Number of (Iobs-Icalc)/SigmaW > 10 Outliers ....
4.776 Check
35 Report
1 Check

\section{Alert level $\mathbf{G}$}

PLAT042_ALERT_1_G Calc. and Reported MoietyFormula Strings Differ

PLAT045_ALERT_1_G Calculated and Reported Z Differ by a Factor...

PLAT398_ALERT_2_G Deviating C-O-C Angle From 120 for 01

PLAT398_ALERT_2_G Deviating C-O-C Angle From 120 for O2

PLAT398_ALERT_2_G Deviating C-O-C Angle From 120 for O1'

PLAT398_ALERT_2_G Deviating C-O-C Angle From 120 for O2'

PLAT720_ALERT_4_G Number of Unusual/Non-Standard Labels .........

PLAT793_ALERT_4_G Model has Chirality at $\mathrm{C}^{\prime}$ (Centro SPGR)

PLAT793_ALERT_4_G Model has Chirality at C2' (Centro SPGR)

PLAT793_ALERT_4_G Model has Chirality at C3' (Centro SPGR)

PLAT793 ALERT $4 \mathrm{G}$ Model has Chirality at C4 (Centro SPGR)

PLAT793_ALERT_4_G Model has Chirality at C5 (Centro SPGR)

PLAT793_ALERT_4_G Model has Chirality at C6 (Centro SPGR)

PLAT793_ALERT_4_G Model has Chirality at C7 (Centro SPGR)

PLAT793_ALERT_4_G Model has Chirality at C7' (Centro SPGR)

PLAT793_ALERT_4_G Model has Chirality at C8 (Centro SPGR)

PLAT793_ALERT_4_G Model has Chirality at C8' (Centro SPGR)

PLAT909_ALERT_3_G Percentage of I>2sig(I) Data at Theta (Max) Still

PLAT913_ALERT_3_G Missing \# of Very Strong Reflections in FCF ....

PLAT978_ALERT_2_G Number C-C Bonds with Positive Residual Density.

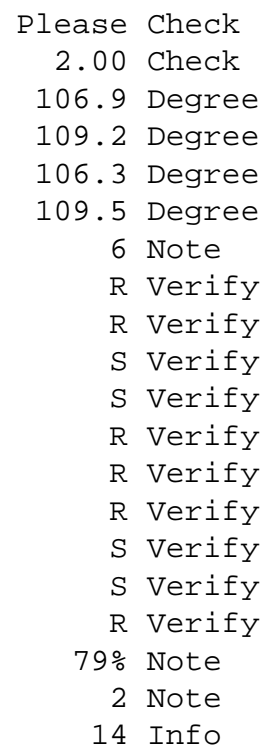

0 ALERT level $\mathbf{A}=$ Most likely a serious problem - resolve or explain

0 ALERT level $\mathbf{B}=A$ potentially serious problem, consider carefully

3 ALERT level $\mathbf{C}=$ Check. Ensure it is not caused by an omission or oversight

20 ALERT level $\mathbf{G}=$ General information/check it is not something unexpected

2 ALERT type 1 CIF construction/syntax error, inconsistent or missing data

5 ALERT type 2 Indicator that the structure model may be wrong or deficient

5 ALERT type 3 Indicator that the structure quality may be low

11 ALERT type 4 Improvement, methodology, query or suggestion

0 ALERT type 5 Informative message, check 
It is advisable to attempt to resolve as many as possible of the alerts in all categories. Often the minor alerts point to easily fixed oversights, errors and omissions in your CIF or refinement strategy, so attention to these fine details can be worthwhile. In order to resolve some of the more serious problems it may be necessary to carry out additional measurements or structure refinements. However, the purpose of your study may justify the reported deviations and the more serious of these should normally be commented upon in the discussion or experimental section of a paper or in the "special_details" fields of the CIF. checkCIF was carefully designed to identify outliers and unusual parameters, but every test has its limitations and alerts that are not important in a particular case may appear. Conversely, the absence of alerts does not guarantee there are no aspects of the results needing attention. It is up to the individual to critically assess their own results and, if necessary, seek expert advice.

\section{Publication of your CIF in IUCr journals}

A basic structural check has been run on your CIF. These basic checks will be run on all CIFs submitted for publication in IUCr journals (Acta Crystallographica, Journal of Applied Crystallography, Journal of Synchrotron Radiation); however, if you intend to submit to Acta Crystallographica Section C or E or IUCrData, you should make sure that full publication checks are run on the final version of your CIF prior to submission.

\section{Publication of your CIF in other journals}

Please refer to the Notes for Authors of the relevant journal for any special instructions relating to CIF submission.

\section{PLATON version of 06/01/2019; check.def file version of 19/12/2018}


Datablock 20181123houysh_chon09_0m_a - ellipsoid plot

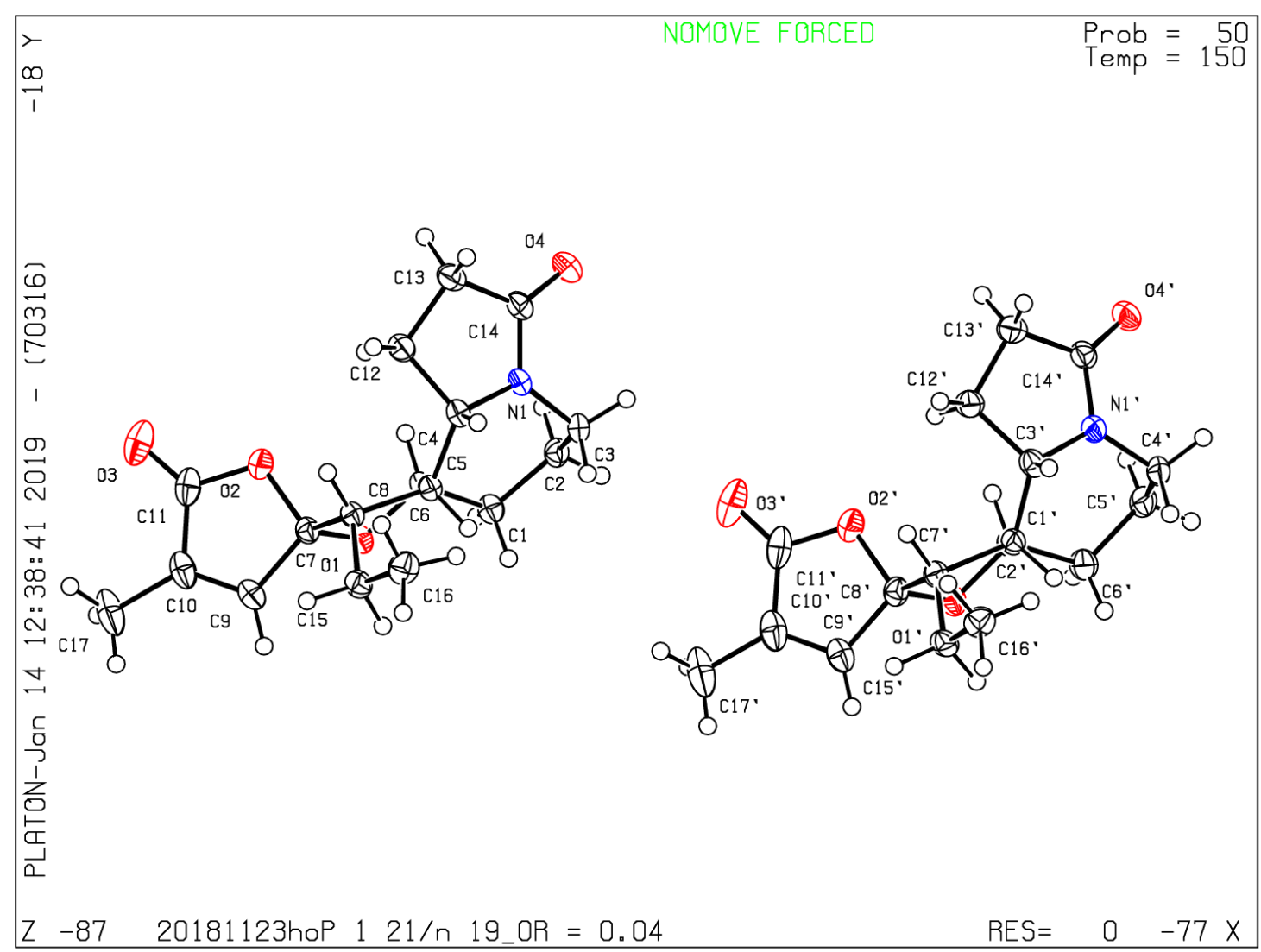

